NASA CONTRACTOR REPOR T

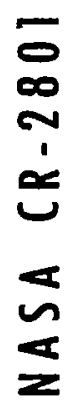

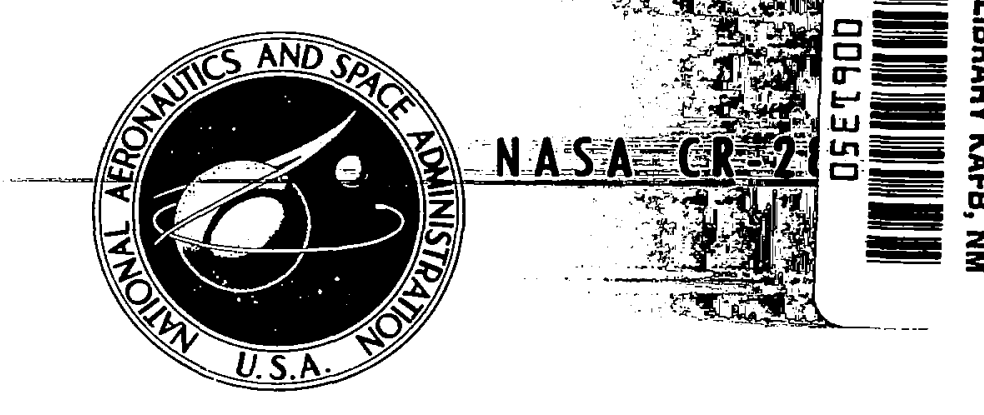

LOAN COPY: PETUPY TO

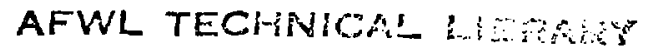
KIRTLAND AFE, N. M.

\title{
DESIGN PROCEDURES FOR FLUTTER-FREE SURFACE PANELS
}

Robert M. Laurenson and J. I. McPherson

Prepared by

MCDONNELL DOUGLAS ASTRONAUTICS COMPANY - EAST

St. Louis, Mo. 63166

for Langley Researcb Center

NATIONAL AERONAUTICS AND SPACE ADMINISTRATION - WASHINGTON, D. C. - MARCH 1977 
0061350

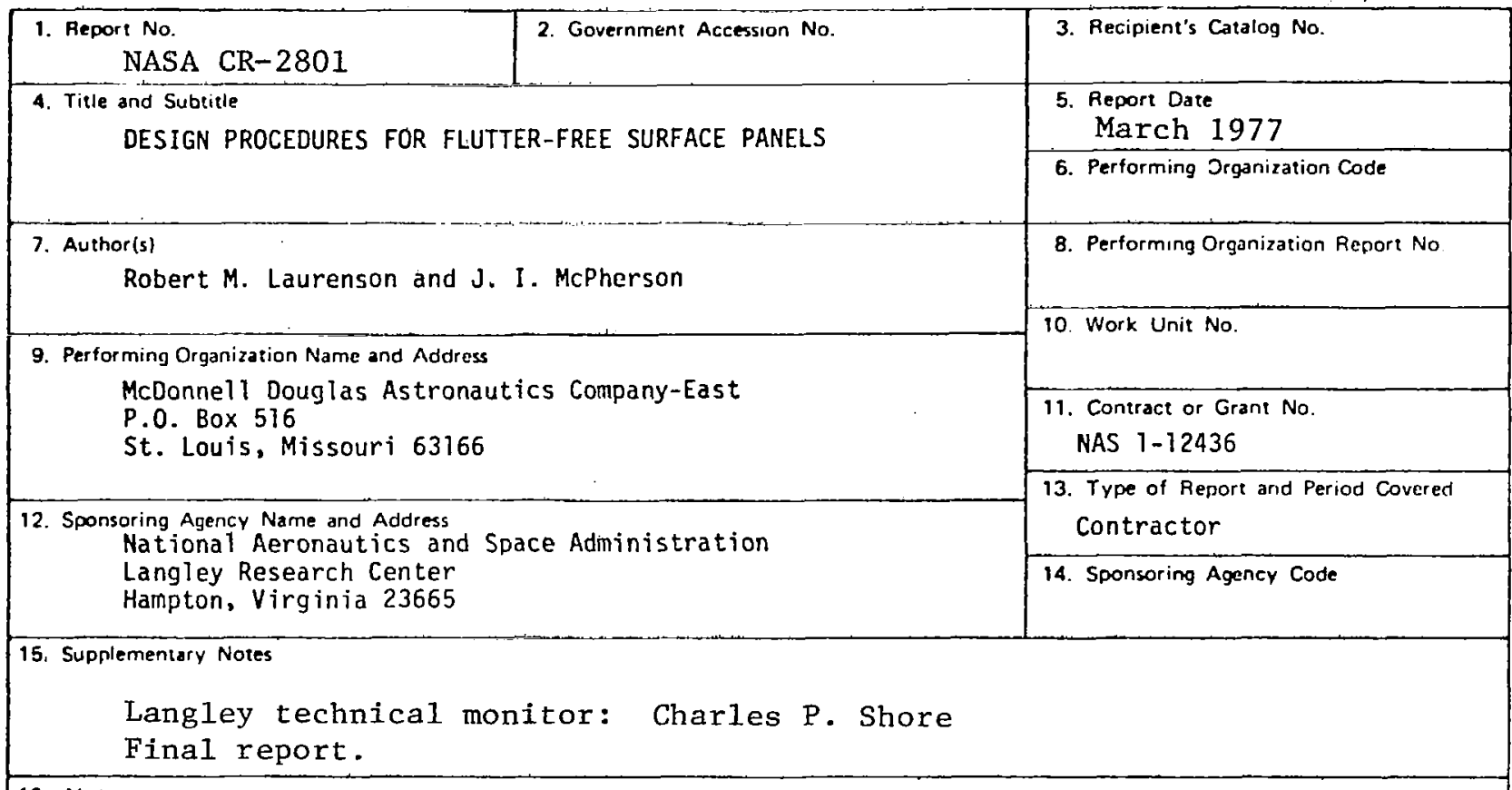

16. Abstract

An approach for the design of lightweight external surface panel configurations to preclude panel flutter has been developed. Design procedures were developed for flat orthotropic panels under the interacting influence of parameters such as support flexibility, inplane loads, pressure differential, and flow angularity. The basic relationships required to define these design procedures were based on theoretical panel flutter analyses. Where possible, the design procedures were verified through comparison with available experimental panel flutter data.

17. Key Words (Sugyested by Author(s))

Panel Fiutter

Vibration

Structural Dynamics

Structures

19. Security Classif. (of this report)

Unclassified
18. Distribution Statement

Unclassified - Unlimited

\footnotetext{
- For sale by the National Technical Information Service. Springfield, Virginia 22161
} 
FOREWORD

The result of this investigation, as presented in this document, is an approach for the design of lightweight external surface panel configurations to preclude panel flutter. The McDonnell Douglas program manager during the initial phase of the investigation was Mr. J. I. McPherson with Dr. Robert M. Laurenson serving in this capacity during the latter portion of the study. In s!upport of this investigation, a survey was made of the current panel flutter work being conducted at academic institutions, governmental agencies, and industrial firms. The information obtained during this survey aided in the definition of the design procedures presented in this document. The participation of the following individuals in this data gathering effort is acknowledged:

Eugene F. Baird

J. B. Bartley

Charles F. Coe

Lt.Col. Duane M. Davis

Ear1 H. Dowe1]

Gordon Getline

G. E. Kahre

R. H. Lassen
Grumman Aerospace Corporation Bethpage, New York 11714

Boeing Commercial Airplane Company Seattie, Washington 98124

Ames Research Center National Aeronautics \& Space Administration Moffett Field, California 94035

Department of the Air Force Air Force Flight Dynamics Laboratory Wright-Patterson Air Force Base, Ohio 45433

Princeton University Princeton, New Jersey 08540

Convair Aerospace Division General Dynamics San Diego, California 92138

McDonnell Douglas Astronautics Co.-West McDonnel1 Douglas Corporation Huntington Beach, Cal ifornia 92647

Space Division Rockwell International Downey, California 90241 
C. E. Lemley

J. Wayne Sawyer

Rona7d 0. Stearman

A. C. Tracy

J. E. Wignot
McDonnell Aircraft Company

McDonnel1 Douglas Corporation

St. Louis. Missouri 63166

Langley Research Center

National Aeronautics \& Space Administration

Hampton, Virginia 23665

The University of Texas of Austin

Austin, Texas 78712

Douglas Aircraft Company

McDonnel1 Douglas Corporation

Long Beach, California 90846

Lockheed - California Company

Burbank, California 91503 
TABLE OF CONTENTS

Section $\underline{\text { Page }}$

FOREHORD .................... . . $i$

TABLE OF CONTENTS ................. . .

LIST OF FIGURES. ................. iv

LIST OF TABLES . . . . . . . . . . . . . . v

SUMMARY. . .................. 1

1.0 INTRODUCTION. . . . . . . . . . . . . . 3

2.0 SYMBOLS ......................... 7

3.0 FLUTTER-FREE PANEL DESIGN BOUNDARIES. . . . . . . . 9

4.0 DESIGN BOUNDARY APPLICATION . . . . . . . . . . 17

4.1 Basic Panel . . . . . . . . . . . . . 19

4.2 Flow Angutarity. . . . . . . . . . . . 21

4.3 Inplane Loads. . . . . . . . . . . . . . 24

4.4 Static Pressure Differential . . . . . . . . 26

4.5 Structurat Damping ............... 27

4.6 Mach Number Effect . . . . . . . . . . . . 30

5.0 EXAMPLE APPLICATIONS OF DESIGN PROCEDURE. . . . . . 33

5.1 Uniform Panel with Inplane Loads . . . . . . . . 33

5.2 Elastically Supported Orthotropic Panel. . . . . . . 35

5.3 Orthotropic Panel with Flow Angularity . . . . . 38

6.0 DESIGN BOUNDARY VERIFICATION. .......... 43

6.1 Basic Panet. . . . . . . . . . . . . 43

6.2 Flow Angularity. . . . . . . . . . . 45

6.3 Inplane Loads. . . . . . . . . . . . . . . 46

6.4 Static Pressure Differential . . . . . . . . . 50

6.5 Structural Damping.............. 53

6.6 Mach Number Effect . . . . . . . . . . 56

7.0 CONCLUDING REMARKS ........................ 59 APPENDICES

A - Orthotropic Panel Stiffness Parameters. . . . . . 61

B - Edge Support Stiffness Expressions. . . . . . . 65

C - Panel on Elastic Foundation . . . . . . . . . 71

C. 1 Rigid Substructure. ........... . 71

C.2 Elastic Substructure. . . . . . . . . . . 75

D - Panel Flutter Test Data . . . . . . . . 83 REFERENCES

Cited References. . . ............ 113

Additional References ............ 115 


\section{LIST OF FIGURES}

Figure No.

Title

1 Surface Panel Configuration ............ 4

2 Flutter-Free Panel Design Boundaries From

Approximate Solutions ........... . 12

3 Flutter-Free Panel Design Boundaries. . . . . . . . 13

4 Panel Design Procedure. ............. 18

5 Panel With Inplane Loading. ........... . . 25

6 Pressure Differential Correction Factor. . . . . . 28

7 Mach Number Correction Factor ............ . 31

8 Uniform Panel with Inplane Loading. . . . . . . . . . . 34

9 Elastically Supported Orthotropic Panei . . . . . 35

10 Flutter Critical Dynamic Pressure Versus Edge

Support Stiffness............. 39

11 Orthotropic Panel with Fiow Angularity. . . . . 40

12 Flutter Critical Dynamic Pressure Versus Flow

Angularity ...................... 41

13 Flutter Data for Basic Panel Configurations .... 44

14 Correlation with Reference 9 Theoretical Results. . . 46

15 Panel Flutter Data Including Influence of Flow

Angularity ...................... 47

16 Correlation with Reference 11 Experimental Results. : 48

17 Flutter Data for Panels with Various a Over b Ratios

and Inplane Loads............. 49

18 PaneT Flutter Data Including Influence of Inplane

Loads . . . . . . . . . . . . . . . . 51

19 Panel Flutter Data Including the Influence of Static

Pressure Differential ............. . 52

20 Correlation with Reference 19 Clamped Panel Results . . 54

21 Influence of High Structural Damping for a Panel

with Inplane Loading. ............. . . 55

22 Panel Flutter Data in Low Supersonic Regime . . . . . . 57

A-1 Orthotropic Panel Configurations. . . . . . . . . 62

B-1 Idealized Stream Edge Spring Supports ....... 65

B-2 Nondimensional Stream Edge Support Stiffness

B-3 Expressions . - . - . . . . . . . . . 66

Stiffness of Panel Edge Support Springs...... . 68

B-4 Edge Support Panel. . . . . . . . . . . . . 70

C-1 Panel on Elastic Foundation . . . . . . . . . 72

C-2 Comparison of Two Mode Solution Including Elastic

Foundation Effects with Reference 34 Results. . . . . . 74

C-3 Flutter Results for Equal Parallel Elastically

Interconnected Isotropic Panels . . . . . . . . . 78

C-4 Flutter Critical Foundation Stiffness Parameter as a Function of Length to Width Ratio for Equal Isotropic Panels................ 79

C-5 Flutter Results for Paraliel Elasticaliy Interconnected Isotropic Panels Having Varying Thickness Ratios. . . 80 


\section{LIST OF TABLES}

Table

No.

Title

Page

D-1

Panel Flutter Data From Reference 10 . . . . . 84

D-2

Panel Flutter Data From Reference 18 . . . . . 86

D-3

Panel Flutter Data From Reference 27 . . . . . . 88

D-4

Panel Flutter Data From Reference 8. . . . . . 91

D-5

Panel Flutter Data From Reference 11 . . . . . 92

D-6

Panel Flutter Data From Reference 12 . . . . . 95

D-7

Panel Flutter Data From Reference 7. . . . . . 102

D-8

Panel Flutter Data From Reference 19 . . . . . 103

D-9

Panel Flutter Data From Reference 23 . . . . . 105

D-10

Panel Flutter Data From Reference 24 . . . . . 106

D-11

Panel Flutter Data From Reference 25 . . . . . 107

D-12

Panel Flutter Data From Reference 26 . . . . . 108

D-13

Panel Flutter Data From Reference 10 . . . . 109

D-14

PaneT Flutter Data From Reference 27 . . . . . . 110

D-15

Panel Flutter Data From Reference 28..... . 111 


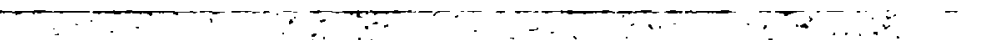




\section{DESIGN PROCEDURES \\ FOR \\ FLUTTER-FREE SURFACE PANELS}

Robert M. Laurenson and J. I. McPherson

McDonne11 Douglas Astronautics Company - East

St. Louis, Missouri

SUMMARY

An approach for the design of lightweight external surface panel configurations to preclude panel flutter has been developed. Design procedures were developed for flat orthotropic panels under the interacting influence of parameters such as support flexibility, inplane loads, pressure differential, and flow angularity. The relationships required to define these design procedures were based on theoretical panel flutter analyses. Where possible, the design procedures were verified through comparison with available experimental panel flutter data. 


\subsection{INTRODUCTION}

Future high velocity cruise aircraft and reusable entry vehicles must cope with environments which place severe thermal and structural demands on the external surfaces. Prevention of panel flutter in these external surfaces is one of many problems which designers must face. Traditionaliy, external panels have been designed by strength, buckling, and fatigue considerations and then checked for panel flutter performance. Such a procedure often leads to "flutter fixes" and additional weight for panel flutter prevention.

To permit consideration of panel flutter early in the design process, design procedures have been developed in a format useful to designers without prior panel flutter experience. The major emphasis is placed on development of flutter design procedures and their application to metallic panels with orthotropic stiffness characteristics and a variety of edge support conditions from nearly free to fully clamped. The panels may also be subjected to various loading and flow conditions. Additionally, results are also presented for surface panels attached to primary structure by an elastic coupling medium. For either panel configuration it should be emphasized that although these design procedures are useful in preliminary design, detailed flutter analyses and/or tests may be necessary to verify the final design of critical panel configurations.

A wealth of theoretical panel flutter investigations and wind tunnel data exists in the literature. The theoretical approaches were employed to establish the trends and relationships required to define these panel flutter design procedures. Experimental flutter data were used to verify the design criteria which are presented in the form of flutter-free panel design boundaries. The flat, orthotropic panel configuration to which this approach has application is illustrated in figure 1. The influence of such interacting parameters as flow angularity, support flexibility, inplane loading, orthotropic panel stiffness characteristics, damping, and static pressure differential on the flutter of external surface panels is included in these procedures. 


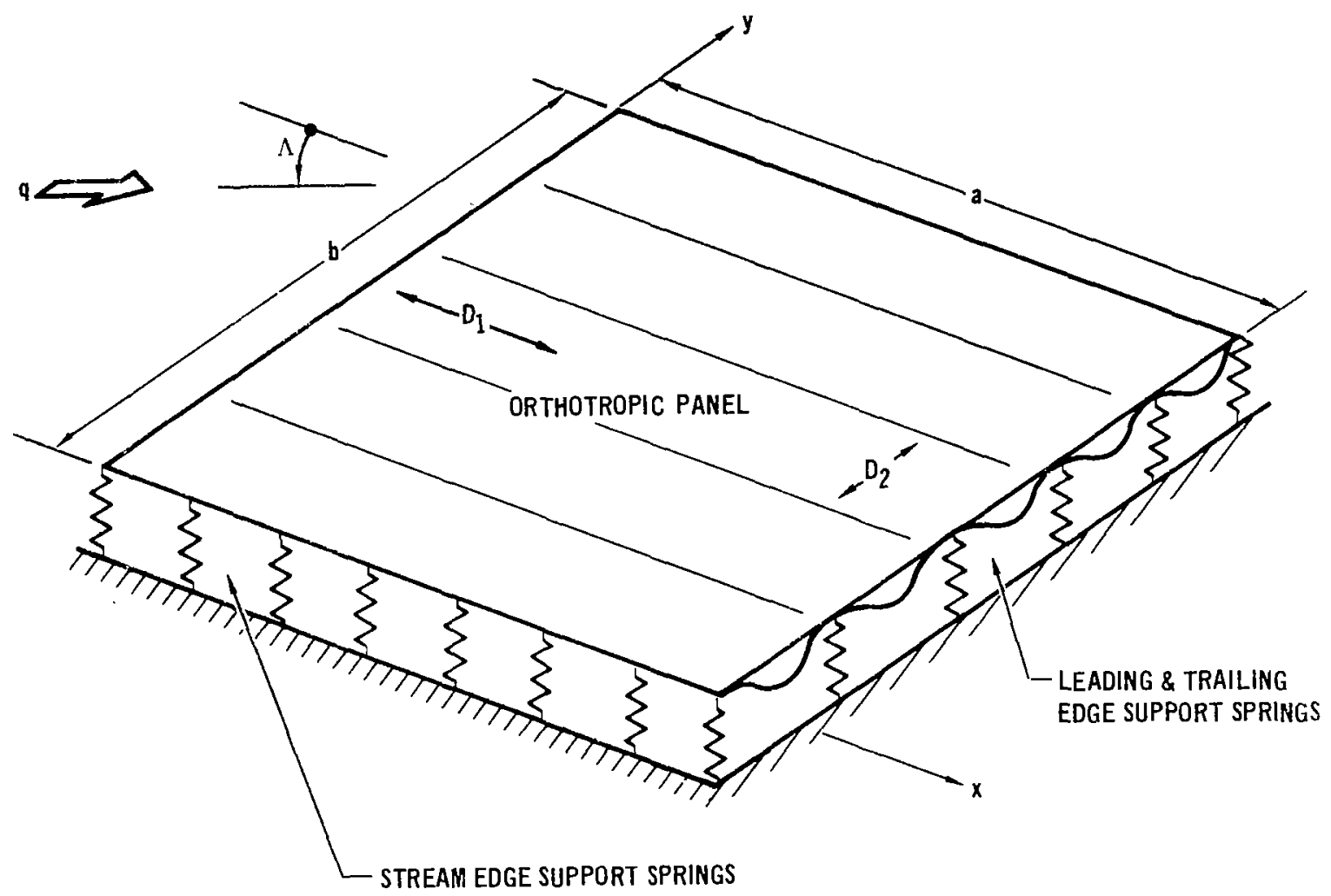

FIGURE 1 SURFACE PANEL CONFIGURATION

Interest in the establishment of panel flutter design procedures has been high for a number of years. An initial attempt to define such procedures is given in reference 1 . In that document, a panel flutter design boundary is defined which envelopes the available experimental data from both unstiffened and corrugation stiffened panels.

Modifications and refinements to this design approach have continued (refs. 2 and 3). In 1964, and later in a revised form in 1972, the National Aeronautics and space Admiristration issued a formal design monograph (ref. 4) to be used as a guide in the formulation of design requirements and specifications dealing with panel flutter. Reference 4 does not provide detailed procedures to be followed for the design of flutter free surface panels but 
rather the philosophy to be followed during the design process. Reference 5 , published in 1968, gives simplified criteria in graphical form for many of the parameters important for panel flutter design; however, effects of panel orthotropy, edge support flexibility, and damping are not included. The panel flutter design procedures presented in this report are extensions of the previously mentioned design approaches. Additional parameters such as panel orthotropy, edge support flexibility, flow angularity, and damping, as understood in the current state of the art, are included in a graphical format which should be useful to designers without prior panel flutter experience. 


\subsection{SYMBOLS}

Definitions of the major symbols required for the application of the panel flutter design procedures are given below. Symbols not having general usage throughout this report are defined as they are introduced.
$a, b$
Panel length in $x$ and $y$ directions, respectively; $m$
D
Isotropic panel stiffness parameter; $\mathrm{N}-\mathrm{m}$
$D_{f}$
Damping factor - equation (41)
$D_{1}, D_{2}, D_{12}$
Orthotropic panel stiffness parameters; $\mathrm{N}-\mathrm{m}$
E
Young's modulus of panel material; $\mathrm{N} / \mathrm{m}^{2}$
$E_{C}$
Panel edge rotational restraint coefficient
$f(M)$
Mach number correction factor - figure 7
FP
Flutter Parameter
Structural damping coefficient
Total damping coefficient
G
Shear modulus of panel material; $\mathrm{N} / \mathrm{m}^{2}$
GP
Geometry Parameter
h
Isotropic panel thickness; $m$
$h_{\text {eq }}$
Equivalent isotropic panel thickness - equation (39); m
Nondimensional leading and trailing edge support stiffness parameter
$\bar{K}_{\mathrm{L} . \mathrm{T}}{ }^{*}$
$\bar{K}_{s}$
$\bar{K}_{S} \star$
M
${ }^{\mathrm{CR}}$ Nondimensional stiffness parameter $\bar{K}_{L T}$ modified for presence of
flow angularity - equation $(29)$
Nondimensional stream edge support stiffness parameter
Nondimensional stiffness parameter $\bar{K}_{S}$ modified for presence of flow angularity - equation (28)
Mach number
Critical buckling load; $\mathrm{N} / \mathrm{m}$ 


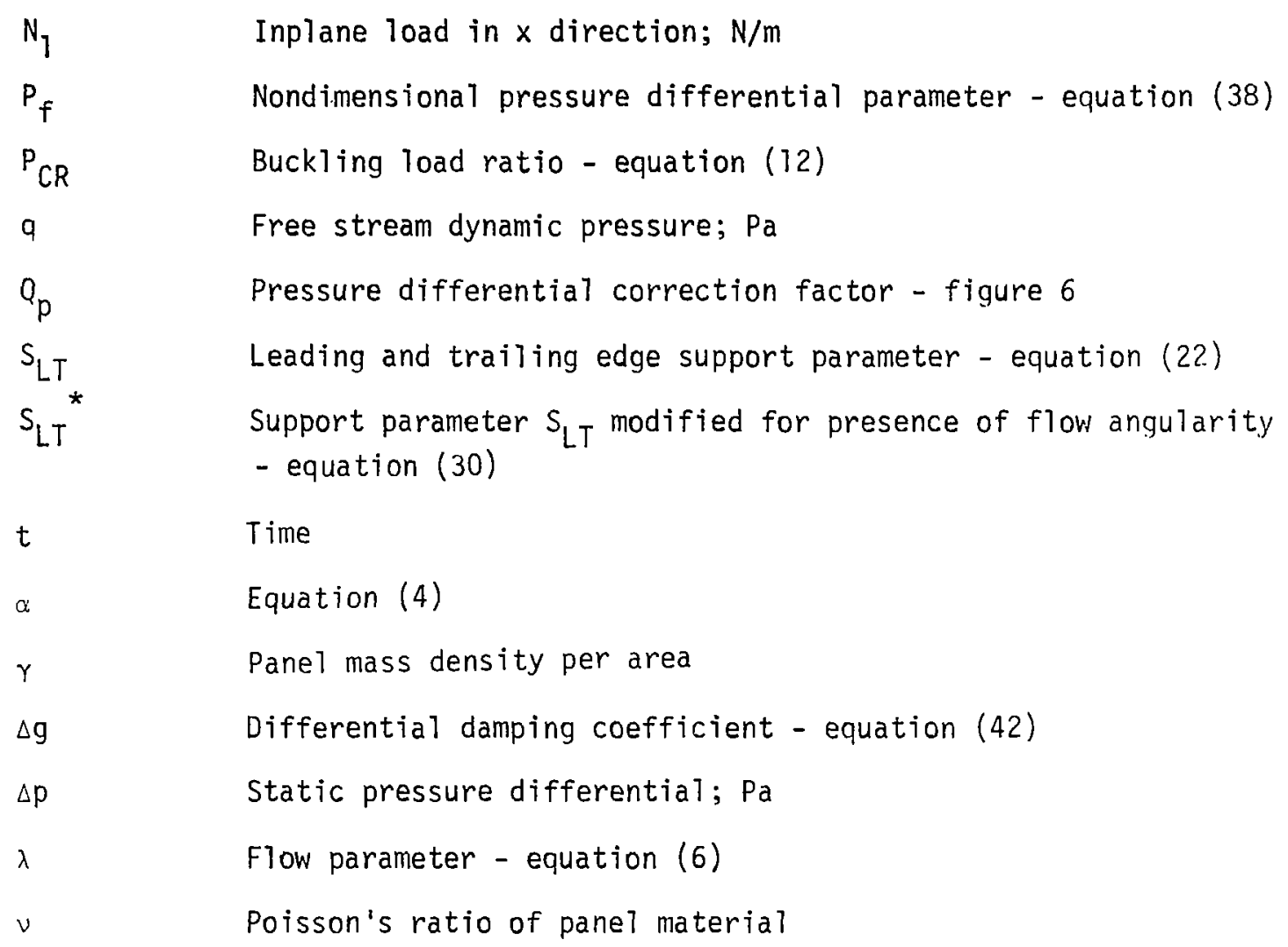

The International System of Units (SI) has been used throughout this report. The appropriate quantities are defined as follows:

$\begin{array}{lcc}\text { Quantity } & \text { Unit } & \text { SI Symbor } \\ \text { length } & \text { meter } & \mathrm{m} \\ \text { force } & \text { newton } & \mathrm{N} \\ \text { pressure } & \text { pascal } & \mathrm{Pa}\end{array}$

Abbreviations for the following prefixes have been employed for multiples of units in this report.

$\begin{array}{lcc}\text { Prefix } & \begin{array}{c}\text { Multiplying } \\ \text { Factor }\end{array} & \text { Abbreviation } \\ \text { milli } & 10^{-3} & \mathrm{~m} \\ \text { kilo } & 10^{3} & \mathrm{k} \\ \text { mega } & 10^{6} & \mathrm{M} \\ \text { giga } & 10^{9} & \mathrm{G}\end{array}$




\subsection{FLUTTER-FREE PANEL DESIGN BOUNDARIES}

To allow designers without prior panel flutter experience to consider panel flutter early in the design process, flutter-free panel design boundaries have been developed in terms of a nondimensional panel geometry parameter GP and a nondimensional flutter parameter FP. Effects of interacting parameters such as panel size, panel stiffness characteristics and panel support conditions are included in the geometry parameter. The flutter parameter contains the effects of free-stream dynamic pressure and Mach number.

The initial definition of the geometry and flutter parameters and their relationship was based on a two mode solution for flutter of simply supported orthotropic panels. The following assumed panel deflection satisfies simply supported boundary conditions

$$
w(x, y, t)=w_{11}(t) \sin \frac{\pi x}{a} \sin \frac{\pi y}{b}+w_{21}(t) \sin \frac{2 \pi x}{a} \sin \frac{\pi y}{b}
$$

The basic partial differential equation for flutter of an orthotropic panel (ref. 6) is of the form

$$
D_{1} \frac{\partial^{4} w}{\partial x^{4}}+2 D_{12} \frac{\partial^{4} w}{\partial x^{2} \partial y^{2}}+D_{2} \frac{\partial^{4} w}{\partial y^{2}}+\frac{2 q}{f(M)} \frac{\partial w}{\partial x}+r \frac{\partial^{2} w}{\partial t^{2}}=0
$$

where the aerodynamic loading has been assumed to be given by two-dimensional static aerodynamics. Employing the assumed panel deflection of equation (1), a Galerkin solution to the above yields the following set of ordinary differential equations:

$$
\begin{aligned}
& \left(\frac{\pi}{a}\right)^{4}\left[D_{1}+2 D_{12}\left(\frac{a}{b}\right)^{2}+D_{2}\left(\frac{a}{b}\right)^{4}\right] w_{11}-\frac{16 a}{3 f(M) a} w_{21}+\gamma \ddot{w}_{11}=0 \\
& \left(\frac{\pi}{a}\right)^{4}\left[16 D_{1}+8 D_{12}\left(\frac{a}{b}\right)^{2}+D_{2}\left(\frac{a}{b}\right)^{4}\right] w_{21}+\frac{16 q}{3 f(M) a} w_{11}+\gamma \ddot{w}_{21}=0
\end{aligned}
$$


Assuming a solution to equation (3) of the form

$$
w_{n 1}(t)=\bar{w}_{n 1} e^{a t}
$$

and solving the corresponding characteristic equation yields the following two mode flutter solution

$$
\lambda=\frac{3 \pi^{4}}{16}\left[15+6\left(\frac{\mathrm{D}_{12}}{\mathrm{D}_{1}}\right)\left(\frac{\mathrm{a}}{\mathrm{b}}\right)^{2}\right]
$$

In equation (5), the flow parameter $\lambda$ is expressed as

$$
\lambda=\frac{2 q a^{3}}{D_{1} f(M)}
$$

The geometry and fiutter parameters are arbitrarily defined as

$$
G P=\frac{a}{b} \sqrt{\frac{D_{12}}{D_{1}}}
$$

and

$$
F P=\frac{D_{1} f(M)}{q a^{3}}
$$

Combining equations (7) and (8) with equation (5) yields the following relationship between GP and FP for simply supported panels

$$
F P=\frac{0.0365}{5+2(G P)^{2}}
$$

A second approximate flutter solution, referred to as the preflutter solution, has been presented in several documents such as reference 7 . This approximate solution is very accurate for simply supported panels for values of GP > .1 and results in the following relationship between GP and FP

$$
F P=\frac{0.0593}{\left(5+G F^{2}\right) \sqrt{4+2 G P^{2}}}
$$


Results from the two mode solution and the preflutter solution are presented in figure 2 where GP is shown as a function of FP. Both solutions have the same trends; however, the two mode solution lacks sufficient accuracy for design purposes and the preflutter solution is not applicable to panels with edge supports which approach a fully clamped condition.

Since the approximate solutions were insufficient for design purposes, reliance was placed on more detailed flutter analyses of panels with boundary condition combinations which varied from nearly free to fully clamped to obtain the final flutter-free panel design boundaries shown in figure 3 . These analyses included both closed form solutions and well converged modal solutions so that accurate results were used to develop the boundaries.

As the effects of different parameters such as inplane loading, flow angularity, and support flexibility were considered it became necessary to redefine the geometry and flutter parameters to maintain the relationship between these two parameters given by the flutter-free pane1 design boundaries shown in figure 3. The required expressions for GP and FP were determined by combined analysis and curve fitting of experimental data. This approach was followed to duplicate the trends obtained in detailed theoretical and experimental panel flutter investigations reported in the literature.

As an example, the two mode flutter solution was extended to include the influence of inplane loads. This analysis resulted in a definition for GP to be used when inplane loads are present. To be specific, it can be shown that the two mode solution, including the influence of an inplane load in the direction of flow, $N_{1}$, takes the form

$$
\lambda=\frac{3 \pi^{4}}{16}\left\{15+6 \frac{D_{12}}{D_{1}}\left(\frac{a}{b}\right)^{2}\left(1-P_{C R}\right)-3 P_{C R}\left[1+\frac{D_{2}}{D_{1}}\left(\frac{a}{b}\right)^{4}\right]\right\}
$$


$\vec{\sim}$

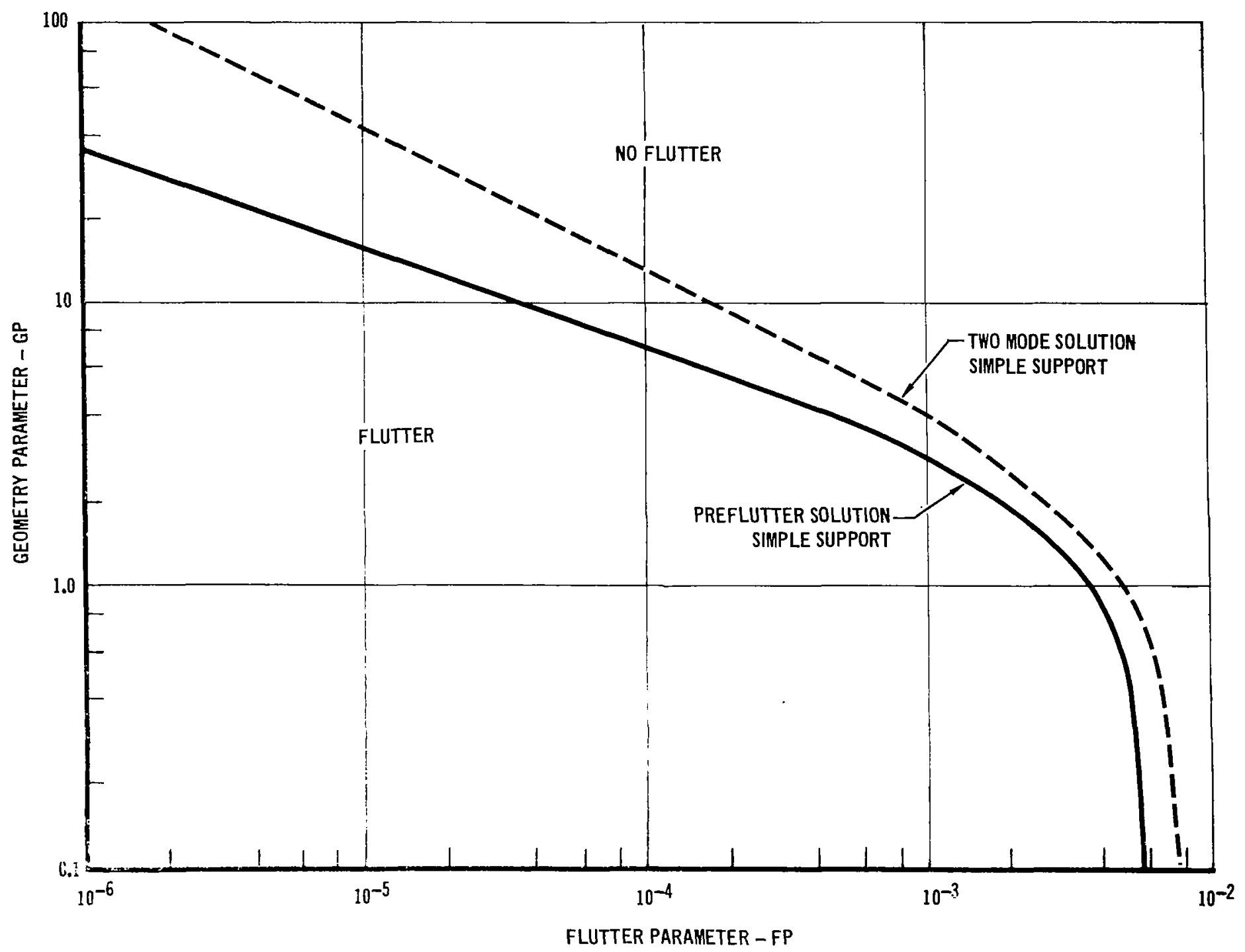

FIGURE 2 FLUTTER-FREE PANEL DESIGN BOUNDARIES FROM APPROXIMATE SOLUTIONS 


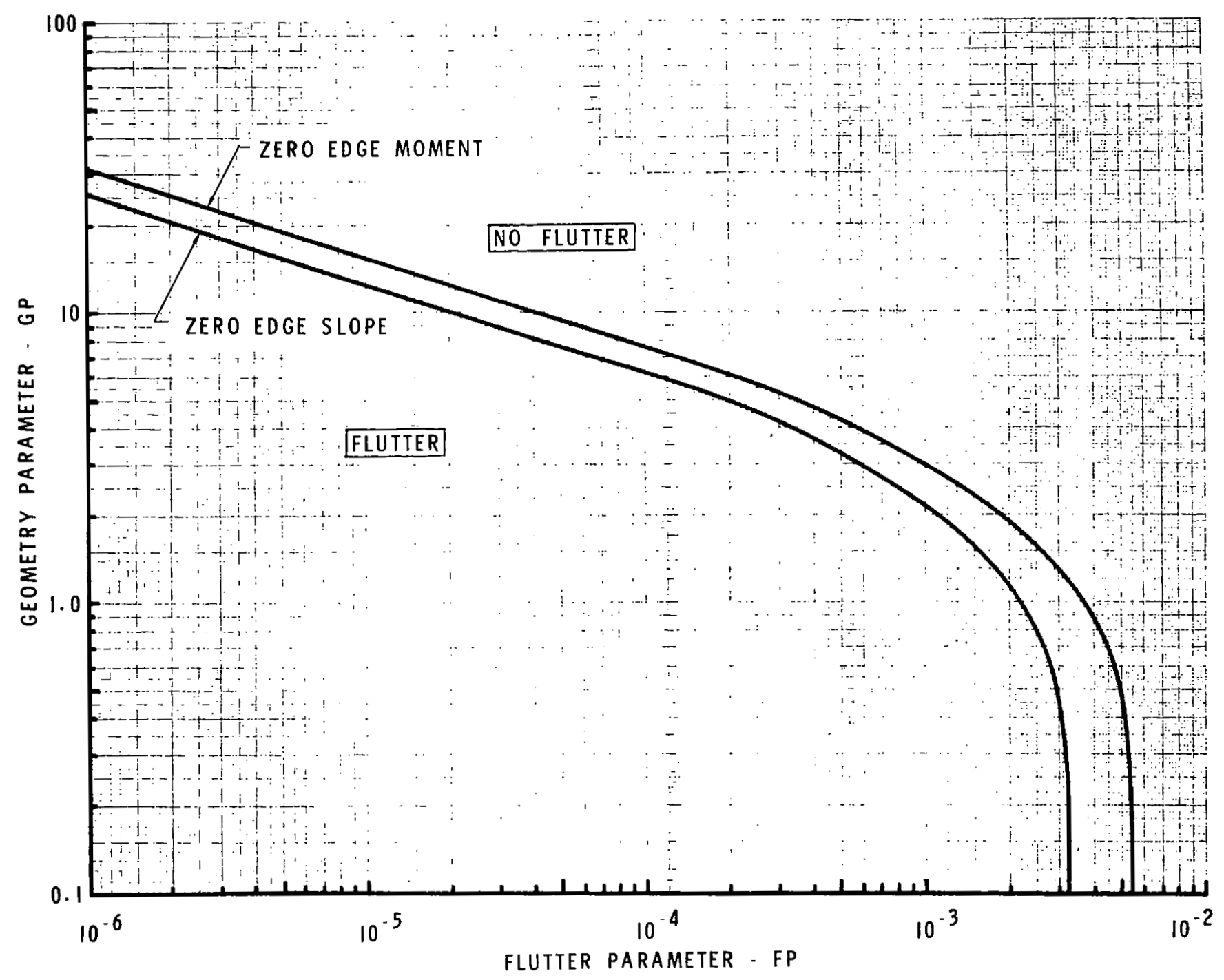


In equation (11) ${ }_{C}$ is the ratio of the inplane load $N_{1}$ to the buckling load $N_{C R}$. Thus,

$$
P_{C R}=N_{7} / N_{C R}
$$

Comparing equations (5) and (11) reveals that the second term of equation (11) indicates a new definition for GP of the form

$$
G P=\frac{a}{b} \sqrt{\frac{D_{12}}{D_{1}}\left(1-P_{C R}\right)}
$$

As will be discussed in Section 4.3, equation (13) is in fact the form for GP that was selected to account for the presence of inplane loads. For a pane1 with inplane loads, modifications to the FP relationship of equation (8) were then made by correlating flutter predictions with available experimental data.

For ease of computer application and to assist the designer in making accurate determinations of FP once GP has been calculated, analytical expressions of the design boundaries were determined by curve fitting techniques. These expressions take the form

$$
F P=\frac{E_{c}}{5+2(G P)^{2}+0.18(G P)^{3}}
$$

where $E_{C}$ is the panel edge rotational restraint coefficient defined as

$$
E_{c}=0.016
$$

for a panel with zero edge slope and

$$
E_{C}=0.027
$$

for a panel with zero edge moment. Thus for a given value of GP, the corresponding magnitude of FP may be obtained from equation (14) with the appropriate $E_{C}$. 
The relationship of equation (14) is valid over the range of GP's between slightly more than zero $(0.1)$ and 5.0. For values of GP lower than 0.1 , the coefficient $E_{C}$ is defined as

$$
E_{C}=0.0157
$$

for a panel with zero edge slope and

$$
E_{C}=0.0292
$$

for a panel with zero edge moment. 


\subsection{DESIGN BOUNDARY APPLICATION}

The steps required in the application of the flutter-free panel design boundary during preliminary design of lightweight external surface panels are detailed in this section. Parameters which are included in this design approach as they influence panel flutter are:

- Panel aspect ratio

- Panel orthotropic properties

- Support flexibility

- Inplane loads

- Static pressure differential

- Flow angularity

- Structural damping

Verification of these design procedures is addressed in Section 6.0 .

In the application of the flutter-free panel design boundary, the basic approach involves the determination of the magnitude of GP for the panel configuration of interest. The design boundary (fig. 3) is then entered with this value and the corresponding magnitude of FP obtained. With this value of the Flutter Parameter, the flutter critical flight condition may be defined. The forms taken by the parameters FP and GP depend on the particular situation under consideration. Definition of these parameters and their application in conjunction with the design boundary is detailed in the following sections.

The steps required for application of the panel flutter design procedure during the design of lightweight surface panels are summarized in figure 4 . The basic geometry data required are the panel length $a$, width $b$, and orthotropic stiffness properties $D_{1}, D_{2}$, and $D_{12}$. A number of techniques for the determination of these panel stiffness parameters are presented in Appendix $A$. For an isotropic panel these three panel stiffness properties are equal and are expressed as

$$
D=\frac{h^{3} E}{12\left(1-v^{2}\right)}
$$




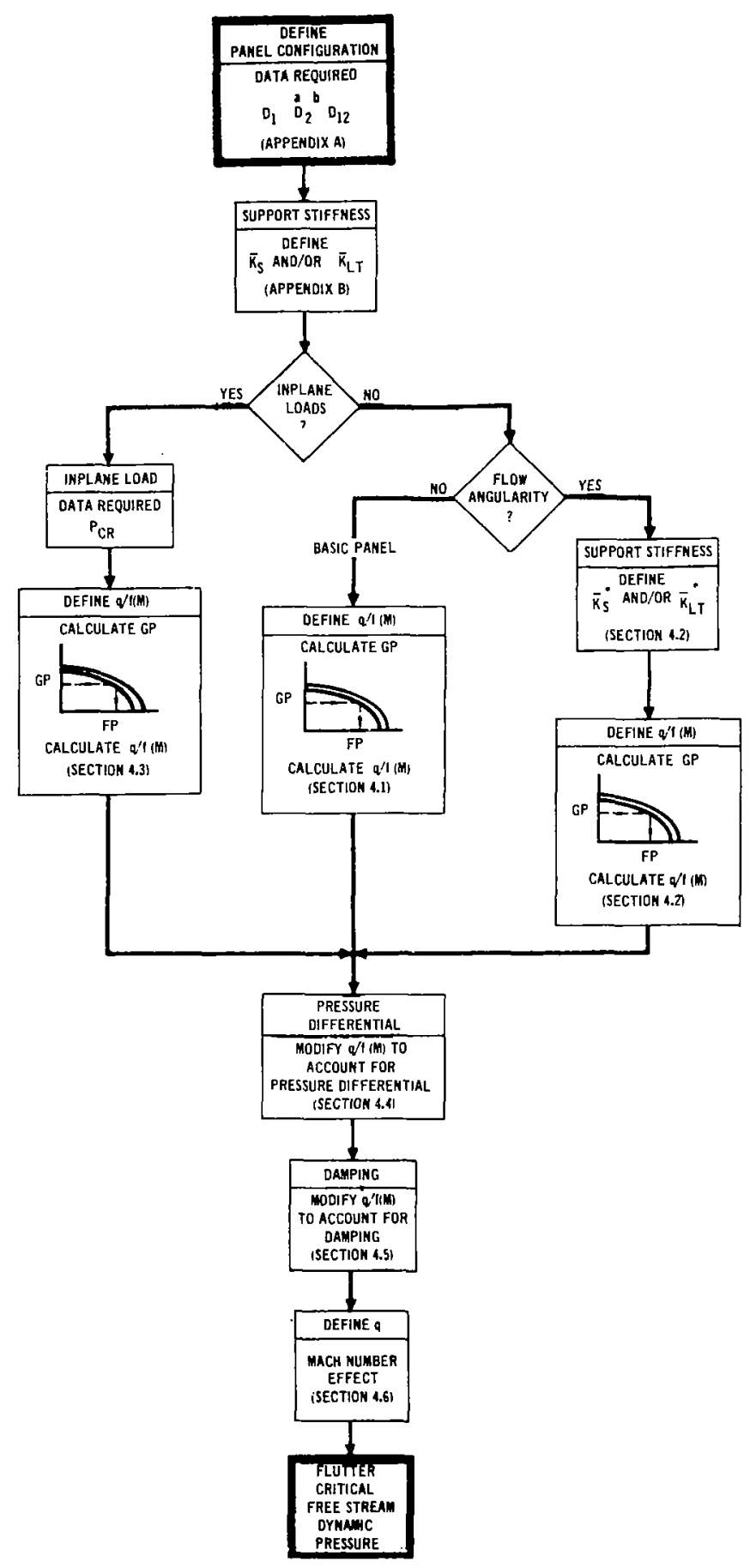

FIGURE 4 PANEL DESIGN PROCEDURE 
When the influence of deflectional support flexibility is to be included in the design the nondimensional stream edge stiffness parameter $\bar{K}_{S}$ and/or leading and trailing edge parameter $\bar{K}_{L T}$ are required. These quantities are defined for a number of support conditions in Appendix B.

Several options available for use with the flutter-free panel design boundary are indicated in figure 4 . This is to aid the designer in selecting the correct procedures to be followed when applying these panel flutter design criteria. For each option, reference is made in the figure to the report section detailing the application of the design boundary to a particular panel configuration. A number of examples detailing the use of these panel design procedures are discussed in Section 5.0 .

The procedures to be followed in defining the magnitude of the geometry parameter for the panel configuration of interest are presented in the following sections. With this quantity, the flutter parameter is obtained from the flutter-free panel design boundary. This value of FP is then used to obtain the critical dynamic pressure parameter $q / f(M)$, where $q$ is the free stream dynamic pressure and $f(M)$ is the Mach number correction factor.

Modifications to the dynamic pressure parameter for a static pressure difference across the panel are covered in Section 4.4. As discussed in Section 4.5 , the quantity $q / f(M)$ may require modification to account for the presence of significant structural damping in the system. With this modified dynamic pressure parameter, the flutter critical dynamic pressure is obtained with the procedures detailed in Section 4.6.

4.1 Basic Panel - For an orthotropic panel with no inplane load and zero flow angularity, the geometry and flutter parameters are defined as

$$
G P=\frac{a}{b} \sqrt{\frac{D_{12} / D_{1}}{1+c^{2} / \bar{K}_{S}}}
$$

and 


$$
F P=S_{L T} \frac{D_{1} f(M)}{q a^{3}}
$$

In equation (20), $\bar{K}_{S}$ is the nondimensional stream edge deflectional support stiffness and in equation (21) $\mathrm{S}_{\mathrm{LT}}$ is the leading and trailing edge support parameter expressed as

$$
S_{L T}=e^{-\left(\frac{7 l}{12 \bar{K}_{L T}+\bar{K}_{L T}{ }^{2}}\right)^{1 / 2}}+e^{\left(\frac{-2 \bar{K}_{L T}}{(a / b)^{2}\left(D_{12} / D_{1}\right)}\right)}
$$

where $\bar{K}_{L T}$ is the nondimensional stiffness parameter associated with the leading and trailing edge support flexibility. Additionally, the quantity $C$ required in equation (20) is defined by the following expression

$$
c=\sqrt{\frac{D_{12}{ }^{2}}{D_{1} D_{2}}}
$$

In this application the concept of support flexibility refers to a panel edge which is not completely restrained against deflections normal to the pane $T$. Thus, in this case the panel boundary condition is less rigid than either a simply supported or clamped edge. Appendix $B$ contains a number of procedures which may be employed to determine the magnitudes of the nondimensional edge support parameters $\bar{K}_{S}$ and $\bar{K}_{L T}$. For panel configurations with unequal flexible supports on opposite edges an average value of the nondimensional edge support parameters $\bar{K}_{S}$ and $\bar{K}_{L T}$ should be used except for values of $\bar{K}_{L T}$ less than about five. At values of $\bar{K}_{L T}$ less than five a flutter analysis should be conducted since theory (ref. 8) indicates large reductions in flutter margins can occur at low values of $\bar{K}_{L T}$ for unequal supports at the panel leading and trailing edges.

The theoretical trends presented in reference 9, of flutter critical flow conditions versus leading and trailing edge support stiffness, were 
employed in obtaining the equation (22) definition of $S_{L T}$. The modifying term $c^{2} / \bar{K}_{S}$ present in equation (20), which accounts for the stream edge support stiffness, was obtained by matching the experimental trends presented in reference 10 .

As the stream edge deflectional support stiffness $\bar{K}_{S}$ approaches infinity the quantity $C^{2} / \bar{K}_{S}$ approaches zero and equation (20) becomes

$$
G P=\frac{a}{b} \sqrt{\frac{D_{12}}{D_{1}}}
$$

Likewise, for a $\bar{K}_{L T}$ approaching infinity, the magnitude of $S_{L T}$ approaches one and equation (21) may be written as

$$
F P=\frac{D_{1} f(M)}{q a^{3}}
$$

With the magnitude of GP defined with either equation (20) or (24), the corresponding value for FP is obtained from the design boundaries in figure 3 . The dynamic pressure parameter $q / f(M)$ may be determined as appropriate, from equation (21) or (25). Potential modifications to $q / f(M)$ for static pressure differential are presented in Section 4.4 and for structural damping are covered in Section 4.5. The evaluation of $f(M)$ allowing definition of the flutter critical dynamic pressure is discussed in Section 4.6.

4.2 Flow Angularity - For flow at an angle, and with edge flexibility included, the geometry and flutter parameters are defined as

$$
G P=\frac{a}{b} \sqrt{\frac{D_{12} / D_{1}}{1+c^{2} / \bar{K}_{S}^{*}}\left[\cos ^{2} \Lambda+\frac{D_{1}}{D_{2}}\left(\frac{b}{a}\right)^{4} \sin ^{2} \Lambda\right]}
$$

\footnotetext{
*Choice of the design boundary is dependent on the degree of rotational restraint along the panel edges. Most panels are probably adequately represented by the zero edge slope boundary; however, a more conservative design results from the zero moment boundary.
} 
and

$$
F P=\frac{D_{1} f(M)}{q a^{3}} \frac{S_{L T}{ }^{*}}{\cos ^{2} \Lambda+\frac{D_{1}}{D_{2}}\left(\frac{b}{a}\right)^{3} \sin ^{2} \Lambda}
$$

In equations (26) and (27), $\Lambda$ is the magnitude of flow angularity show in figure 1 and $\bar{K}_{S}{ }^{*}$ and $S_{L T}{ }^{*}$ are edge support flexibility parameters modified to account for the flow angularity.

The modified nondimensional edge support stiffness parameters including the influence of flow angularity are given as

$$
\overline{\mathrm{K}}_{\mathrm{S}}^{*}=\frac{1}{\frac{\cos ^{2} \Lambda}{\bar{K}_{S}}+\frac{\sin ^{2} \Lambda}{\bar{K}_{L T}}}
$$

and

$$
\bar{K}_{L T}^{*}=\frac{1}{\frac{\sin ^{2} \Lambda}{\bar{K}_{S}}+\frac{\cos ^{2} \Lambda}{\bar{K}_{L T}}}
$$

The modified leading and trailing edge support parameter $S_{L T}{ }^{*}$ is of the form

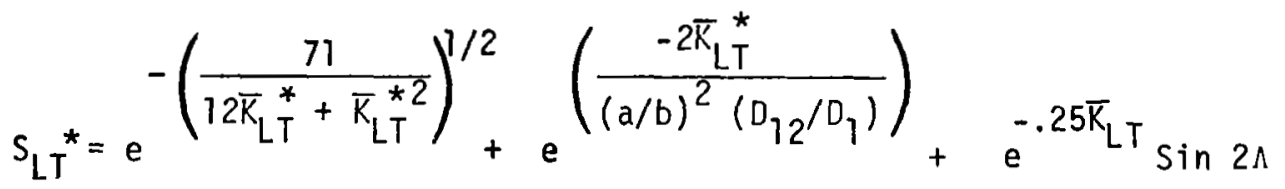

The expressions for GP and FP given by equations (26) and (27) were chosen to assure correct results for a flow angle of 90 degrees. That is, for a 90 degree flow angle, the $a$ and $b$ panel dimensions and the panel stiffness properties are properly interchanged. The combination of flow angularity and panel edge support flexibility has been expressed in terms of effective 
edge support stiffness parallel and perpendicular to the flow. Thus, the modified edge support stiffness parameters of equations (28) and (29) are based on the assumption that the leading and trailing edge springs act in parallel with the stream edge springs. The last term of equation (30) is included to match the experimental trends for panels with flow angularity such as presented in reference 11 .

For panel configurations which include both edge support flexibility and flow angularity, the application of equations (28) through (30) in combination with the relations presented for FP and GP can result in inaccurate flutter predictions. This occurs when the second term in the expression for $S_{L T}$ [eq. (22)] is not small when compared to the magnitude of the first term. To overcome this difficulty, an equivalent nondimensional leading and trailing edge support stiffness was defined as

$$
\bar{K}_{L T} \text { eq }=\sqrt{\frac{71}{\ln ^{2}\left(S_{L T}\right)}+36}-6
$$

where $S_{L T}$ is obtained from equation (22) for the particular value of $\bar{K}_{L T}$. The magnitudes of GP and FP are then obtained from equations (26) and (27) where $S_{L T}$ * and $\bar{K}_{S}$ * are based on the quantities $\bar{K}_{S}$ and $\bar{K}_{L T}$ eq.

For configurations where the edge support stiffness parameters $\bar{K}_{S}$ and $\bar{K}_{L T}$ approach infinity (total edge deflection restraint), equations (26) and (27) become

$$
G P=\frac{a}{b} \sqrt{\frac{D_{12}}{D_{1}}\left[\cos ^{2} \Lambda+\frac{D_{1}}{D_{2}}\left(\frac{b}{a}\right)^{4} \sin ^{2} \Lambda\right]}
$$

and

$$
F P=\frac{D_{1} f(M)}{q a^{3}}\left\lfloor\frac{1}{\cos ^{2} \Lambda+\frac{D_{1}}{D_{2}}\left(\frac{b}{a}\right)^{3} \sin ^{2} \Lambda}\right]
$$


It should be noted that the definitions for the geometry and flutter parameters and the edge support stiffness parameters are based on data at flow angles of zero and in the range from about 15 to 90 degrees. Analysis (ref. 6) indicates that slight variations in flow angle in the region of zero to 15 degrees can have large effects on flutter conditions. Due to lack of experimental flutter data for flow angles of zero to 15 degrees some uncertainty exists about the validity of the current design approach in this region. When effects of flow angularity are to be included a conservative design can be obtained if the panel is considered for both zern and 90 degree flow and the design based on the worst case.

With the magnitude of FP obtained for the appropriate deflection edge support condition, the dynamic pressure parameter $q / f(M)$ can be evaluated. The effects of static pressure differential, Section 4.4; structural damping, Section 4.5; and Mach number, Section 4.6, should be examined and included in the determination of the flutter critical dynamic pressure when significant.

4.3 Inplane Loads - The flutter-free panel design boundary has application to panels subjected to inplane loading if the flow is parallel to the $x$ axis. In addition, the panel stream edges may have either total deflectional restraint or some edge support flexibility as defined by $\bar{K}_{S}$. The leading and trailing edges are assumed to have complete deflectional restraint. Figure 5 illustrates a panel subjected to inplane loading.

For this configuration the geometry parameter is given as

$$
G P=\frac{a}{b} \sqrt{\frac{D_{12}}{D_{1}} \frac{1-P_{C R}}{1+C^{2} / \bar{K}_{S}}}
$$

and the corresponding expression for the flutter parameter is

$$
F P=\frac{D_{1} f(M)}{q a^{3}}\left[\frac{1}{1+\left(P_{C R}\right)^{2 b / a}\left(\frac{D_{1}}{D_{2}}\right)\left(2 \pi \frac{b}{a}\right)^{2}}\right]
$$




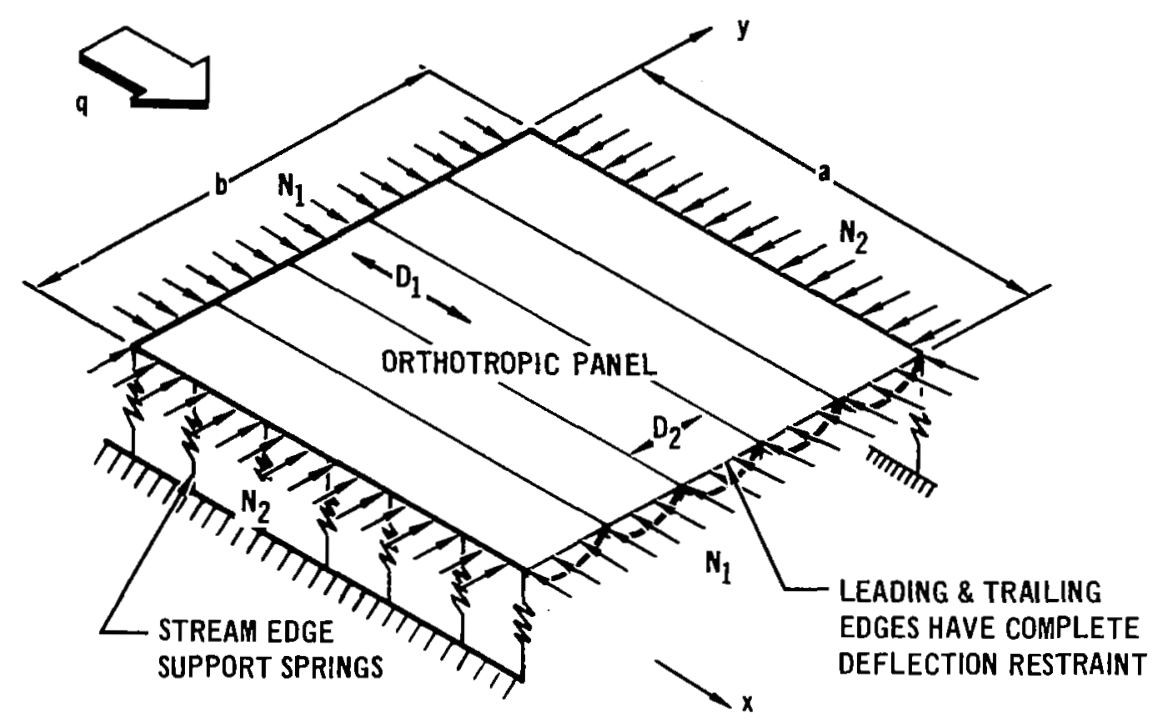

FIGURE 5 PANEL WITH INPLANE LOADING

The quantity $P_{C R}$, equations (34) and (35), is the ratio of the inplane load $\mathrm{N}_{1}$ in the $x$ direction to the critical buckling load $\mathrm{N}_{\mathrm{CR}}$, Thus

$$
P_{C R}=N_{l} / N_{C R}
$$

As indicated in Section 3.0 by equation (13), the basic form for GP including the influence of inplane loads is based on the two mode flutter solution. The $C^{2} / \bar{K}_{S}$ term in equation (34) was added to yield results consistent with equation (20). The form of the flutter parameter given by equation (35) was obtained by matching trends in experimental panel flutter data, primarily from reference 12 .

To make flutter predictions for a panel with inplane loading, the magnitude of $N_{C R}$ is required for use in equation (36). Evaluation of this buckiing load parameter must account for both the $N_{1}$ and $N_{2}$ loadings (fig. 5). Procedures for obtaining $\mathrm{N}_{C R}$ are presented in references 13 and 14 . 
Often in preliminary design neither the magnitude of the inplane loads nor the critical buckling load are known with any degree of confidence. As indicated in reference 15, for a given panel configuration subjected to inplane loading, the minimum dynamic pressure for pane1 flutter occurs at the transition point between an unbuckled and buckled panel. Thus, a conservative approach, when the effects of inplane loading are desired, would be to assume a value for $P_{C R}$ of one. Equation (34) shows that when $P_{C R}$ equals one the geometry parameter equals zero. In this situation the magnitude of the flutter parameter may be obtained from equation (14). The flutter critical dynamic pressure is then obtained from equation (35).

The design approach is limited to panel configurations with normal inplane loads and does not account for the possibility of inplane shear loading. A recent theoretical investigation of this question of combined normal and shear inplane loads is presented in reference 16. The conclusion of this study is that designs for panels at buckling due to inplane shear or combinations of inplane shear and normal loads will be conservative if it is assumed that the panels buckle due to $\mathrm{N}_{7}$ alone.

With the established value of $F P$, the magnitude of $q / f(M)$ is determined from equation (35). The flutter critical dynamic pressure $q$ is then obtained after consideration of the effects of static pressure differential, Section 4.4; structural damping, Section 4.5; and Mach number, Section 4.6.

\subsection{Static Pressure Differential - It has been shown experimentally} (refs. 17 and 18) that a static pressure differential $\Delta p$ across the panel has a significant effect on the panel flutter boundary. This effect is due to the inplane stresses that are induced by this pressure differential. These stresses are always tensile regardless of the direction in which $\Delta p$ acts and increase the effective stiffness of the panel. Thus, the effect of this differential pressure is to raise the panel's flutter boundary.

In reference 17, the effect of a pressure differential is described through a nondimensional parameter given as

$$
P=\frac{\Delta p a^{4}}{D h}
$$


where an isotropic panel is assumed. For an orthotropic panel an analogous nondimensional parameter of the form

$$
P_{f}=\frac{\Delta p a^{4}}{D_{1} h_{e q}}
$$

has been defined. In this expression $h_{e q}$ is an equivalent isotropic panel thickness quantity related to the orthotropic panel stiffness properties and is defined as

$$
h_{\text {eq }}=\frac{1}{2}\left(\sqrt[3]{\frac{12 D_{1}}{E}}+\sqrt[3]{\frac{12 D_{2}}{E}}\right)
$$

The dynamic pressure parameter including the influence of a static pressure differential becomes

$$
\frac{q_{p}}{f(M)}=q_{p} \frac{q}{f(M)}
$$

where $Q_{p}$ is the ratio of the dynamic pressure parameter $q_{p} / f(M)$, which includes the effects of $\Delta p$, to $q / f(M)$ which does not include pressure differential effects. Shown in figure 6 , as a function of $P_{f}$, is the parameter $Q_{p}$ for panels with several length to width ratios. These trends are based on experimental data discussed in references 17 and 18 .

The results summarized in figure 6 form the basis for including the influence of a $\Delta p$ in the panel design. Following the determination of the flutter critical parameter $q / f(M)$, as covered in the preceding sections, the magnitude of $P_{f}$ is calculated from equation (38). With this value of $P_{f}$, the appropriate $Q_{p}$ is obtained from figure 6 and the updated quantity $q_{p} / f(M)$ obtained.

4.5 Structural Damping - The influence of structural damping in a panel system with inplane loading is accounted for through a damping factor 


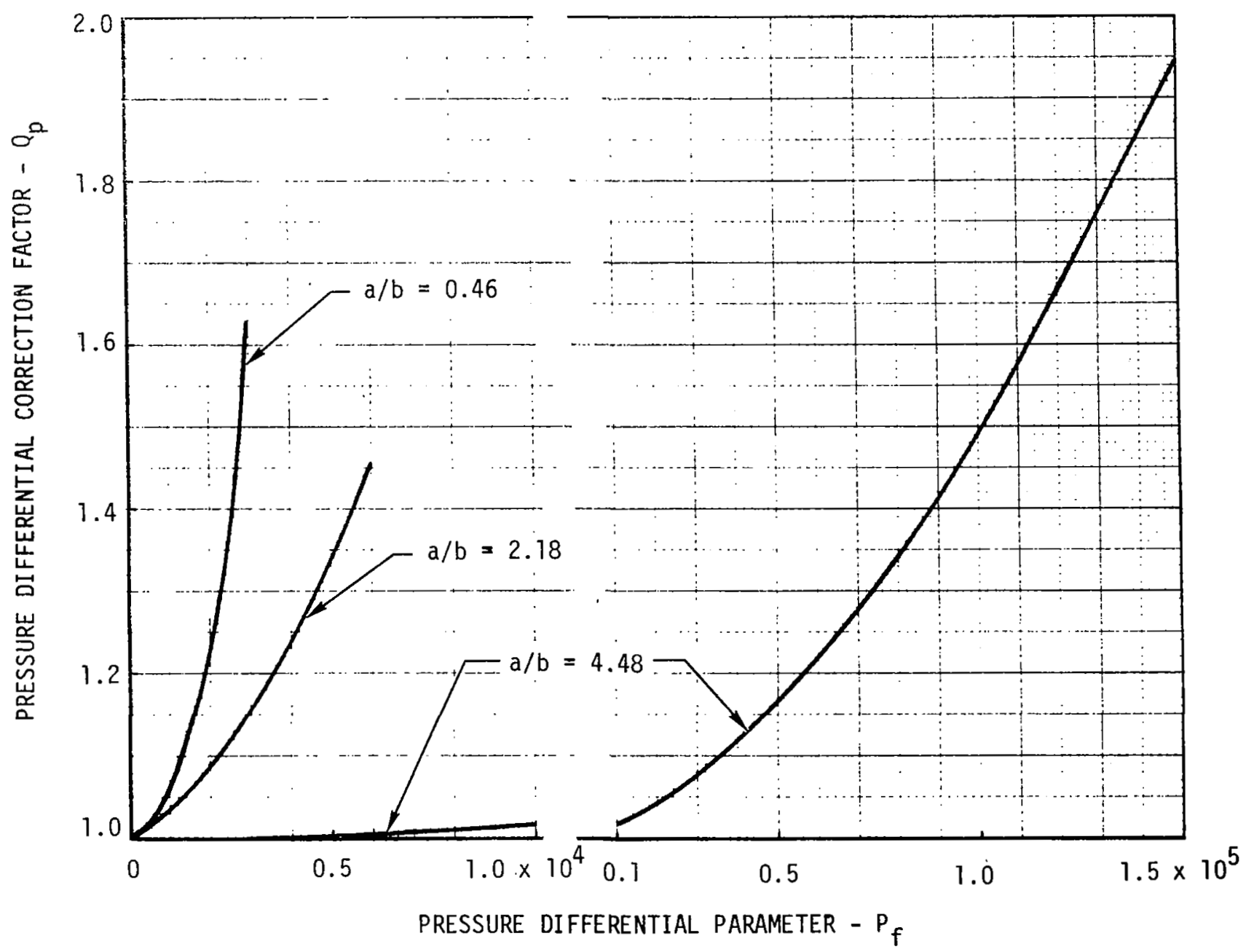

FIGURE 6 PRESSURE DIFFERENTIAL CORRECTION FACTOR 
$D_{f}$, defined as

$$
D_{f}=\left[1+100 P_{C R} \Delta g\right]
$$

In the above $P_{C R}$ is the buckling load ratio of equation (36) and the quantity $\Delta \mathrm{g}$ is expressed as

$$
\Delta g=g-0.01
$$

where $\mathrm{g}$ is the damping coefficient assumed in the system.

With the definition of $D_{f}$, equation (41), the dynamic pressure parameter including the influence of damping is obtained from the following relationship.

$$
\frac{q_{d}}{f(M)}=D_{f} \quad \frac{q}{f(M)}
$$

The quantity $q / f(M)$ in equation (43) is the result of the flutter prediction employing the flutter-free design boundary as discussed in the previous sections, and $q_{d} / f(M)$ is the updated quantity including the effects of damping.

The quantity $\Delta \mathrm{g}$ is defined as indicated by equation (42) because application of the design procedures produce results which compare well with theoretical results for panels with inplane loading and panel damping represented by a structural damping coefficient of 0.01 . Thus, results obtained from the design boundary may be thought of as including "nominal" damping of this magnitude. The parameter $\Delta g$ is introduced in the damping factor to account for panel damping which is higher than this nominal value.

The above form of $D_{f}$ was obtained through comparison with the results of references 15 and 19 . These references present trends, obtained during detailed theoretical investigations, of flutter critical flow conditions as influenced by inplane loading and structural damping. 
4.6 Mach Number Effect - Use of the dynamic pressure parameter $q / f(M)$ to describe the flutter critical free stream flow conditions is based on the commonly used linear piston theory, reference 20 , to represent the aerodynamic forces acting on the panel. As indicated in reference 20 , experience has shown that use of this aerodynamic theory in conjunction with $f(M)$ defined as

$$
f(M)=\sqrt{M^{2}-1}
$$

yields flutter boundaries that exhibit excellent agreement with those given by more refined theories, provided the Mach number is higher than approximately 1.6 to 2.0 .

For application with the flutter-free panel design boundary, $f(M)$ is assumed to take the form of equation (44) for Mach numbers greater than 2.0 and is defined as shown in figure 7 for Mach numbers in the range of 1.0 to 2.0. These curves were derived from experimental data discussed in reference 18. Following determination of the parameter $q / f(M)$ through application of the design boundary and including modifications for potential static pressure differential and damping effects, the flutter critical free stream dynamic pressure is obtained for the Mach number correction factor defined by either equation (44) or figure 7. 


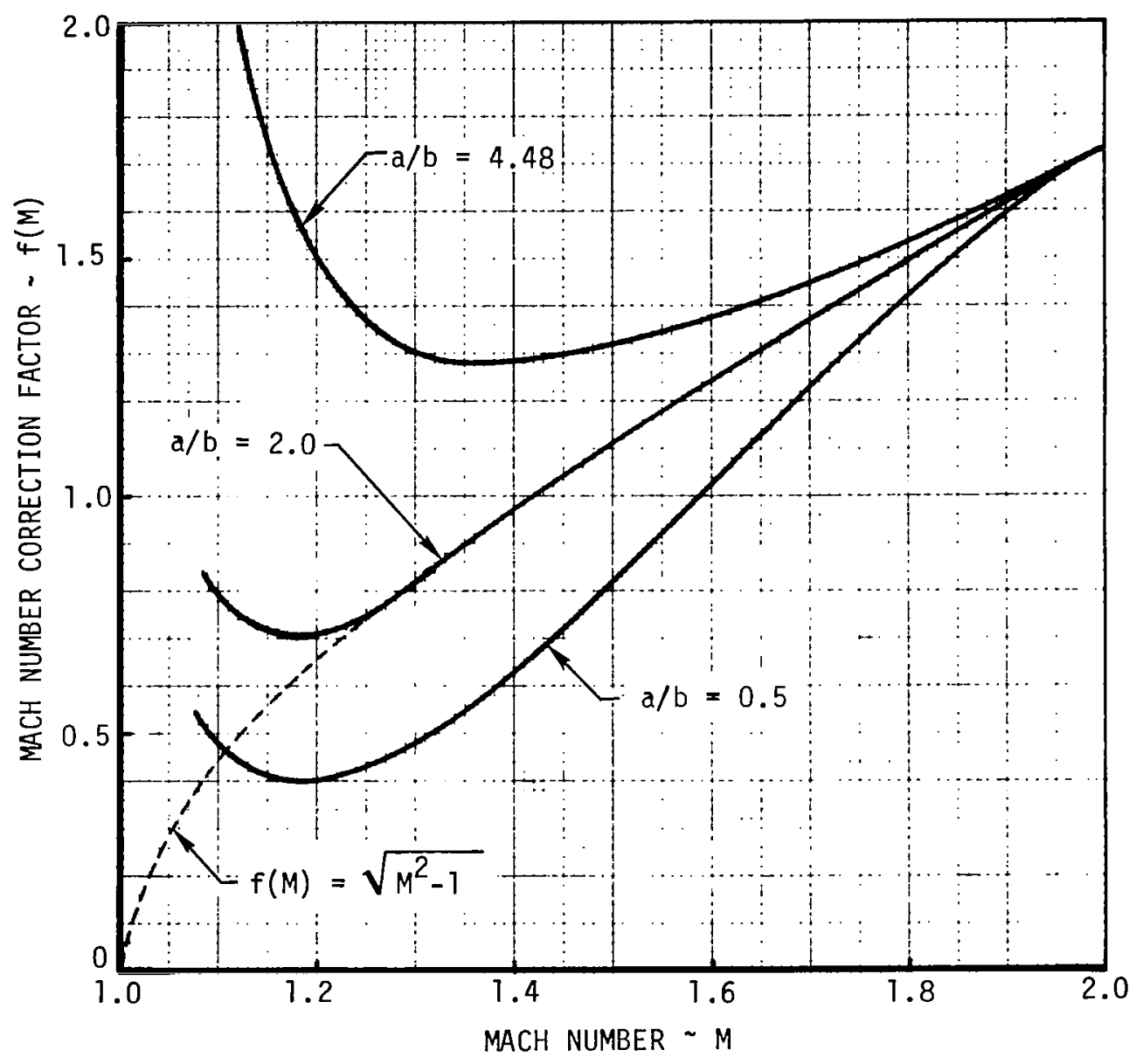

FIGURE 7 MACH NUMBER CORRECTION FACTOR 



\subsection{EXAMPLE APPLICATIONS OF DESIGN PROCEDURE}

Several examples are presented which illustrate the use of the panel design procedures detailed in Section 4.0. Both isotropic and orthotropic panels with various combinations of support conditions, inplane loading, and flow angularity are discussed. In all cases, it has been assumed that the applicable factors of safety have been considered in arriving at the stated free stream dynamic pressure requirements.

5.1 Uniform Panel with Inplane Loads - It is desired to determine the thickness of a uniform aluminum panel required to preclude flutter when the panel is subjected to an inplane load that is 75 percent of its buckling load. A sketch of the panel is shown in figure 8 and details of this configuration are as follows:

$$
\begin{aligned}
& \text { Simply supported panel } \\
& \mathrm{a}=0.25 \mathrm{~m} \\
& \mathrm{~b}=0.65 \mathrm{~m} \\
& \mathrm{E}=69 \mathrm{GN} / \mathrm{m}^{2} \\
& P_{C R}=0.75 \\
& M=2.5 \\
& q=40 \mathrm{kPa}
\end{aligned}
$$

Figure 4 shows that the design approach for a panel with inplane loading is detailed in Section 4.3. For an isotropic panel, the panel stiffness properties $D_{1}$ and $D_{12}$ are equal and equation (34) becomes

$$
G P=\frac{a}{b} \sqrt{1-P_{C R}}
$$

The above expression also reflects that for a panel simply supported at all edges, the quartity $\bar{K}_{S}$ approaches infinity and thus, the $c^{2} / \bar{K}_{S}$ term of equation (34) approaches zero. Thus the magnitude of the geometry parameter for this particular panel configuration becomes:

$$
G P=0.192
$$




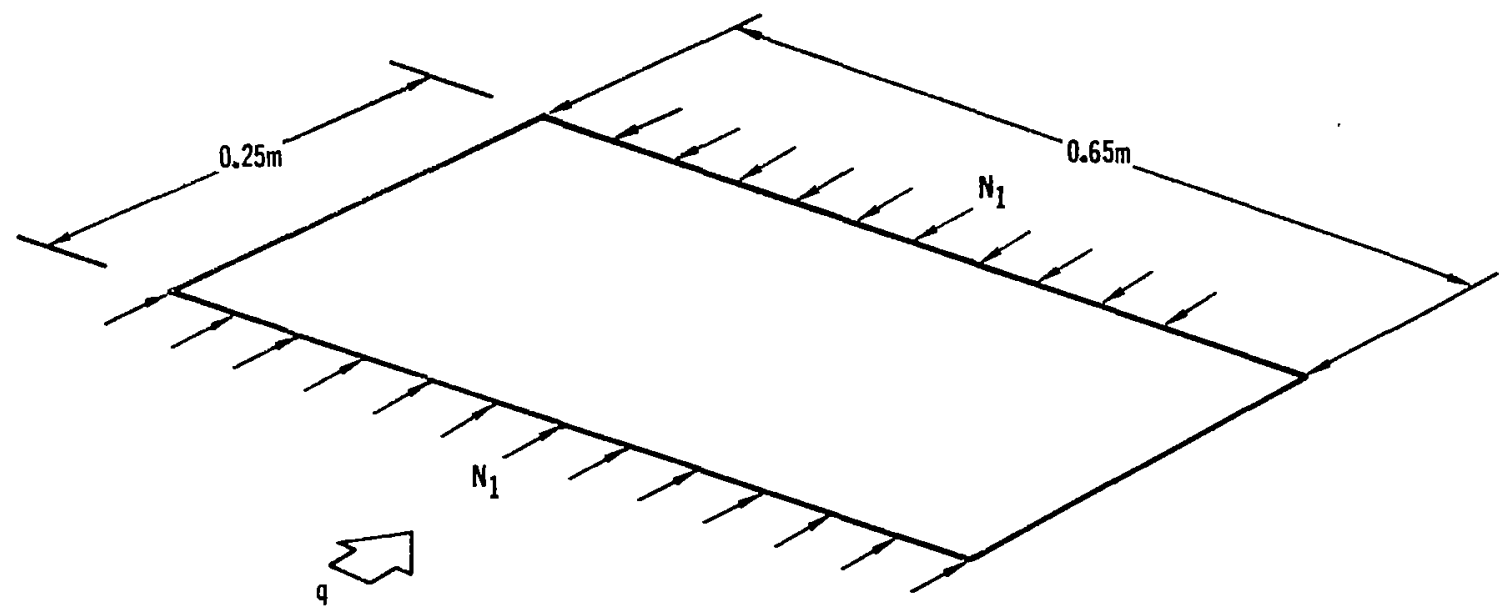

SIMPLE SUPPORT AT ALL EDGES

FIGURE 8 UNIFORM PANEL WITH INPLANE LOADING

From equation (14) with an $E_{C}$ of 0.027 or from figure 3 , the magnitude of the flutter parameter is determined to be

$$
F P=0.00532
$$

From equation (35) the panel stiffness parameter to preclude flutter may be expressed as

$$
D=\frac{F P g a^{3}}{f(M)}\left[1+(P C R)^{2 b / a}\left(2 \pi \frac{b}{a}\right)^{2}\right]
$$

where $q$ is the free stream dynamic pressure requirement. Note that it has been assumed that no modifications to the dynamic pressure which account for damping or pressure differential effects are required. The Mach number correction factor (Sec. 4.6) is given as

$$
f(M)=\sqrt{M^{2}-1}=2.29
$$

and the resulting panel stiffness requirement becomes

$$
D=88.26 \mathrm{~N}-\mathrm{m}
$$


For an isotropic panel, the panel stiffness is expressed as

$$
D=\frac{h^{3} E}{12\left(1-v^{2}\right)}
$$

where $E$ is the material modulus of elasticity, $h$ the panel thickness, and $v$ the material Poisson's ratio. Using a value of 0.3 for $v$, the panel thickness requirement to preclude fiutter becomes

$$
h=2.4 \mathrm{~mm}
$$

\subsection{Elastically Supported Orthotropic Panel - An orthotropic panel}

simply supported at the leading and trailing edges and elastically supported at the stream edges as shown in figure 9 is to be evaluated for flutter. The influence of stream edge flexibility on the flutter critical dynamic pressure at a Mach number of 1.7 is required to aid in the definition of the support springs. The physical characteristics for the panel are as follows:

$$
\begin{aligned}
a & =0.45 \mathrm{~m} \\
b & =0.90 \mathrm{~m} \\
E & =70 \mathrm{GN} / \mathrm{m}^{2}
\end{aligned}
$$

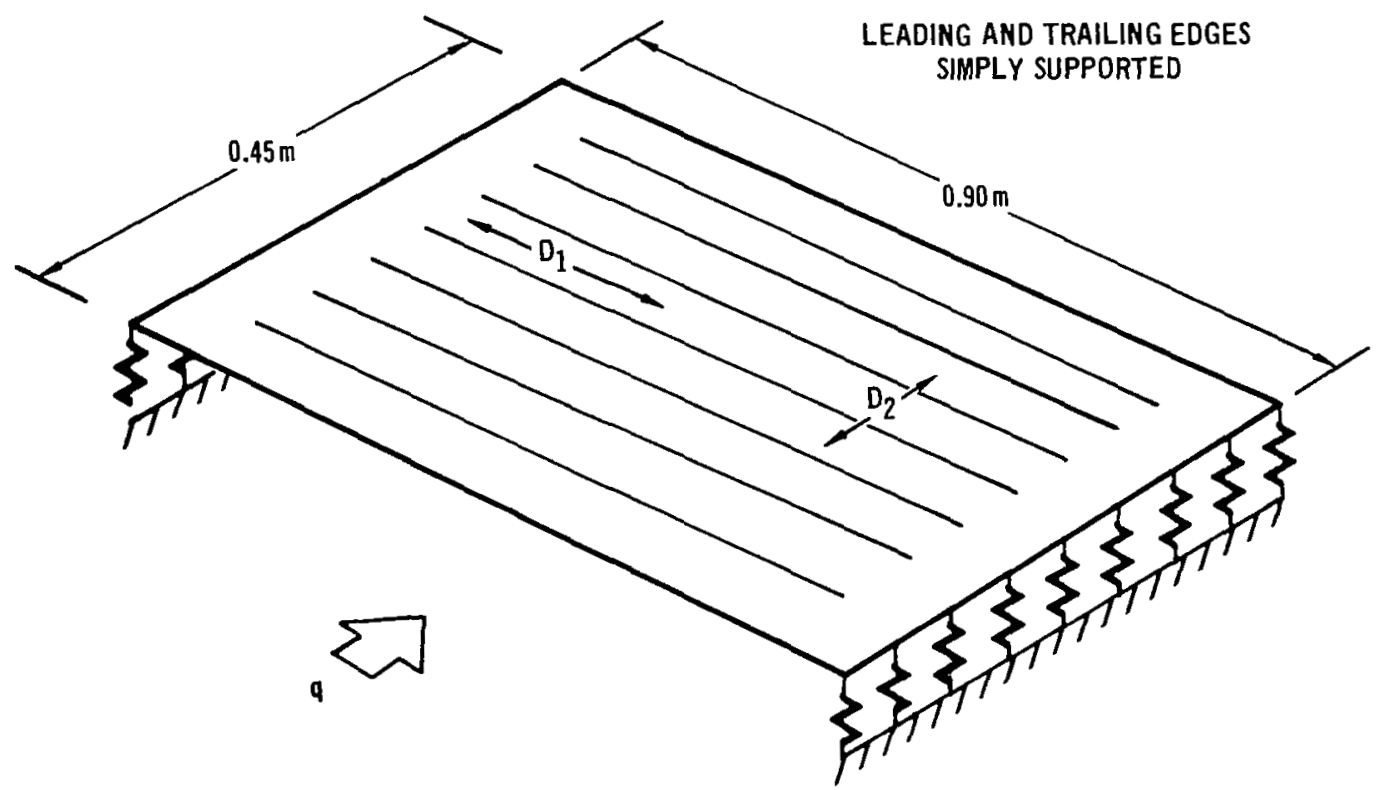

FIGURE 9 ELASTICALLY SUPPORTED ORTHOTROPIC PANEL 


$$
\begin{aligned}
& D_{1}=10 \mathrm{~N}-\mathrm{m} \\
& D_{2}=2000 \mathrm{~N}-\mathrm{m} \\
& D_{12}=750 \mathrm{~N}-\mathrm{m} \\
& \Delta \mathrm{p}=2 \mathrm{kPa} \\
& K_{D}=\text { range of } 2 \text { to } 20 \mathrm{MN} / \mathrm{m} / \mathrm{m} \\
& \text { Zero flow angle }
\end{aligned}
$$

From figure 4 the design procedure to be followed in this instance is detailed in Section 4.1. The expressions for the geometry and flutter parameters are given by equations (20) and (21):

$$
\begin{aligned}
& G P=\frac{a}{b} \sqrt{\frac{D_{12 /} D_{1}}{1+c^{2} / \bar{K}_{S}}} \\
& F P=\frac{D_{1} \frac{f(M)}{q a^{3}}}{}
\end{aligned}
$$

The fact that the leading and trailing edges have complete deflectional restraint (simply supported) has been reflected in the above by setting the nondimensional support parameter $S_{L T}[$ eq. (22)] equal to one. Thus, for the particular panel configuration of interest

$$
\begin{gathered}
G P=\frac{1}{2} \sqrt{\frac{75}{1+28.13 / K_{S}}} \\
\frac{q}{f(1)}=\frac{109.7}{F P}
\end{gathered}
$$

It is assumed that the stream edge supports take the form of a running spring. From figure B-2 of Appendix B the nondimensional support stiffness is given as

$$
\bar{K}_{S}=\frac{K_{D} b^{3}}{\pi^{3} D_{2}}
$$


which becomes

$$
\overline{\mathrm{K}}_{\mathrm{S}}=1.18 \times 10^{-5} \mathrm{~K}_{\mathrm{D}}
$$

for the configuration under consideration.

From figure 7 , with an a over $b$ ratio of one half and a Mach number of 1.7, the Mach number correction factor has a magnitude of

$$
f(M)=1.23
$$

From equation (38), the pressure differential parameter is

$$
P_{f}=\frac{\Delta p \quad a^{4}}{D_{1} h_{e q}}
$$

where $h_{\text {eq }}$ is given by equation (39) and has the following value for this particuiar configuration

$$
h_{\text {eq }}=4.1 \mathrm{~mm}
$$

Thus, the pressure differential parameter becomes

$$
P_{f}=2000
$$

and from figure 6 the pressure differential correction factor is determined to be

$$
Q_{p}=1.2
$$

Combining the above, the relationship between the flutter critical dynamic pressure and the flutter parameter is given as

$$
q=\frac{109.7}{F P} f(M) Q_{P}=\frac{167.3}{F P}
$$


The resulting influence of the stream edge support stiffness on the critical dynamic pressure is illustrated in figure 10. It must be noted that since GP is always less than five, the corresponding values for FP are obtained from equation (14). The zero moment boundary condition value of $E_{C}$ is employed for the calculations summarized in figure 10.

5.3 Orthotropic Panel with Flow Angularity - The flutter sensitivity of a clamped orthotropic panel to angular flow is to be evaluated. Physical characteristics of the panel in question, shown in figure 11, are as follows:

$$
\begin{aligned}
& \mathrm{a}=1.1 \mathrm{~m} \\
& \mathrm{~b}=0.7 \mathrm{~m} \\
& \mathrm{D}_{1}=2500 \mathrm{~N}-\mathrm{m} \\
& D_{2}=10 \mathrm{~N}-\mathrm{m} \\
& D_{12}=50 \mathrm{~N}-\mathrm{m} \\
& M
\end{aligned}
$$

From figure 4 the procedures of interest for this case are presented in Section 4.2. For a panel with complete deflectional restraint (fully clamped) the desired relationships for GP and FP are given by equations (32) and (33). These relationships become

and

$$
G P=0.222 \sqrt{\cos ^{2} \Lambda+41 \sin ^{2} \Lambda}
$$

$$
q=\frac{6300}{F P\left[\operatorname{Cos}^{2} \Lambda+64.4 \sin ^{2} \Lambda\right]}
$$

for this particular parel configuration. Reflected in the above expression for the flutter critical $q$ is the evaluation of the Mach number correction factor from equation (44).

$$
f(M)=\sqrt{M^{2}-1}=3.354
$$




\begin{tabular}{|c|c|c|c|c|}
\hline $\begin{array}{c}K_{D} \\
(\mathrm{MN} / \mathrm{m} / \mathrm{m})\end{array}$ & $\bar{K}_{S}$ & $G P$ & $\mathrm{FP}$ & $\begin{array}{c}q \\
(\mathrm{kPa})\end{array}$ \\
\hline 0.1 & 1.18 & 0.87 & $4.07 \times 10^{-3}$ & 41 \\
0.5 & 5.9 & 1.80 & $2.15 \times 10^{-3}$ & 78 \\
1 & 11.8 & 2.35 & $1.46 \times 10^{-3}$ & 114 \\
5 & 59 & 3.56 & $7.00 \times 10^{-4}$ & 239 \\
10 & 118 & 3.89 & $5.88 \times 10^{-4}$ & 284 \\
\hline
\end{tabular}

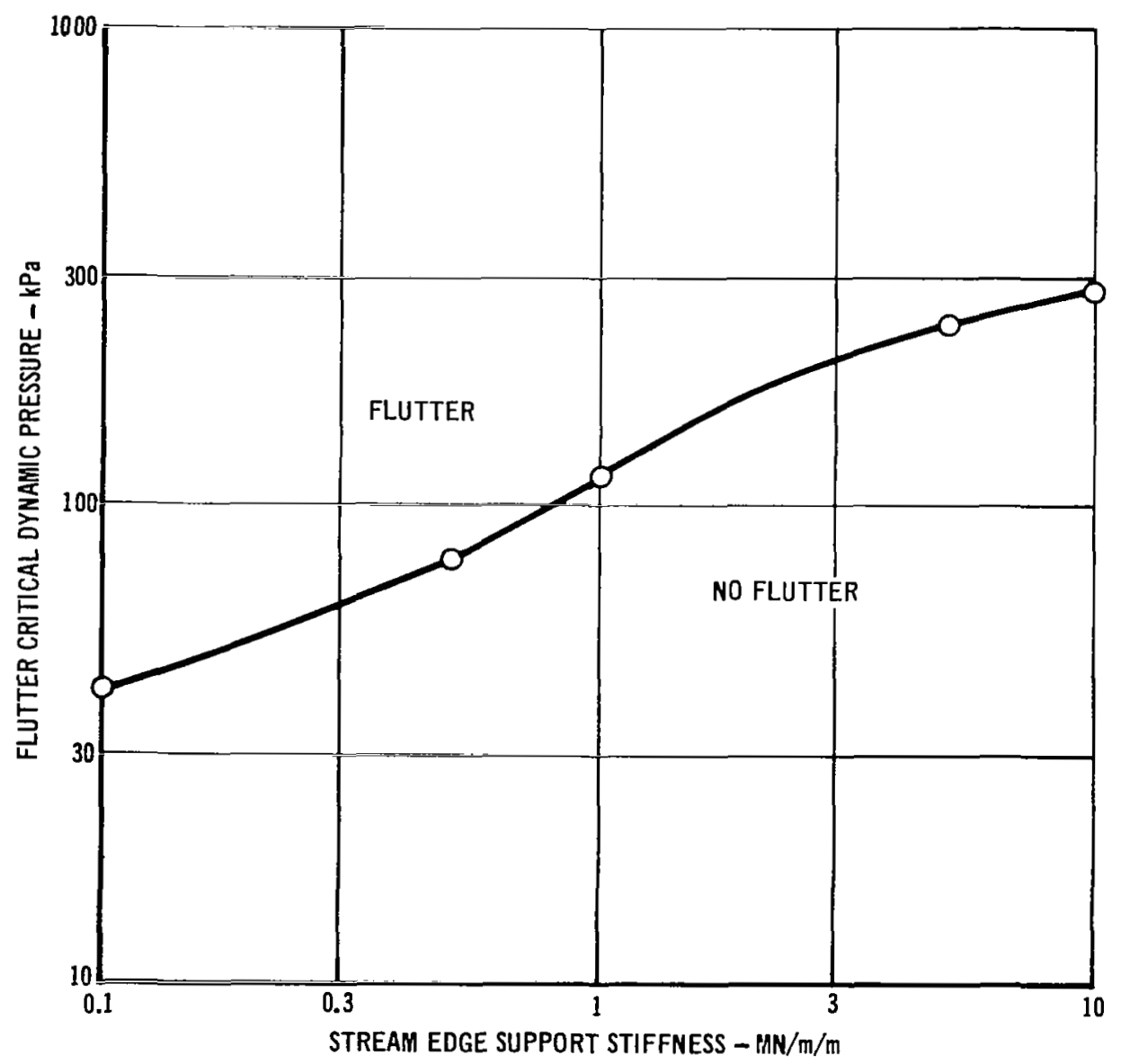

FIGURE 10 FLUTTER CRITICAL DYNAMIC PRESSURE VERSUS EDGE SUPPORT STIFFNESS 
The preceding expression for GP has been evaluated for various magnitudes of flow angularity $\Lambda$. The corresponding value for FP was obtained from equation (14) using the zero slope boundary condition value for $E_{C}$. The flutter critical dynamic pressure was then obtained and the resulting relationship between $q$ and $\Lambda$ is shown in figure 12 .

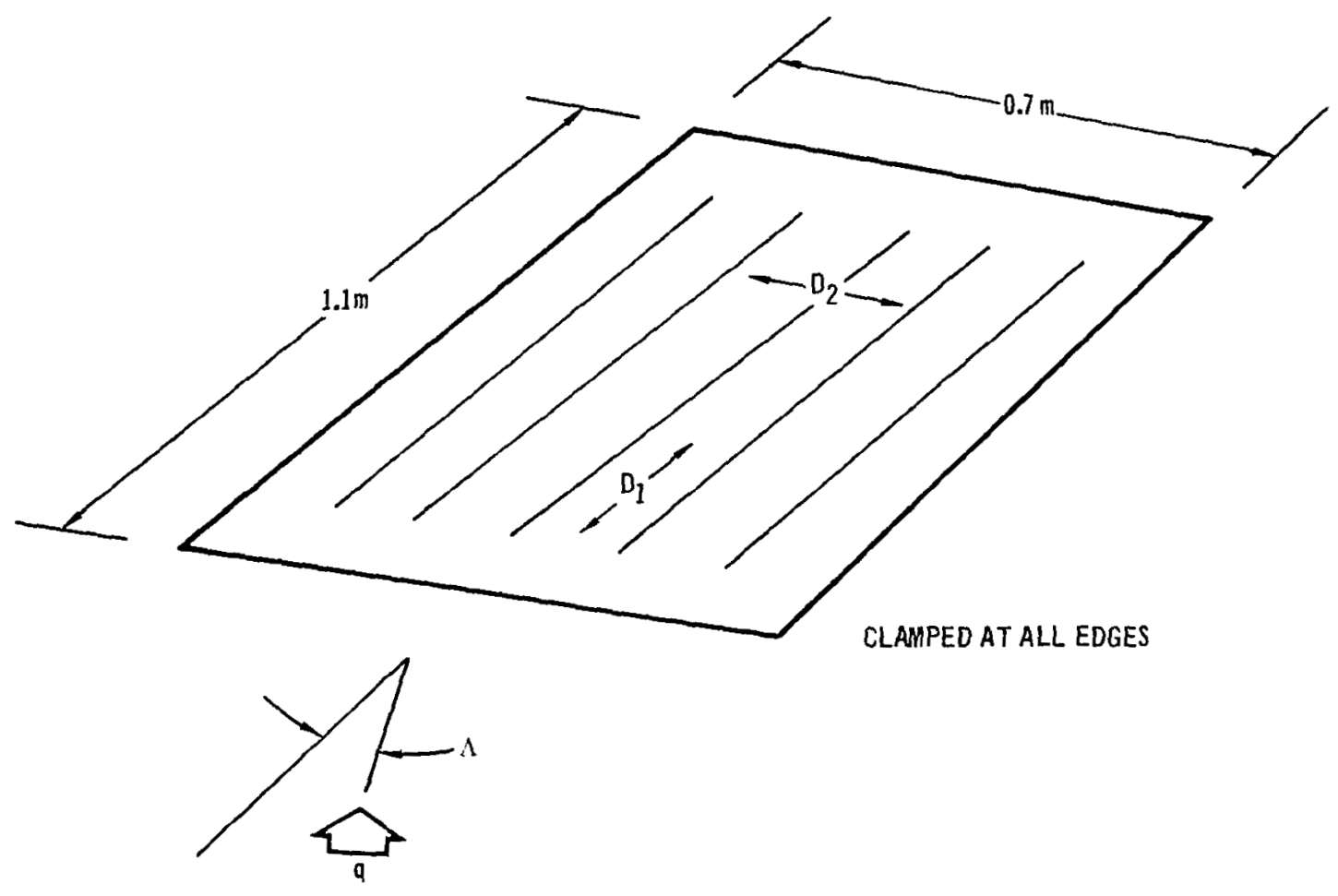

FIGURE 11 ORTHOTROPIC PANEL WITH FLOW ANGULARITY 


\begin{tabular}{|c|c|c|r|}
\hline $\begin{array}{c}\mathcal{( d e g} \\
\text { (de) }\end{array}$ & GP & FP & $\begin{array}{c}q \\
(\mathrm{kPa})\end{array}$ \\
\hline 0 & 0.222 & 0.00302 & 2086 \\
15 & 0.426 & 0.00298 & 403 \\
30 & 0.736 & 0.00260 & 146 \\
45 & 1.017 & 0.00221 & 87 \\
60 & 1.236 & 0.00191 & 68 \\
75 & 1.374 & 0.00179 & 60 \\
90 & 1.421 & 0.00167 & 59 \\
\hline
\end{tabular}

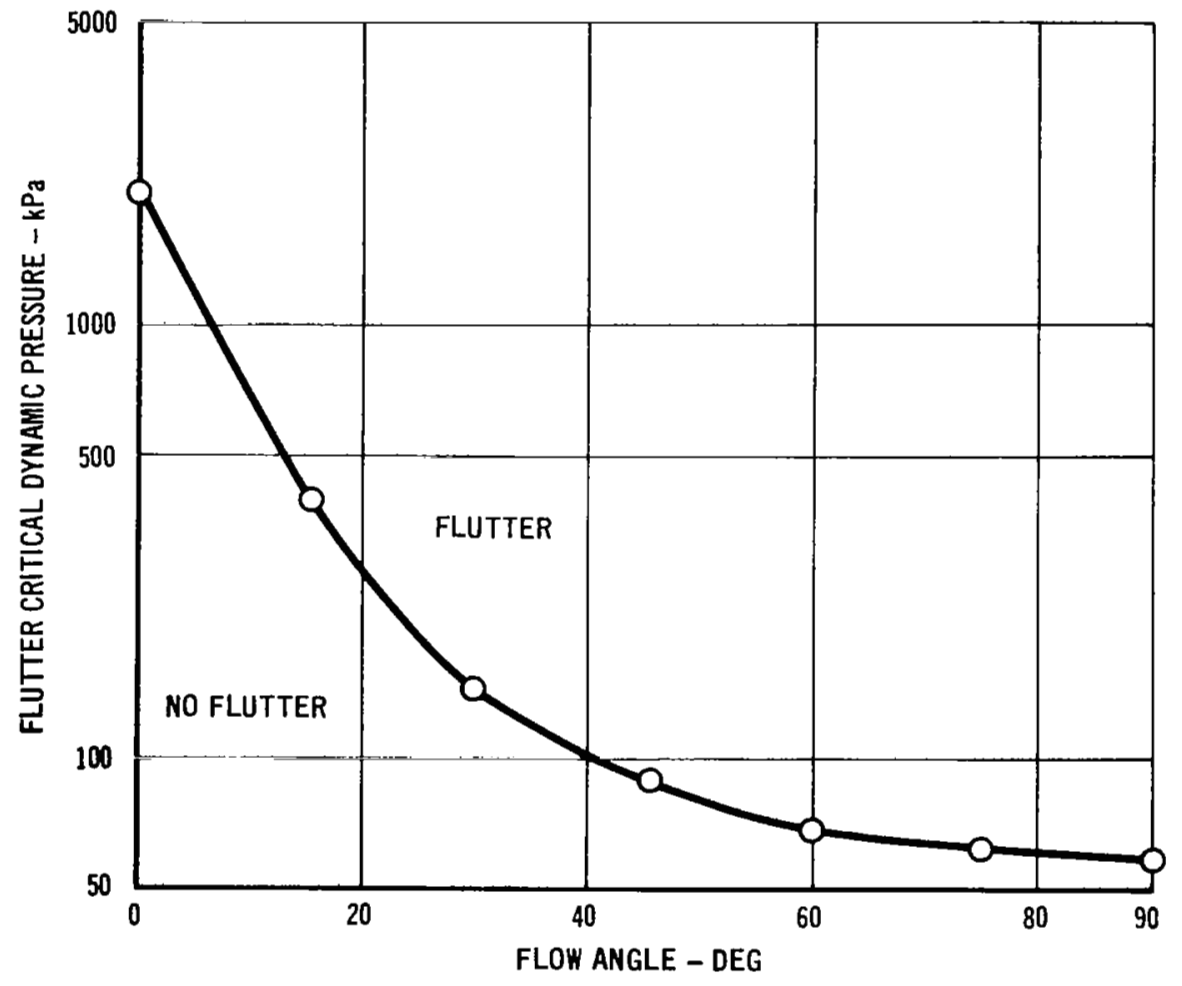

FIGURE 12 FLUTTER CRITICAL DYNAMIC PRESSURE VERSUS FLOW ANGULARITY 


\subsection{DESIGN BOUNDARY VERIFICATION}

The preceding section describes a design approach, in conjunction with the flutter-free panel design boundary, developed for use in the preliminary design of flutter free lightweight external panels. In this section, the validity of the approach, as it applies to various panel configurations, is evaluated by comparing results from the preliminary design predictions with appropriate existing experimental data. Where no experimental data exist, comparisons are made with the results of detailed theoretical analyses. The experimental panel flutter data employed in the following sections are tabulated in Appendix $D$ and cross-referenced to the appropriate figures in the following sections.

6.1 Basic Panel - A large amount of experimental and flight flutter data for the basic panel configuration is available. In this context, "basic" panel configuration refers to a flat orthotropic panel (fig. 1) with either complete edge deflectional restraint or edge support flexibility effects. The influence of additional parameters such as flow angularity, inplane loads, etc., is considered in later sections.

The panel flutter data for the basic panel configuration obtained from references 10, 18, and 21 are shown in figure 13. The data of references 18 and 21 are for isotropic panels with total edge deflection restraints. As seen in figure 13, a majority of these data compare well with the flutter-free panel design boundary. The reference 18 data were obtained for a number of uniform panels of the same thickness and length to width ratios. For this panel configuration, the 37 experimental data points (represented by the straight line connecting the circular symbols) all fall within the flutter boundary. The data of reference 21 are for clamped isotropic panels of varying thickness and length to width ratios. These experimental results also compare well with the design boundary.

Data from an experimental investigation on the flutter characteristics of orthotropic panels are given in reference 10. These results are for a 


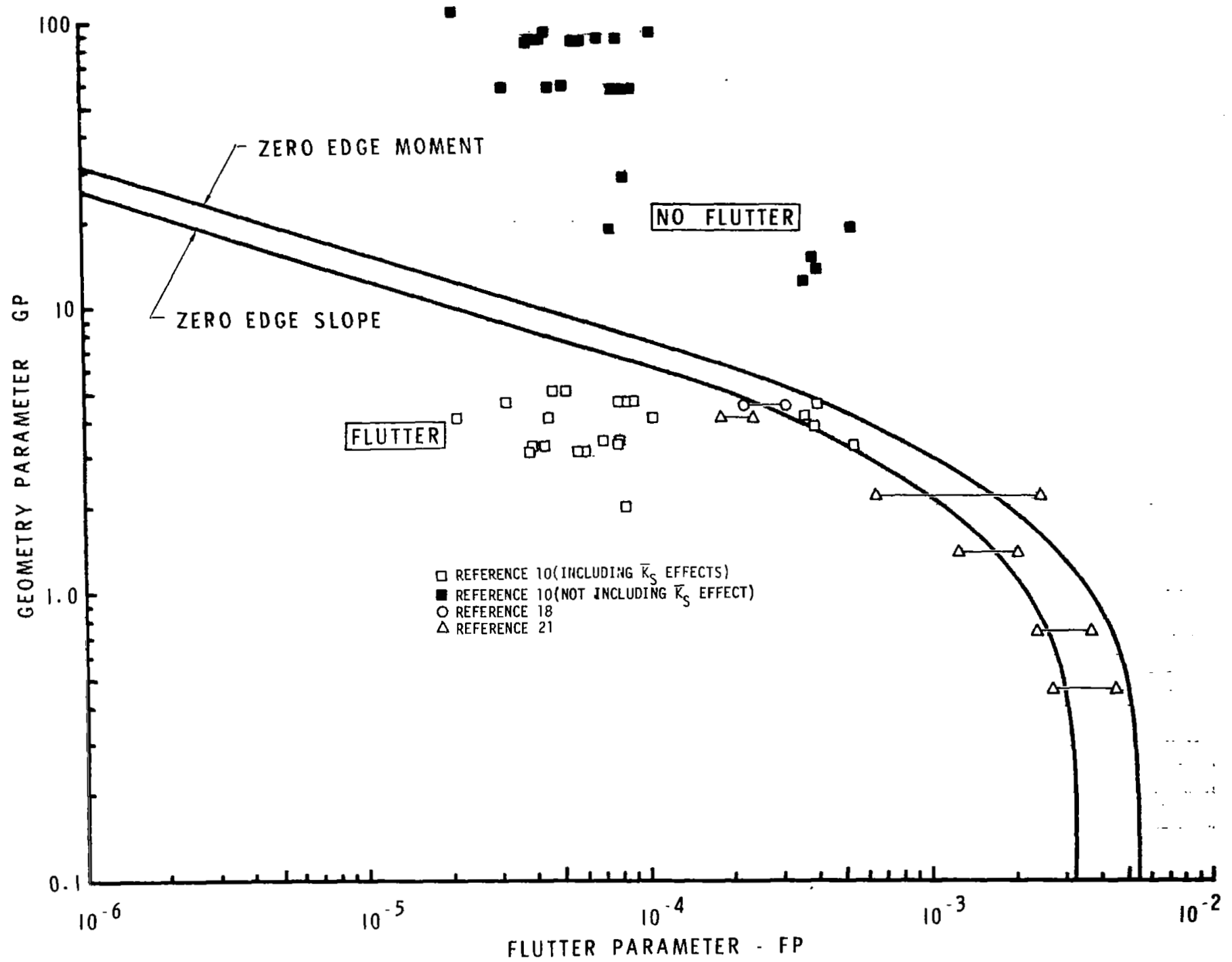

FIGURE 13 FLUTTER DATA FOR BASIC PANEL CONFIGURATIONS 
wide variety of panel configurations and stream edge flexibility support conditions. Their comparison with the flutter-free panel design boundary shows the boundary to be conservative. Indicated in figure 13 is the importance of the $c^{2} / \vec{K}_{S}$ term in the geometry parameter of equation (20). The solid points shown in this figure present the reference 10 data without accounting for the stream edge support flexibility while the open symbols include the influence of this support flexibility. It can be seen that when the edge flexibility effects are neglected the design boundary is very unconservative.

The lack of experimental data for panels with leading and trailing edge support flexibility precludes the comparison of the design boundary with test data. As an alternate, predictions obtained through application of the flutter-free panel design boundary are compared with theoretical results of reference 9. This comparison is shown in figure 14 and as can be seen there is adequate correlation between the trends obtained with the design boundary and the theoretical results of reference 9 .

6.2 Flow Angularity - A limited amount of experimental flutter data, as presented in references 8,11 , and 22 , exist for panels exposed to flow not parallel to one side. Note that the results presented in reference 22 are a duplication of the reference 11 information. All of these data, except for panel 1 of reference 11, are for orthotropic panels with leading and trailing edge support flexibility with respect to zero angle flow. The panel 1 configuration was an orthotropic panel clamped along all sides.

Comparison of these data with the design boundary is shown in figure 15. As can be seen, for a majority of these experimental data the correlation with the design boundary is conservative. Shown in figure 16 are the experimental and predicted $\lambda$ 's as a function of flow angle for the panel 2 (ref. 11) data. This figure illustrates the adequacy of the design approach in predicting the influence of flow angle on the flutter critical flow conditions of an orthotropic panel. 


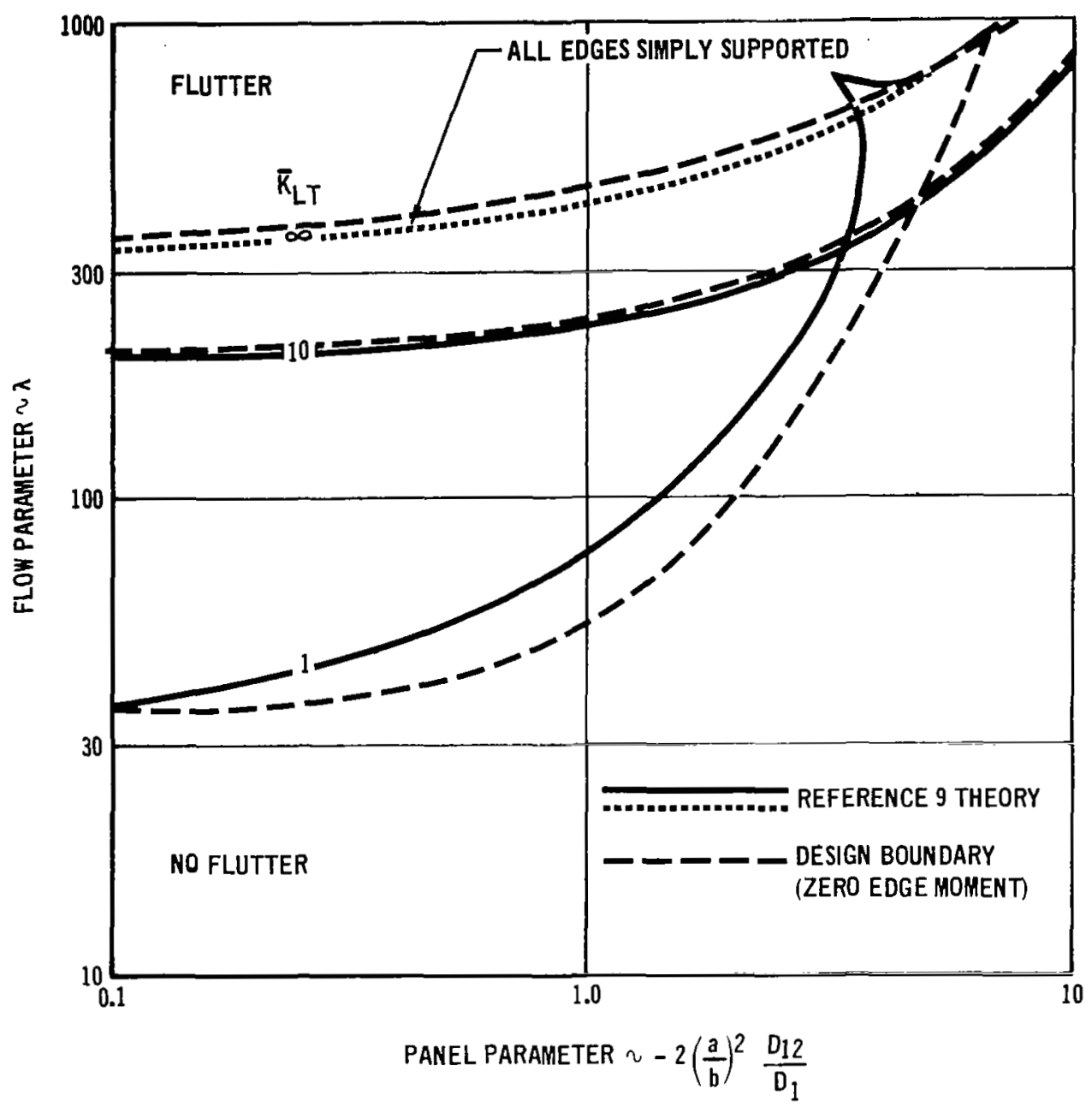

FIGURE 14 CORRELATION WITH REFERENCE 9 THEORETICAL RESULTS

\subsection{Inplane Loads - Experimental data obtained during an extensive}

wind tunnel test program conducted to evaluate the influence of inplane loads on panel flutter (ref. 12) are compared with the design boundary in figure 17. These data are for isotropic panels with a wide range of panel a over $b$ ratios. During the test program mechanical inplane loading was introduced by hydraulic actuators. As indicated in this figure, the correlation between these data and the flutter-free panel design boundary is conservative. 


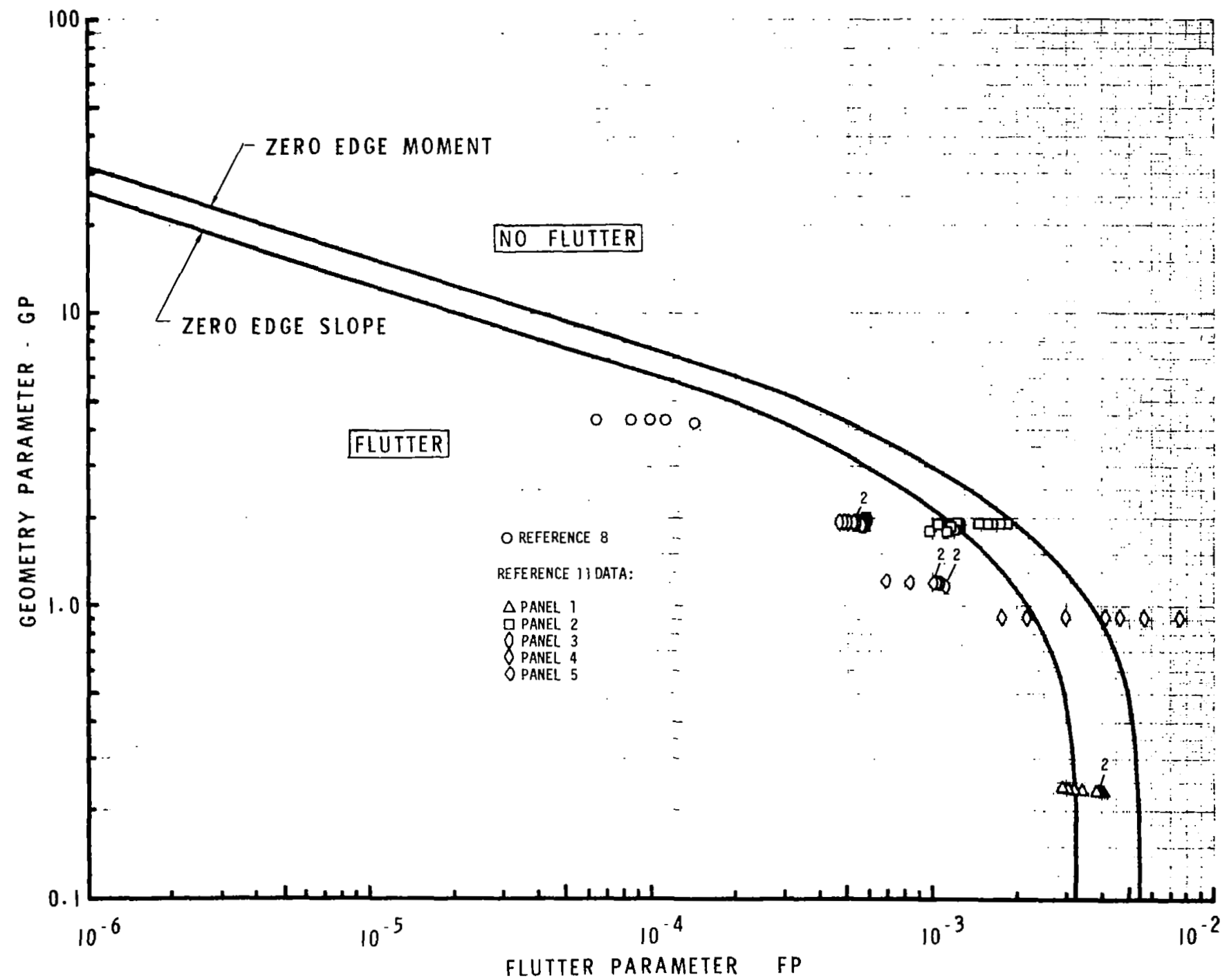




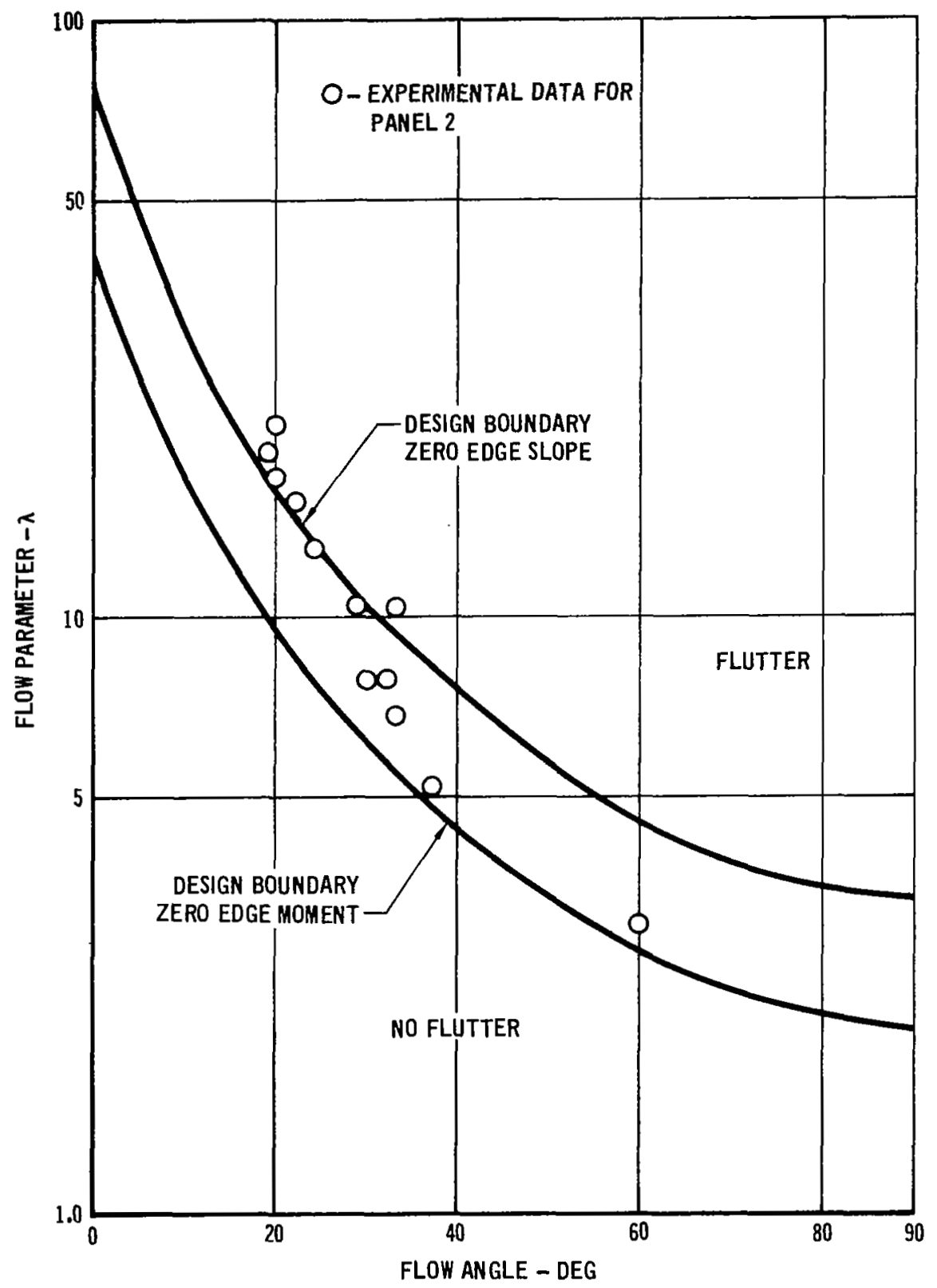

FIGURE 16 CORRELATION WITH REFERENCE 11 EXPERIMENTAL RESULTS 


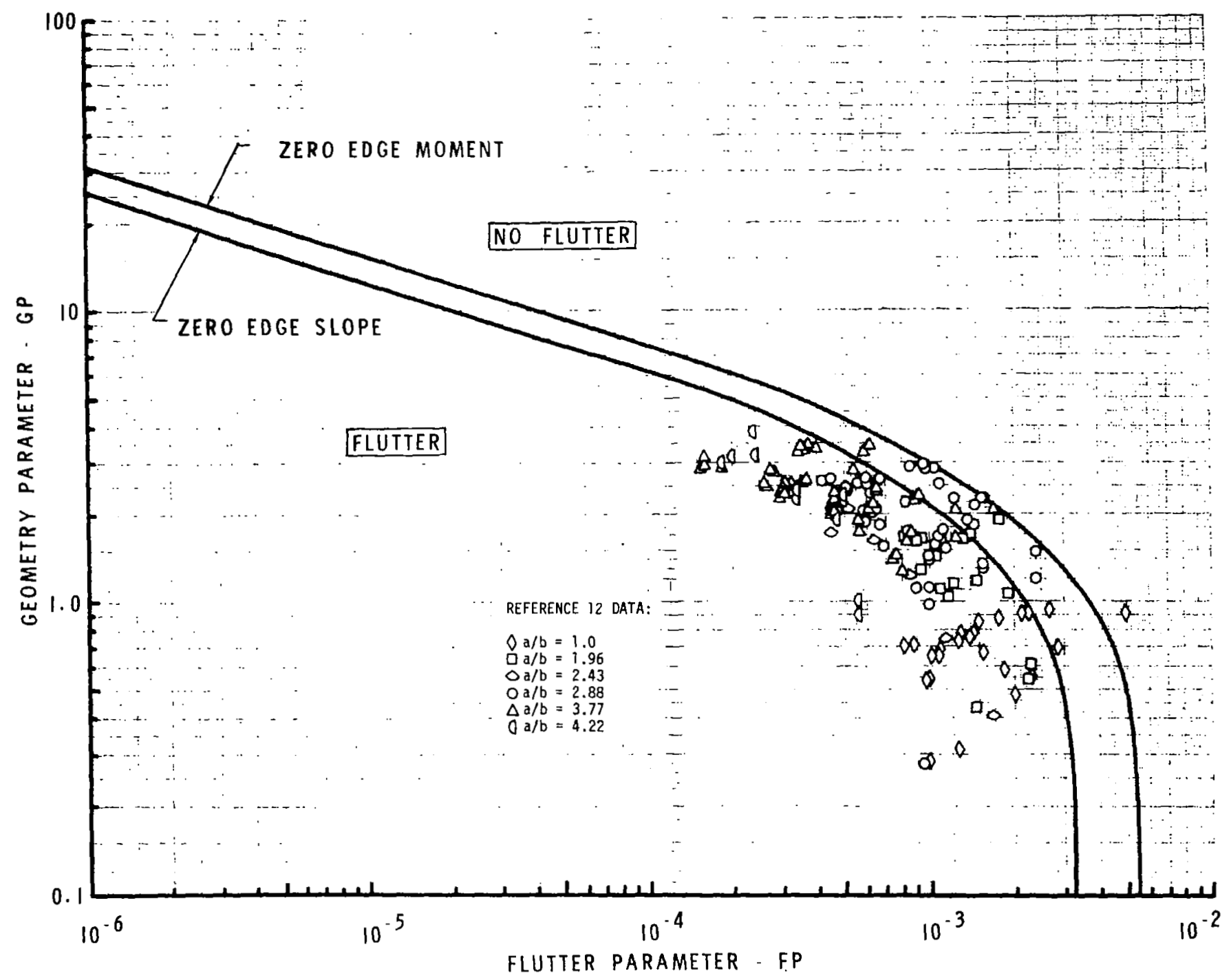

FIGURE 17 FLUTTER DATA FOR PANELS WITH VARIOUS a OVER b RATIOS AND INPLANE LOADS 
It is assumed in reference 12 that the test panels have complete deflectional support at the edges. However a review of the test setup indicates that some stream edge support flexibility existed. This effect, as presented in Table D-6 was included in the calculation of GP for the data shown in figure 17.

Additional experimental panel flutter results, including the influence of inplane loads, are given in references 7,19 , and 23 through 26 . Test data as presented in these references are plotted on the panel design boundary in figure 18 The overal1 comparison between these data and the design boundary is in general conservative. For all these panels the inplane loads are the result of panel aerodynamic heating. The data shown on figure 18 are for isotropic panels except those discussed in references 7 and 26 .

6.4 Static Pressure Differential - The design procedure to be followed in evaluating the influence on panel flutter of a pressure differential is based on experimental results presented in references 17 and 18 . These wind tunnel data were obtained for isotropic panels having complete restraint (clamped or simply supported) at the panel boundaries.

Limited amounts of additional data including pressure differential effects are available for correlation with the recommended design approach. The available data (ref. 10) are compared with the design boundary in figure 19. These data are for a highly orthotropic panel with stream edge support flexibility and an a over b ratio of one.

The closed symbols are for this experimental data before the pressure differential correction factor $Q_{p}$ has been applied. Application of the procedures of Section 4.4 to modify the experimental $q / f(M)$ value by the appropriate magnitude of $Q_{p}$ results in the comparison with the design boundary as indicated by the open symbols in figure 19. 


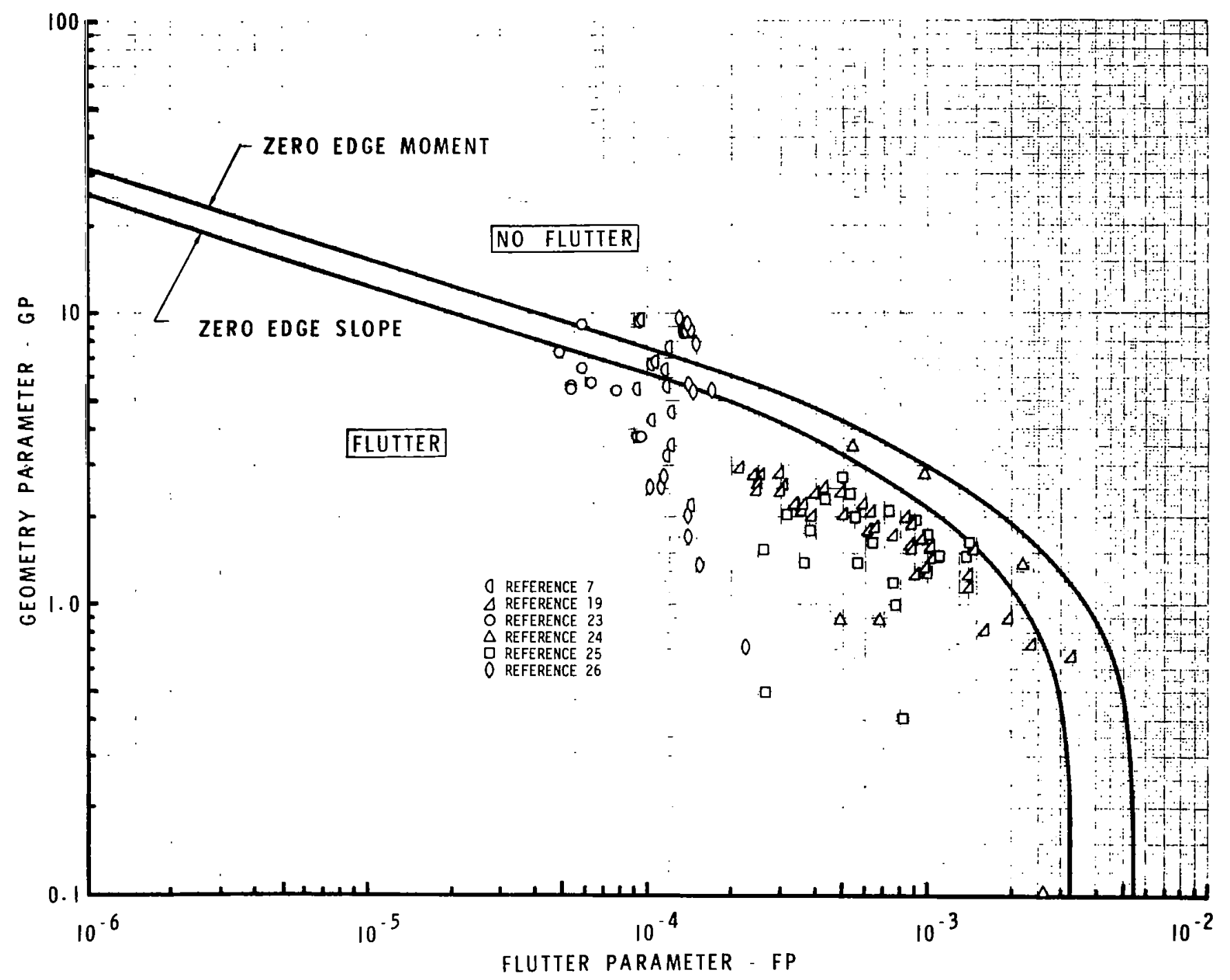




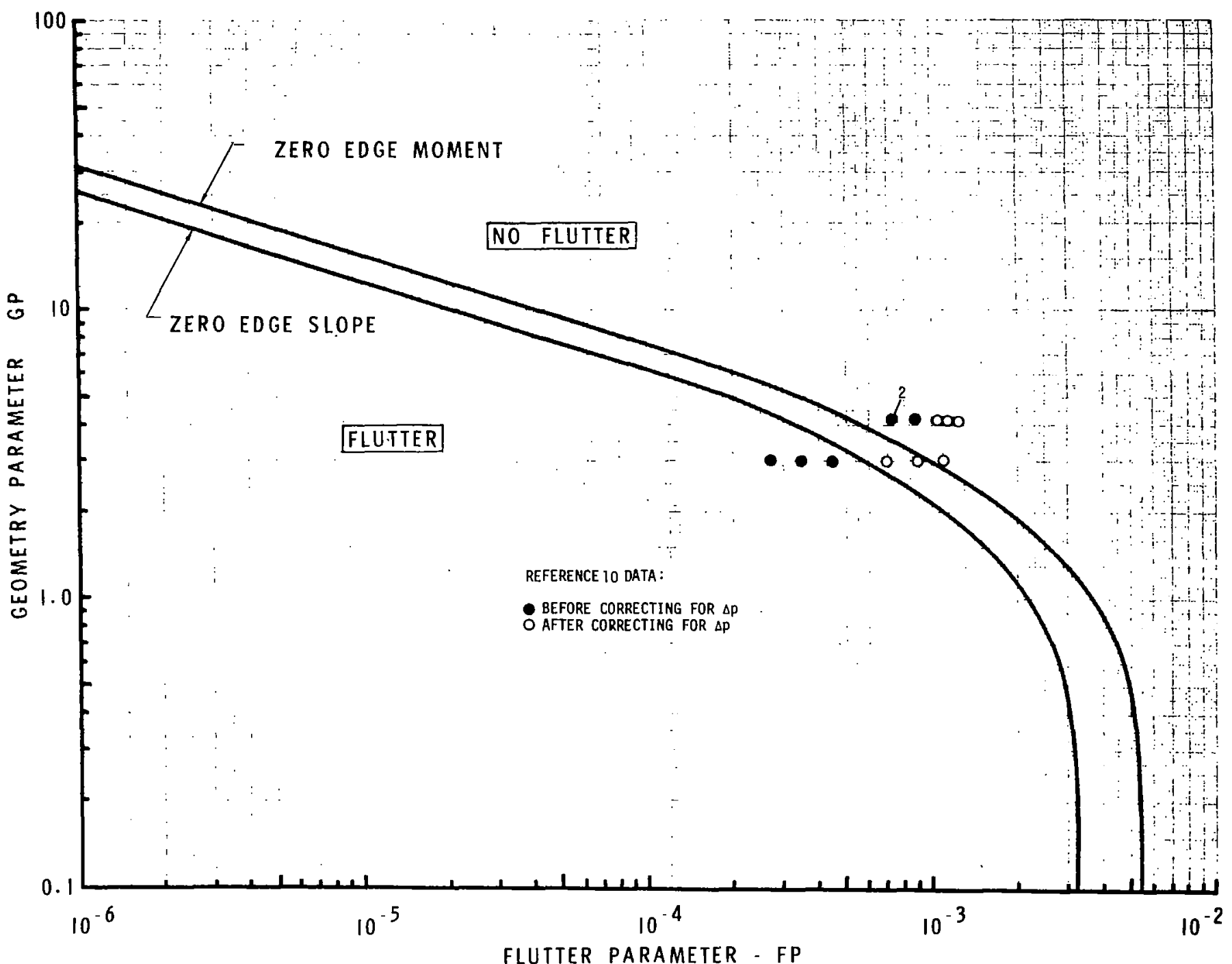

FIGURE 19 PANEL FLUTTER DATA INCLUDING THE INFLUENCE OF STATIC PRESSURE DIFFERENTIAL 
Other data with pressure differential effects included are available in reference 10. However, these configurations result in magnitudes for the pressure differential parameter $P_{f}$ which exceed the range covered in figure 6 . This indicates that the design procedure of Section 4.4 is 1 imited to pane 1 configurations whose characteristics result in magnitudes of $P_{f}$ covered by figure 6 .

\subsection{Structural Damping - A procedure is described in Section 4.5} which allows evaluation of the influence of structural damping in combination with inplane loads. With this procedure the dynamic pressure parameter $q / f(M)$ obtained through application of the design boundary is modified by the damping factor $D_{f}[$ eq. (41)] to account for the presence of the damping.

For a panel with inplane loading, results obtained from application of the flutter-free panel design boundary with no added damping compare well with detailed theoretical analyses that include a structural damping coefficient of 0.01 . Such a comparison is shown in figure 20, where both experimental data and theoretical results for a clamped panel detailed in reference 19 are shown. Thus, results obtained from the design boundary may be thought of as including "nominal" structural damping on the order of 0.01 . For panels having higher damping characteristics $(g>0.01)$ and inplane loads, the damping factor $D_{f}$ as defined by equation (41) is to be employed.

Many data points for panels with inplane loading shown in figure 17 appear quite conservative. As discussed in reference 12, significant structural damping, up to five percent, was measured for a number of the panels. The presence of such magnitudes of damping can have a large influence on the flutter susceptibility of panels with inplane loading. Referring to equation (41), the damping factor is dependent on the magnitudes of both the structural damping and inplane loading. Figure 21 shows the influence of structural damping on panel 4 of reference 12. The lower flutter boundary results from the design boundary $(g=0.01)$ and the upper boundary results from the damping factor $D_{f}$ defined by equation (41). The good agreement between the experimental data and the predicted boundary for the average measured structural 


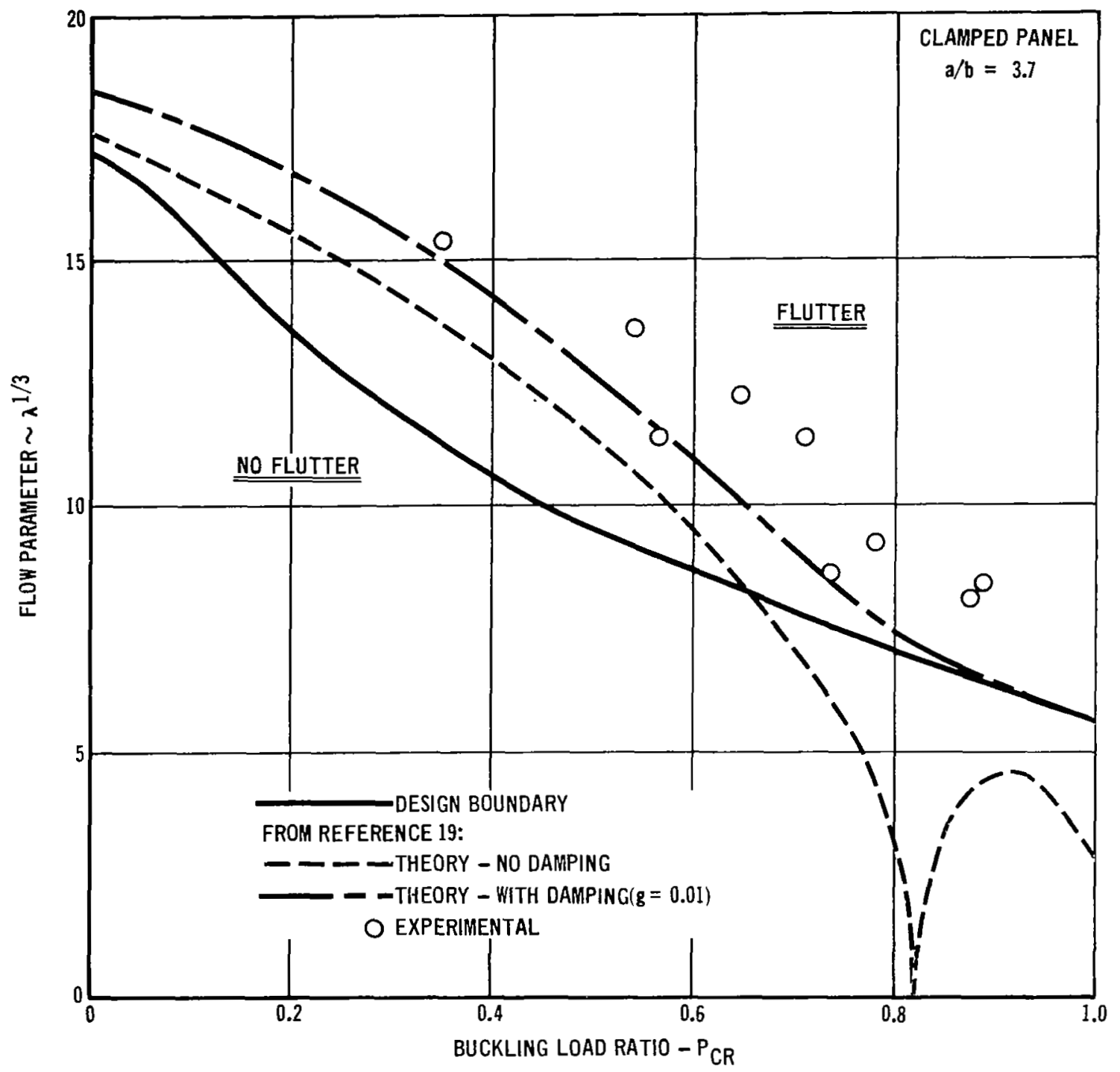

FIGURE 20 CORRELATION WITH REFERENCE 19 CLAMPED PANEL RESULTS 


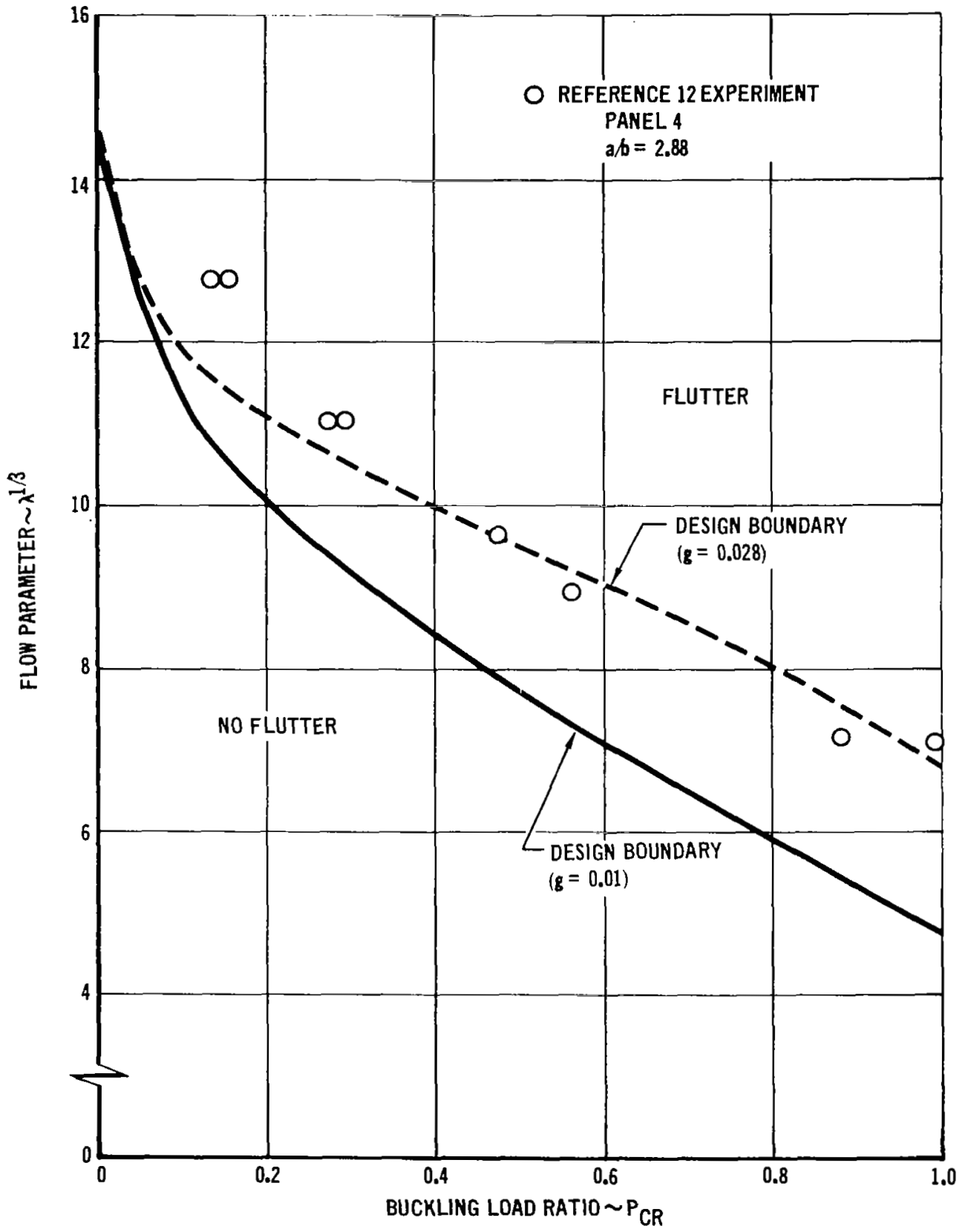

FIGURE 21 INFLUENCE OF HIGH STRUCTURAL DAMPING FOR A PANEL WITH INPLANE LOADING 
damping $g=0.028$ indicates that equation (41) is sufficiently accurate for flutter design of panels with significant structural damping.

6.6 Mach Number Effect - The definition of the Mach number correction factor $f(M)$ as given in figure 7 is based on experimental panel flutter results in the low supersonic Mach number regime. The trends illustrated in figure 7 are established in reference 18 and are based on results obtained during wind tunnel test programs such as those discussed in references 18 and 21 .

Further verification of these relationships between $f(M)$ and Mach number is illustrated in figure 22. Here data obtained during extensive panel flutter test programs detailed in references 27 and 28 are compared with predictions obtained with the flutter-free panel design boundary when modified by $f(M)$. The data from reference 27 are for a clamped isotropic panel while those of reference 28 were obtained for a panel having less than a fully clamped boundary condition. The spread in test data indicated in figure 22 for a particular Mach number is related to the boundary layer thickness at the test conditions. 


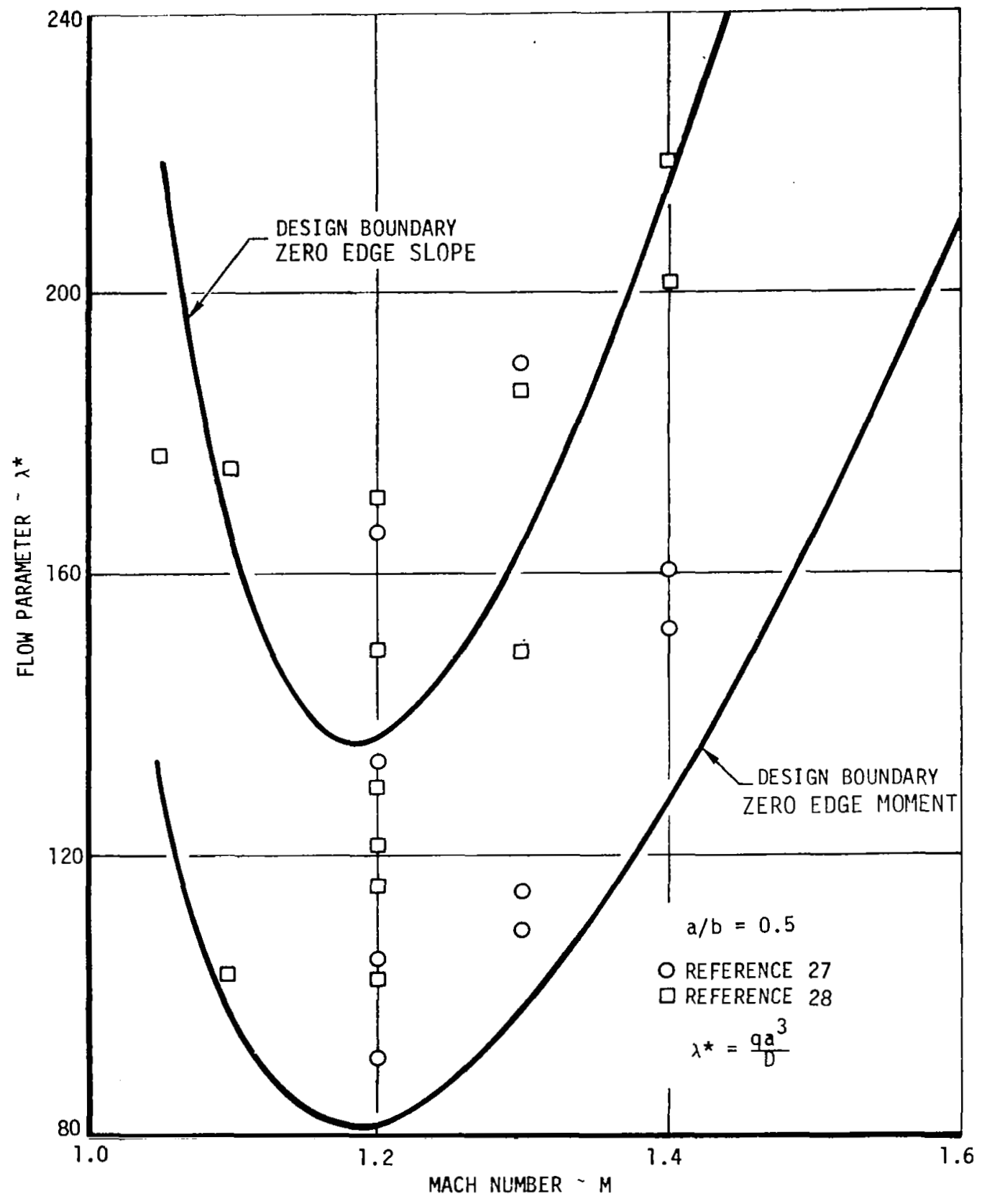

FIGURE 22 PANEL FLUTTER DATA IN LOW SUPERSONIC REGIME 

- 


\subsection{CONCLUDING REMARKS}

Criteria and procedures for their application in the preliminary design of flutter free lightweight external surface panels have been presented in a format which permits their use by individuals without prior panel flutter experience. The major area of application for these procedures is in the design of orthotropic metaliic panels which stand off from primary structure. Examples which illustrate the use of these criteria and procedures are given.

The panel design approach presented in this report is a logical extension of previous work done in this area. The design criteria account for most of the interacting parameters which significantly influence panel susceptibility to flutter. Parameters included in these design procedures are

- Panel aspect ratio

- Panel orthotropic properties

o Support flexibility

- Inplane loads

- Static pressure differential

- Flow angularity

- Structural damping

The validity of the flutter-free panel design boundary (fig. 3) and its application (Section 4.0) to preliminary panel design has been demonstrated by comparison of predicted flutter results with experimental data. Included in this verification process are data for panels ranging from isotropic to those having highly orthotropic stiffness characteristics. In addition, data for panels including the influence of parameters such as edge support conditions, inplane loads, flow angularity, etc., were available and used. As discussed in Section 6.0, application of the design procedures resulted in the conservative prediction of flutter points for a vast majority of the existing experimental data.

External panels on discrete flexible supports are being strongly considered for use as a high performance vehicle thermal protection system. The influence 
of this type of support condition was not incorporated into the design procedure due to a limited availability of information (ref. 29) for this configuration. Further theoretical considerations and corresponding panel flutter test programs are needed to investigate this support condition.

Limited experimental data exist for the flutter of orthotropic panels including the influence of flow angularity. In addition, no data exist for panels subjected to the combined conditions of inplane loads and flow angular$i$ ty. Comprehensive theoretical investigations of these aspects of the panel flutter problem have been conducted and are documented in the $7 i$ terature. Further testing to provide the data needed to evaluate these theoretical results is required. 


\section{APPENDIX A \\ ORTHOTROPIC PANEL STIFFNESS PARAMETERS}

of basic importance to the use of the flutter-free panel design boundary is knowledge of the panel orthotropic stiffness properties. A number of techniques which may be employed to obtain these quantities are presented in this appendix.

For panels with closed corrugations [fig. A-l(a)] the use of the procedures detailed in reference 30 are recommended. Determination of the panel stiffness properties for the other two configurations shown in figure $A-1$ is discussed in reference 31. For a panel with equidistant ribs [fig. $A-1(b)]$ reference 31 gives the following expressions for $D_{1}, D_{2}$, and $D_{12}$

$$
\begin{gathered}
D_{1}=\frac{E h^{3}}{12\left(1-v^{2}\right)} \frac{\ell}{\left[\ell-t+(h / H)^{3} t\right]} \\
D_{2}=\frac{E I_{1}}{\ell} \\
D_{12}=\frac{E h^{3}}{12\left(1-v^{2}\right)}+\frac{G J}{\ell}
\end{gathered}
$$

where $I_{1}$ is the moment of inertia of the cross-hatched area defined in figure $A-1(b)$ and $G J$ is the torsional rigidity of one rib.

The stiffness properties for the corrugated sheet [fig. A-l(c)] as defined in reference 31 are expressed as

$$
\begin{gathered}
D_{1}=\frac{\ell}{s} \frac{E h^{3}}{12\left(1-\nu^{2}\right)} \\
D_{2}=E I_{1} \\
D_{12}=\frac{s}{l} \frac{E h^{3}}{12(1+v)}
\end{gathered}
$$




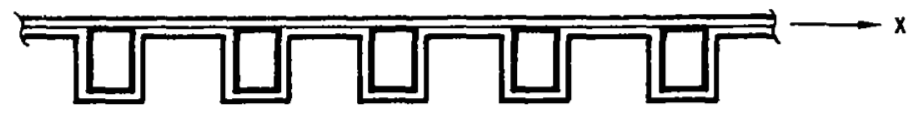

(a) CLOSED CORRUGATIONS

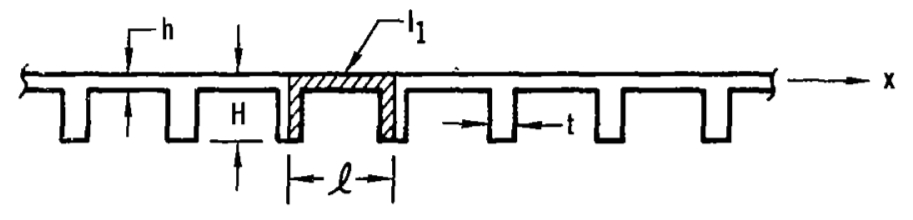

(b) EQUIDISTANT RIBS

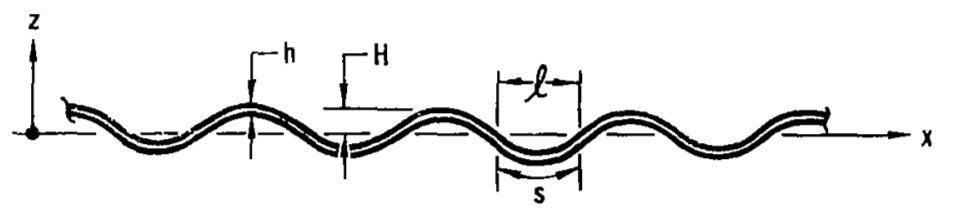

FORM OF CORRUGATION: $z=H \operatorname{SIN} \frac{\pi x}{l}$

(c) CORRUGATED SHEET

FIGURE A-1 ORTHOTROPIC PANEL CONFIGURATIONS 
where

$$
\left.s \approx l[]+\left(\frac{\pi H}{2 l}\right)^{2}\right]
$$

and

$$
I_{1}=\frac{H^{2} h}{2}\left[1-\frac{.81}{1+.625(H / \ell)^{2}}\right]
$$

An approach for obtaining initial estimates for the stiffness properties of an orthotropic panel is implied by Timoshenko in reference 31 . With this approach, the panel bending rigidities are related to the properties of a beam of unit width. Thus, considering the case illustrated in figure $A-1(b)$, we have

$$
\begin{aligned}
& D_{1}=\frac{E h^{3}}{12} \\
& D_{2}=\frac{E I_{1}}{\ell}
\end{aligned}
$$

where $I_{1}$ has previously been defined. Following the approach mentioned in reference 31 , the quantity $D_{12}$ is then estimated as

$$
\mathrm{D}_{12}=\sqrt{\mathrm{D}_{1} \mathrm{D}_{2}}
$$

The above is not a recommended procedure for general usage, but does allow initial estimates of the panel's stiffness characteristics to be readily made.

Experimental procedures for obtaining these panel parameters are discussed in references 32 and 33 . These experimental approaches do not have application during preliminary design, but are mentioned here for completeness. 


\section{APPENDIX B \\ EDGE SUPPORT STIFFNESS EXPRESSIONS}

Techniques have been developed for the estimation of the nondimensional stiffness parameters for various panel edge support configurations. An energy approach is used to obtain these expressions. In this approach, for an assumed deflection pattern, the strain energy stored in an idealized support spring configuration ( $f i g . B-1$ ) is equated to the energy stored in the configuration of interest.

A summary of these results is given in figure B-2. Expressions are presented in this figure for the support stiffnesses along with sketches defining each support's geometric characteristics. The results presented in figure B-2 are for support springs located along the panel stream edges as illustrated in figure B-1. Similar expressions for leading and trailing edge support springs are obtained by interchanging the geometric quantities associated with the panel coordinate system. The stiffness expressions are given in the nondimensional form required for application with the flutter-free panel design boundary.

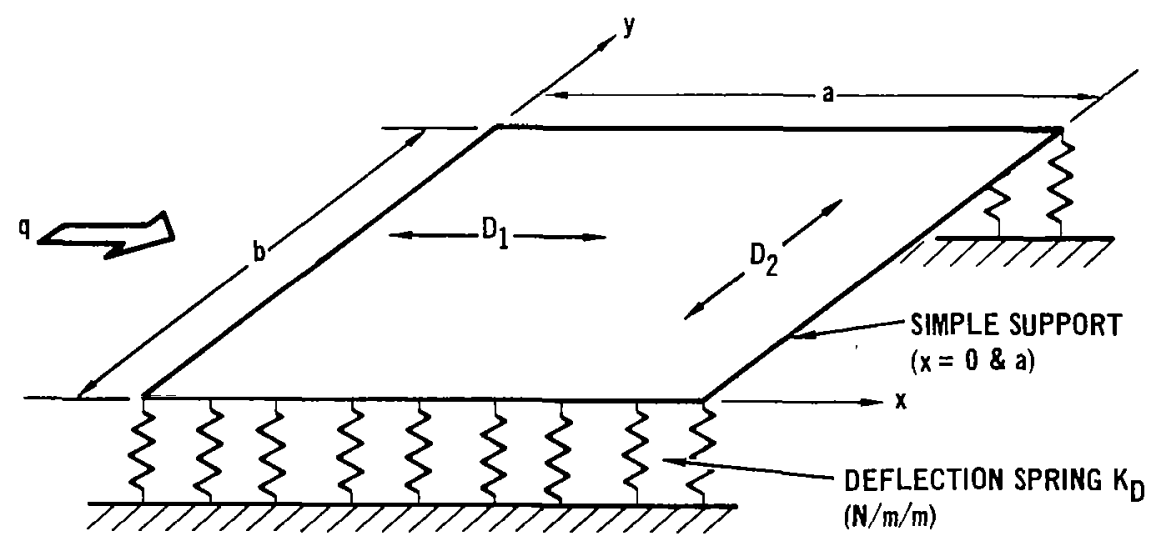

FIGURE B-1 IDEALIZED STREAM EDGE SPRING SUPPORTS 


\begin{tabular}{|c|c|c|c|}
\hline $\begin{array}{l}\text { SUPPORT } \\
\text { CONDITION }\end{array}$ & $\begin{array}{l}\text { SUPPORT } \\
\text { TYPE }\end{array}$ & SUPPORT CONFIGURATION & NONDIMENSIONAL SUPPORT STIFFNESS \\
\hline 1 & $\begin{array}{l}\text { RUNNING } \\
\text { SPRING }\end{array}$ & $(\mathrm{N} / \mathrm{m} / \mathrm{m})$ & $\bar{K}_{s}=\frac{K_{D} b^{3}}{\pi^{3} D_{2}}$ \\
\hline 2 & $\begin{array}{l}\text { DISCRETE } \\
\text { SPRING }\end{array}$ & (N/m) & $\bar{K}_{s}=\frac{2}{a} \frac{K_{d}}{D_{2}}\left(\frac{b}{\pi}\right)^{3} \sum_{j} \sin ^{2}\left(\frac{\pi x_{j}}{a}\right)$ \\
\hline 3 & $\begin{array}{l}\text { EDGE } \\
\text { SUPPORT } \\
\text { PANEL }\end{array}$ & & $\bar{K}_{s}=\frac{D_{0}}{D_{2}}\left(\frac{b}{\pi}\right)^{3}+\left[\frac{17}{35}\left(\frac{\pi}{a}\right)^{4}+\frac{12}{5}\left(\frac{\pi}{a l}\right)^{2}+\frac{3}{1^{4}}\right]$ \\
\hline 4 & $\begin{array}{l}\text { TAPERED } \\
\text { EDGE SUPPORT } \\
\text { PANEL }\end{array}$ & $K_{0}^{1}$ & $\begin{array}{l}\overline{\mathrm{K}}_{\mathrm{s}}=\alpha\left(\frac{\mathrm{b}}{\pi}\right)^{3} \mathrm{I}\left[\frac{17}{35}\left(\frac{\pi}{\mathrm{a}}\right)^{4}+\frac{12}{5}\left(\frac{\pi}{\mathrm{al}}\right)^{2}+\frac{3}{\mathrm{I}^{4}}\right] \\
\text { WHERE } \\
\alpha=\frac{1}{20}\left(\frac{\mathrm{s}}{\mathrm{l}}\right)^{3}+\frac{\mathrm{D}_{0}}{\mathrm{D}_{2}}\left[1-\frac{1}{20}\left(\frac{\mathrm{s}}{\mathrm{l}}\right)^{3}\right]\end{array}$ \\
\hline 5 & DOUBLER & & $\bar{K}_{s}=\frac{E I_{0}}{D_{2}}\left(\frac{b}{a}\right)^{3}\left(\frac{\pi}{a}\right)$ \\
\hline
\end{tabular}

FIGURE B-2 NONDIMENSIONAL STREAM EDGE SUPPORT STIFFNESS EXPRESSIONS 
A summary of the stiffness properties for a number of support clips or standoffs is presented in figure B-3. These quantities are presented in terms of the stiffness associated with a discrete spring. The corresponding running or 7 ine spring for a number of $k_{d}$ discrete springs is defined as

$$
K_{D}=\frac{N K_{d}}{a}
$$

where $N$ is the number of discrete springs located down the panel side of length $a$.

To illustrate the procedure that was employed to obtain the information presented in figure $B-2$, the analys is of an edge support panel (support condition 3) will be presented in detail. Referring to figure B-7, the strain energy stored in the idealized support springs is given as

$$
\begin{aligned}
U_{I} & =\frac{1}{2} \int_{0}^{a} k_{D} w^{2} d x \\
& =c^{2} \frac{a}{4} k_{D}
\end{aligned}
$$

where it has been assumed that the deflection at the support springs is given as

$$
w=C \sin \frac{\pi x}{a}
$$

Introducing the nondimensional spring rate notation

$$
\bar{K}_{D}=\frac{K_{D} b^{3}}{\pi^{3} D_{2}}
$$

equation ( $B-2)$ becomes

$$
U_{I}=C^{2} \frac{a}{4}\left(\frac{\pi}{b}\right)^{3} D_{2} \quad \bar{K}_{D}
$$

Since for stream edge support flexibility we have

$$
\bar{K}_{S}=\bar{K}_{D}
$$




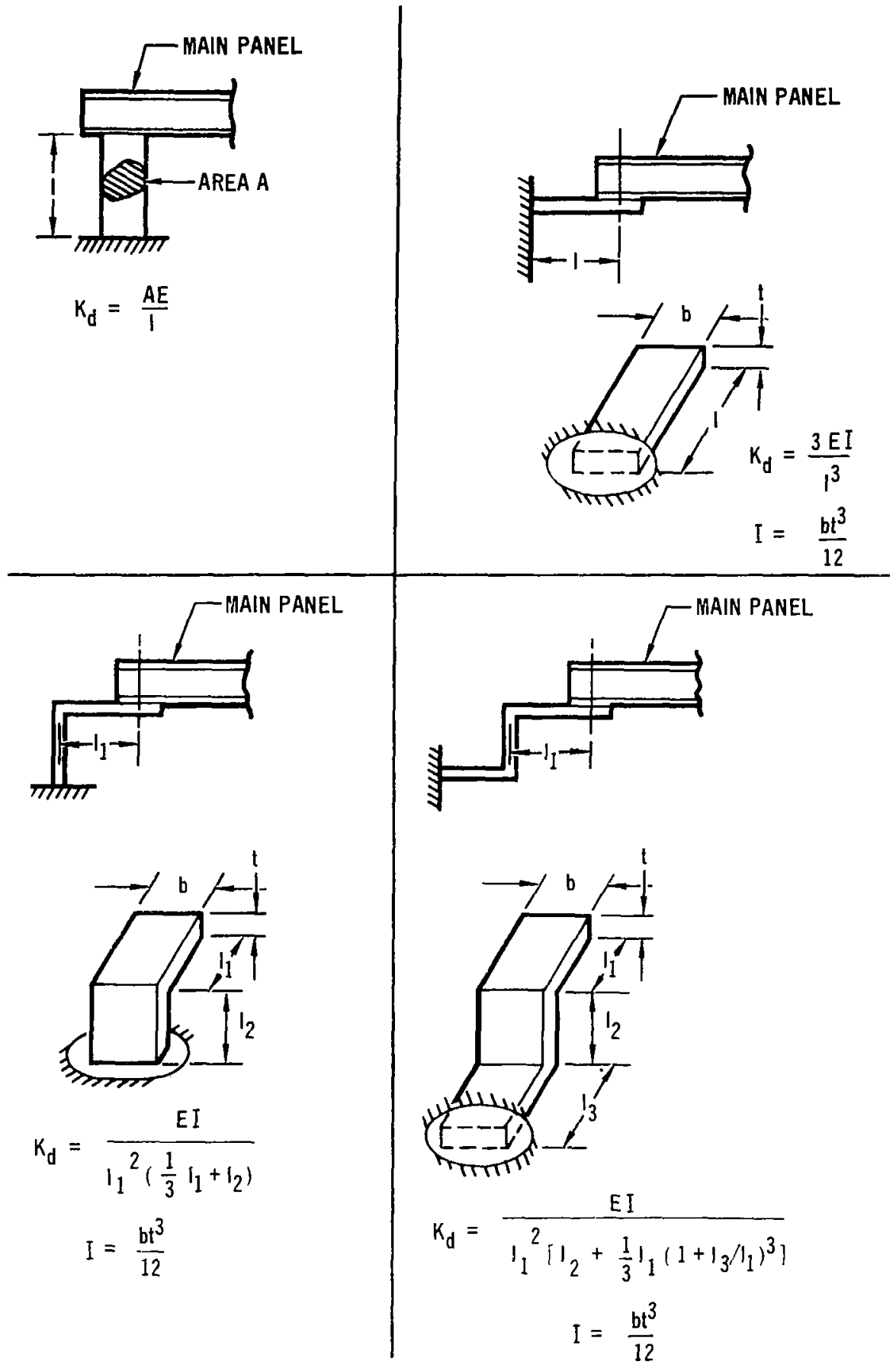

FIGURE B-3 STIFFNESSES OF PANEL EDGE SUPPORT SPRINGS 
equation ( $B-5)$ may be written as

$$
U_{I}=c^{2} \frac{a}{4}\left(\frac{\pi}{b}\right)^{3} D_{2} \bar{K}_{S}
$$

For the edge support panel illustrated in figure B-4 the energy stored in the edge panel is given by

$$
U_{S}=\frac{1}{2} D_{0} \int_{0}^{\ell} \int_{0}^{a}\left\{\left(\frac{\partial^{2} w}{\partial x^{2}}+\frac{\partial^{2} w}{\partial y^{2}}\right)^{2}-2(1-v)\left[\frac{\partial^{2} w}{\partial x^{2}} \frac{\partial^{2} w}{\partial y^{2}}-\left(\frac{\partial^{2} w}{\partial x \partial y}\right)^{2}\right]\right\} d x d y
$$

It is assumed that the deflection throughout the edge panel is given as

$$
w=\frac{c}{2}\left[3 \frac{y}{\ell}-\left(\frac{y}{\ell}\right)^{3}\right] \sin \frac{\pi x}{a}
$$

The use of this deflection shape is analogous to assuming that the main panel is infinitely stiff relative to the stiffness of the edge panel in the $y$ direction. Combining equations $(B-8)$ and $(B-9)$ yields the following expression for the strain energy stored in the edge panel

$$
U_{S}=\frac{1}{4} C^{2} D_{0} \frac{a \ell}{4}\left[\frac{68}{35}\left(\frac{\pi}{a}\right)^{4}+\frac{48}{5}\left(\frac{\pi}{a \ell}\right)^{2}+12 \frac{1}{\ell^{4}}\right]
$$

Equating equations $(B-10)$ and $(B-7)$, the expression for the nondimensional stiffness of an edge support panel becomes

$$
\bar{K}_{S}=\ell \frac{D_{0}}{D_{2}}\left(\frac{b}{\pi}\right)^{3}\left[\frac{17}{35}\left(\frac{\pi}{a}\right)^{4}+\frac{12}{5}\left(\frac{\pi}{a \ell}\right)^{2}+\frac{3}{\ell^{4}}\right]
$$




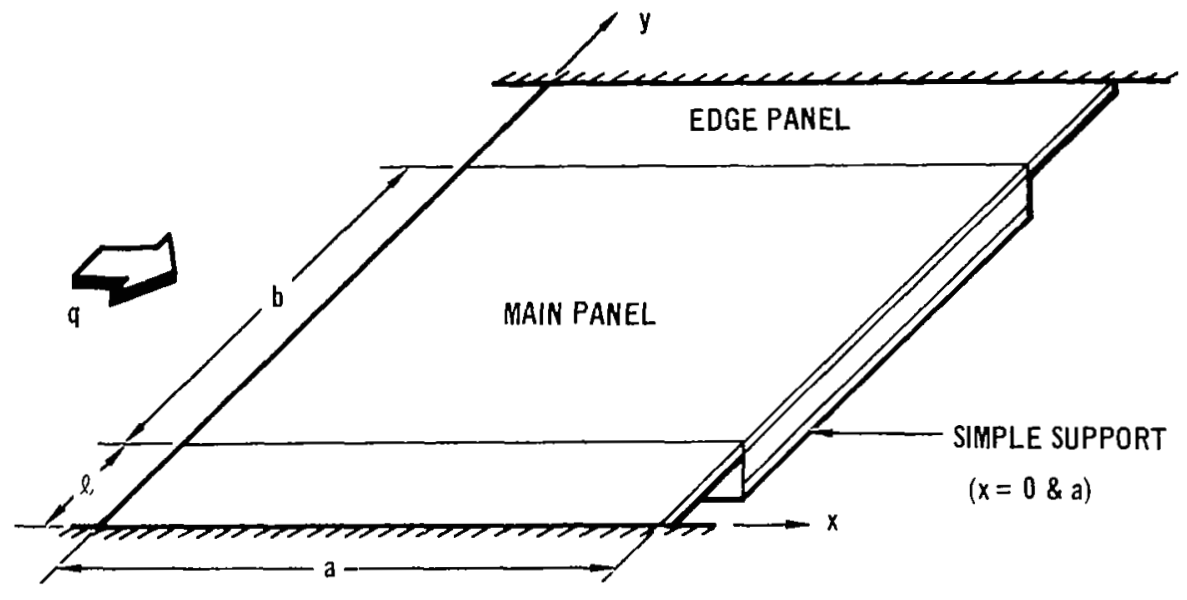

(a) OVERALL CONFIGURATION

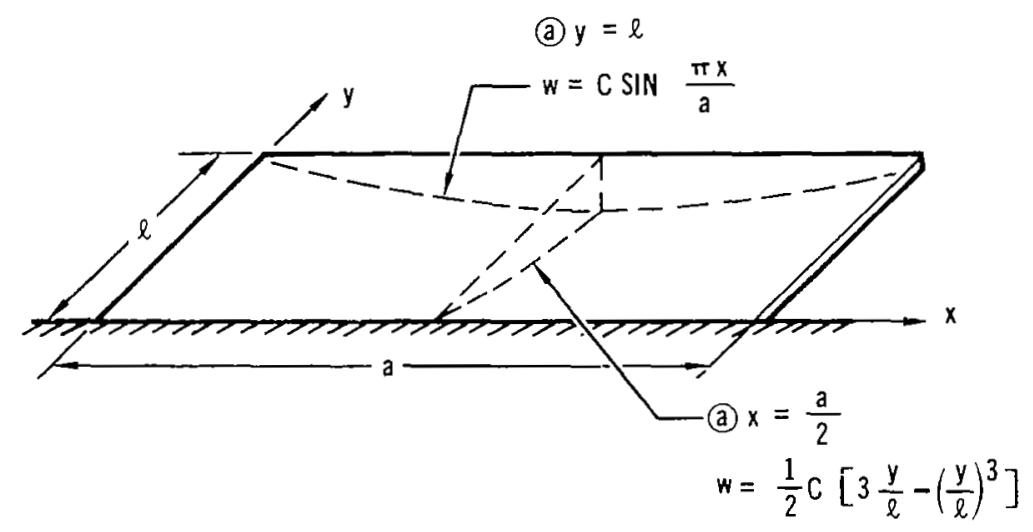

(b) ASSUMED DEFLECTION PATTERN

FIGURE B-4 EDGE SUPPORT PANEL 
APPENDIX C

PANEL ON ELASTIC FOUNDATION

The question of the flutter sensitivity of a panel on an elastic foundation falls into two categories. The first of these, with a rigid substructure, is illustrated in figure $\mathrm{C}-1(\mathrm{a})$. It consists of a flexible panel exposed to the flow while supported by an elastic medium or foundation. This elastic foundation is in turn mounted to an essentially rigid base. In the second, the lower surface of the elastic medium is mounted to a second flexible panel or elastic substructure as shown in figure $C-1(b)$. These two different configurations are treated separately in the following sections.

\section{1 Rigid Substructure - In the absence of damping it can be shown} (ref. 34) that the critical flow conditions for flutter of a simply supported isotropic panel resting on an elastic foundation with a rigid substructure are unaffected by the foundation. In reference 34 a winkler foundation model was employed wherein a point load on the foundation gives rise to a deflection at the same point but nowhere else. The distinction between this winkler foundation representation and a foundation model which allows deflections at points surrounding a point load is discussed in reference 35 .

The fact that a Winkler foundation has no influence on the flutter of a simply supported panel, can be explained by the way in which the foundation contributes to the panel dynamic characteristics. The effect of the foundation is to increase the panel natural frequencies, but not to change the frequency separation between the various modes. This results in the same flutter $q$ for a given panel configuration with or without the elastic foundation. As discussed in reference 34, when aerodynamic damping or an effective structural damping (viscous type) is included in the analysis the flutter conditions can be significantiy affected by the foundation depending upon the magnitude of the foundation stiffness. 


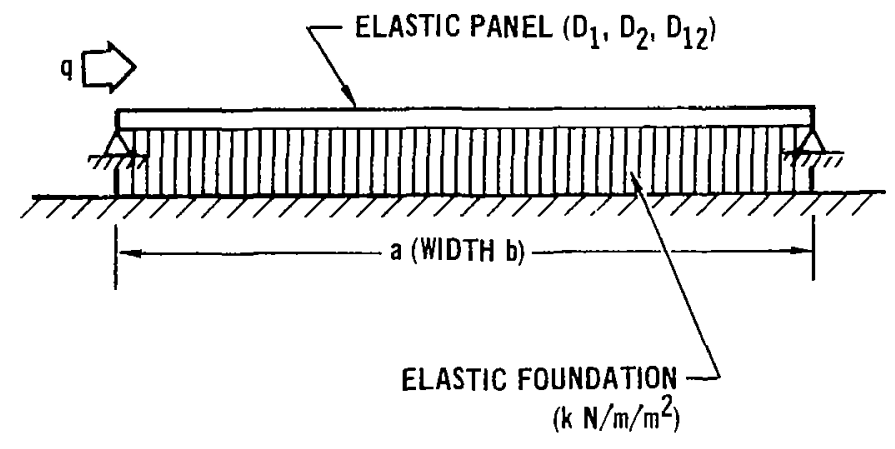

(a) Rigid Substructure

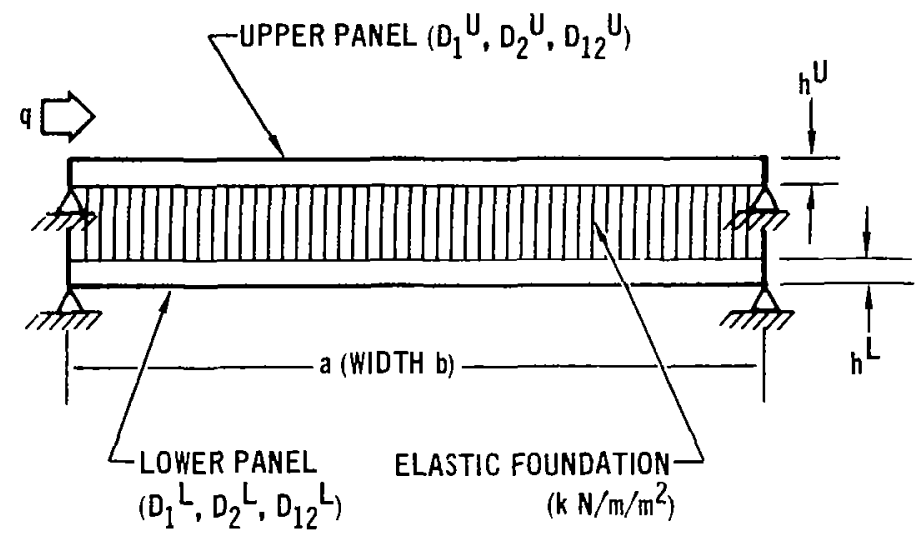

(b) Elastic Substructure

FIGURE C-1 PANEL ON ELASTIC FOUNDATION 
Results of a two mode flutter solution for an isotropic panel presented in reference 34 have been extended to the case of an orthotropic panel rest.. ing on an elastic foundation. These results are expressed as

$$
\begin{aligned}
& \lambda=18.26\left\{\left[15+6 \frac{D_{12}}{D_{1}}\left(\frac{a}{b}\right)^{2}\right]^{2}+\right. \\
& \left.2 g_{T}^{2}\left[17+10 \frac{D_{12}}{D_{1}}\left(\frac{a}{b}\right)^{2}+2 \frac{D_{2}}{D_{1}}\left(\frac{a}{b}\right)^{4}+2 k\right]\right\}^{1 / 2}
\end{aligned}
$$

where $\lambda$ is defined by equation (6). In this expression, $g_{T}$ is a damping coefficient which combines both aerodynamic and structural damping, $k$ is the elastic foundation stiffness parameter given as

$$
k=\frac{k a^{4}}{\pi^{4} D_{1}}
$$

with other quantities defined in figure $\mathrm{C}-1(\mathrm{a})$.

The design procedure for this panel configuration employs the flutterfree panel design boundary to estimate a flutter critical condition neglecting $g_{T}$ and elastic foundation effects. With equation $(C-1)$, the ratio of flow parameters with and without elastic foundation and damping effects is obtained. The critical parameter obtained from the design boundary is then modified by this ratio to account for damping and foundation stiffness.

Results obtained from this approach for a panel configuration with a rigid substructure are shown in figure $c-2$. The relationship between the flow parameter ratio $\lambda / \lambda_{0}$ obtained from equation $(C-1)$ as a function of the nondimensional foundation parameter $K[$ eq. $(C-2)]$ and damping is illustrated. In this context $\lambda_{0}$ is the flow parameter at flutter neglecting damping and elastic foundation effects while $\lambda$ is the corresponding parameter including these effects. These results are compared with the analytical results from reference 34. 


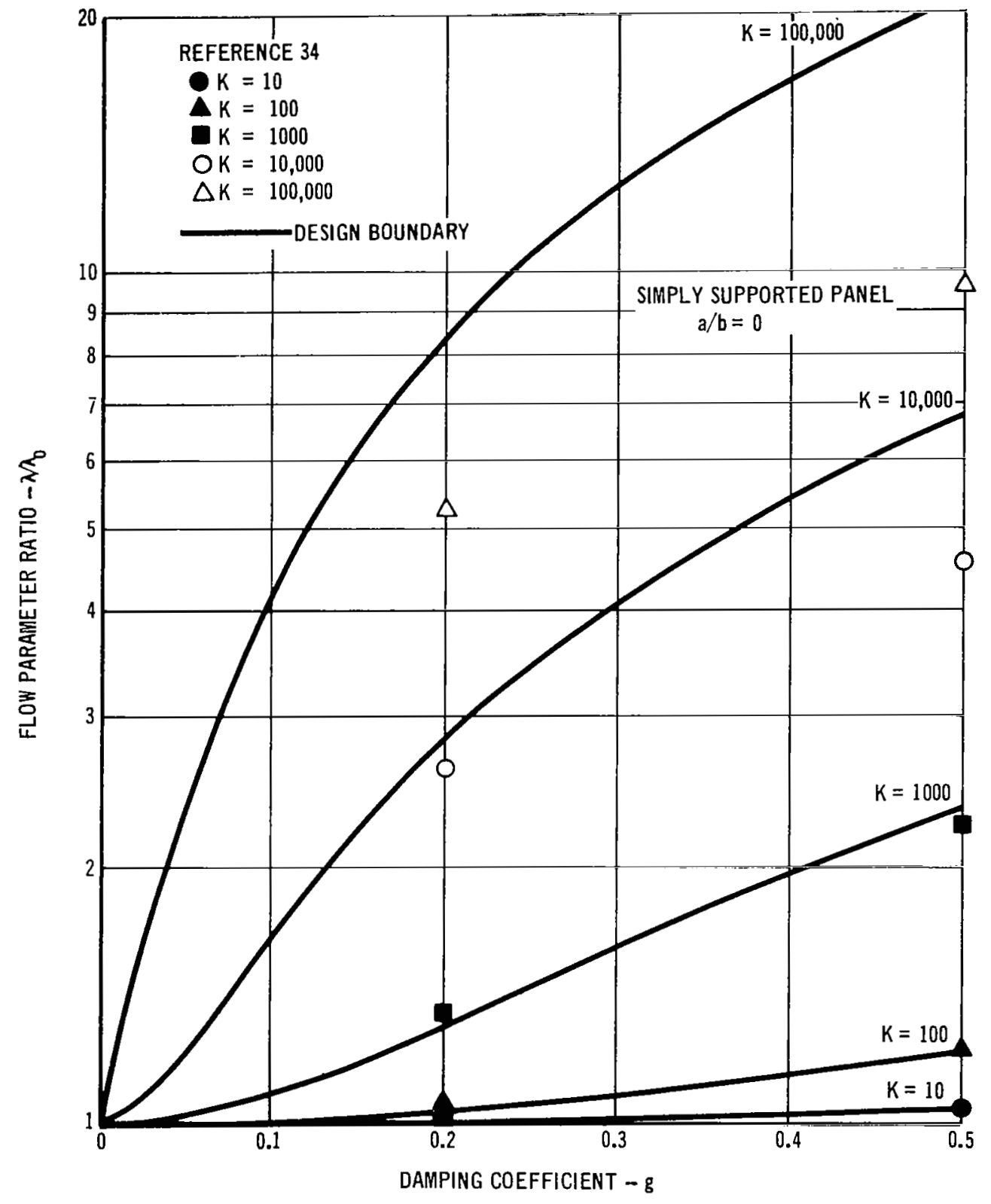

FIGURE C-2 COMPARISON OF TWO MODE SOLUTION INCLUDING ELASTIC FOUNDATION EFFECTS WITH REFERENCE 34 RESULTS 
As indicated by the data presented in figure $\mathrm{C}-2$, this procedure has application only at lower values of $K(K \leq 1000)$. It must be emphasized that this approach has the inherent limitations of a two mode flutter solution and a reliable panel design effort must include a detailed flutter analysis including the influence of the elastic foundation.

C.2 Elastic Substructure - Theoretical considerations for two parallel isotropic simply supported elastic panels interconnected by an elastic medium are given in references 36 and 37 . Results shown in these references illus. trate the complex interplay between the stiffness characteristics of the elastic medium, panel configurations, and magnitude of inplane loading. Representation of these complex interactions in terms of design criteria does not appear feasible. However, the two mode theoretical approach of references 36 and 37 has been modified for orthotropic panels and additional panel flutter trends obtained.

Following the analytical procedure of references 36 and 37 and neglecting the influence of inplane loads, the two mode solution for parallel, elastically interconnected simply supported orthotropic panels is

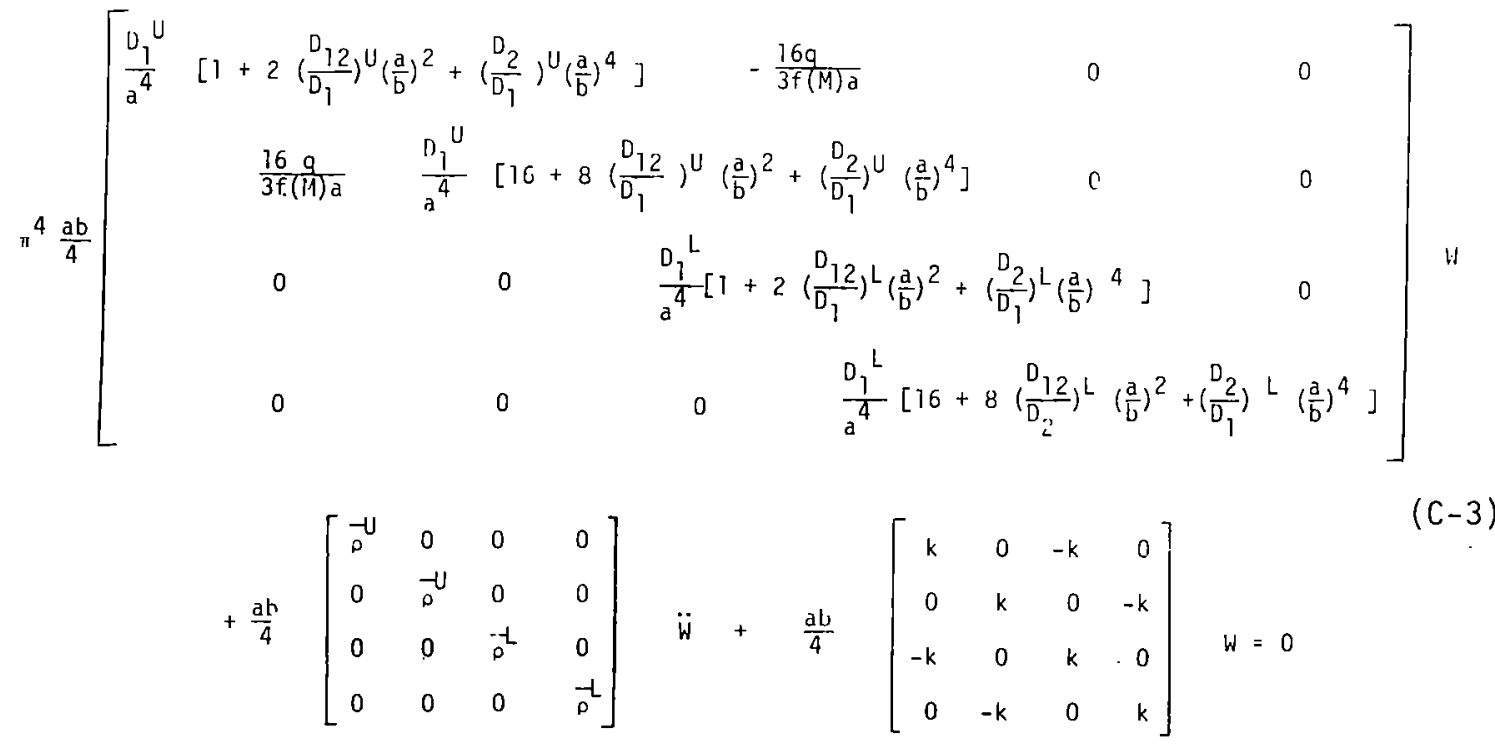


where $\bar{\rho}$ is the mass per unit area for the particular panel. In figure $C-1(b)$ the superscripts $U$ and $L$ refer to the upper and lower panels, respectively. The form of equation (C-3) assumes deflection solutions for the upper panel as follows

$$
w^{U}(x, y, t)=w_{11}^{U}(t) \sin \frac{\pi x}{a} \sin \frac{\pi y}{b}+w_{21}^{U}(t) \sin \frac{2 \pi x}{a} \sin \frac{\pi y}{b}
$$

with similar expressions for the lower panel.

Equation $(\mathrm{C}-3)$ is nondimensionalized with respect to the lower panel by employing the following relationships

$$
\begin{array}{ll}
D_{1}^{U}=\varepsilon D_{1}^{L} & \lambda=\frac{2 q a^{3}}{f(M) D_{1}^{L}} \\
-U=n \rho^{-L} & K=\frac{k a^{4}}{\pi^{4} D_{1}^{L}}
\end{array}
$$

Thus, equation $(\mathrm{C}-3)$ may be written as

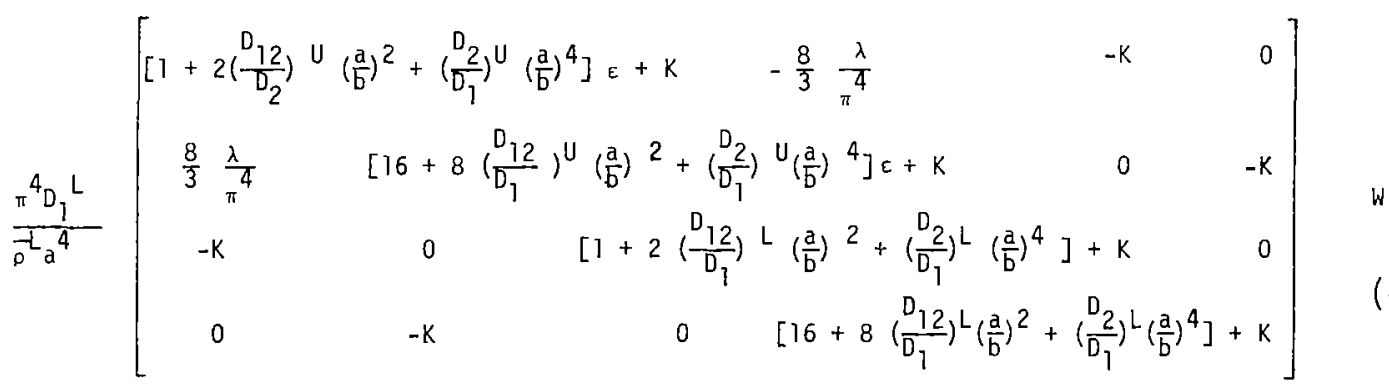

$$
\begin{aligned}
& +\left[\begin{array}{llll}
n & 0 & 0 & 0 \\
0 & n & 0 & 0 \\
0 & 0 & 1 & 0 \\
0 & 0 & 0 & 1
\end{array}\right] \quad \ddot{w}=0
\end{aligned}
$$


The eigenvalue problem associated with equation (C-6) was formulated and programmed on the digital computer. An interative procedure was then used to obtain the flutter critical $\lambda$ for a given panel configuration. In this procedure the value of $\lambda$ is systematically varied and the lowest value of $\lambda$ for which two of the eigenvalues coalesce is sought. The procedure was used to generate trends for flutter of coupled orthotropic panels. These trends are presented so that the designer is aware of the potential fiutter problems with parallel elastically coupled panels.

Typical results for interconnected parallel panels are illustrated in figure $\mathrm{C}-3$ where the critical flow parameter $\lambda$ as a function of panel a over $b$ ratio and elastic medium stiffness is shown for identical upper and lower isotropic panels $(\varepsilon=\eta=1.0)$. As can be seen there is a significant dip in the critical flow parameter as a function of the a over b ratio. A plot of the elastic medium stiffness versus panel aspect ratio for this dip in critical $\lambda$ is given in figure $\mathrm{C}-4$.

A portion of the results presented in figure C-3 can be compared with the data presented in reference 37 . Shown on figure $\mathrm{C}-3$ is the comparison which indicates that the trends presented here are consistent with the reference 37 results.

If it is assumed that the two panels have different thicknesses, but are constructed of the same material, the quantities $\varepsilon$ and $n$ of equation ( $C-5$ ) become

$$
\begin{aligned}
& \varepsilon=T_{r}^{3} \\
& n=T_{r}
\end{aligned}
$$

where $T_{r}$ is the thickness ratio expressed as

$$
T_{r}=h U / h^{L}
$$




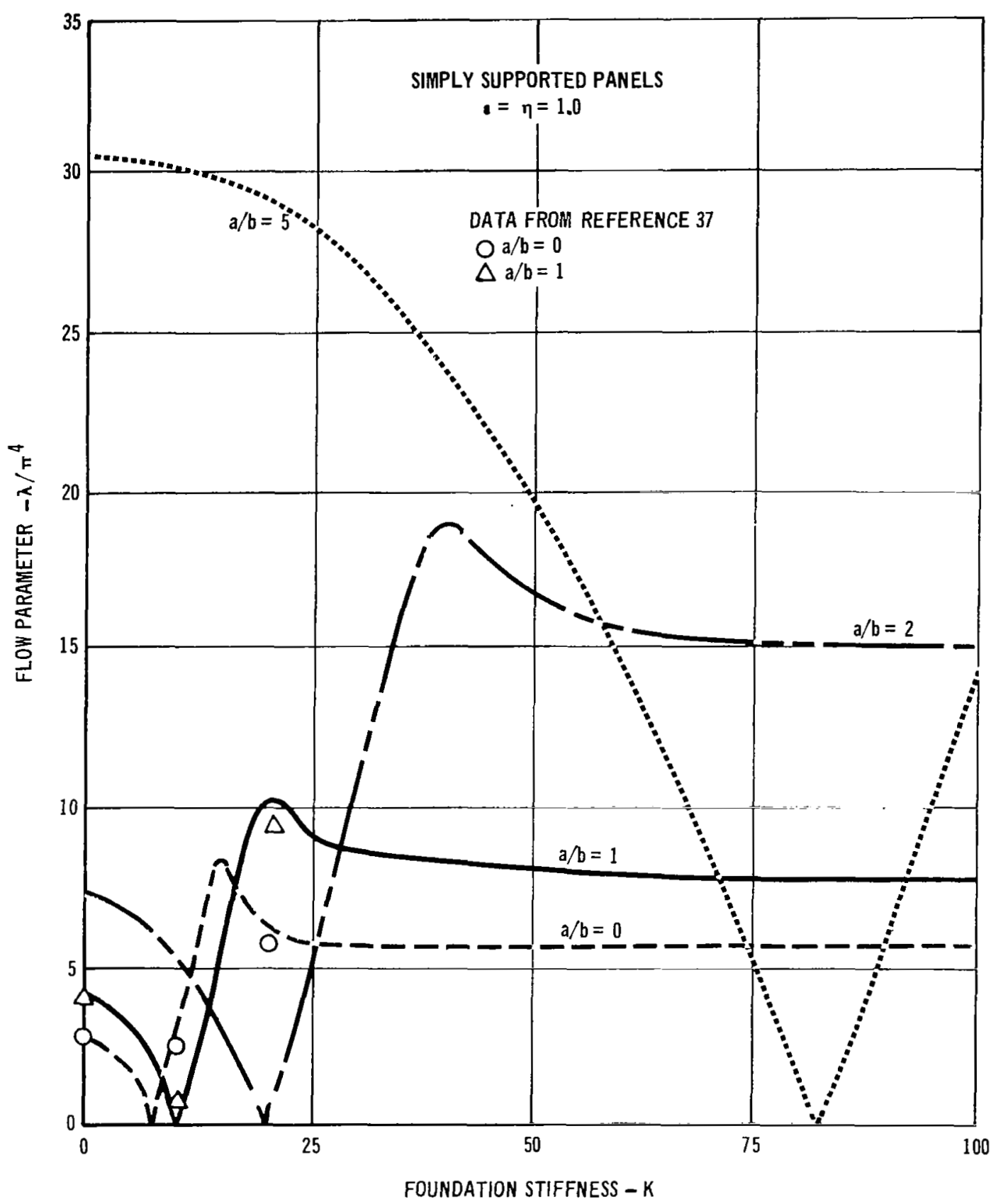

FIGURE C-3 FLUTTER RESULTS FOR EQUAL PARALLEL ELASTICALLY INTERCONNECTED ISOTROPIC PANELS 


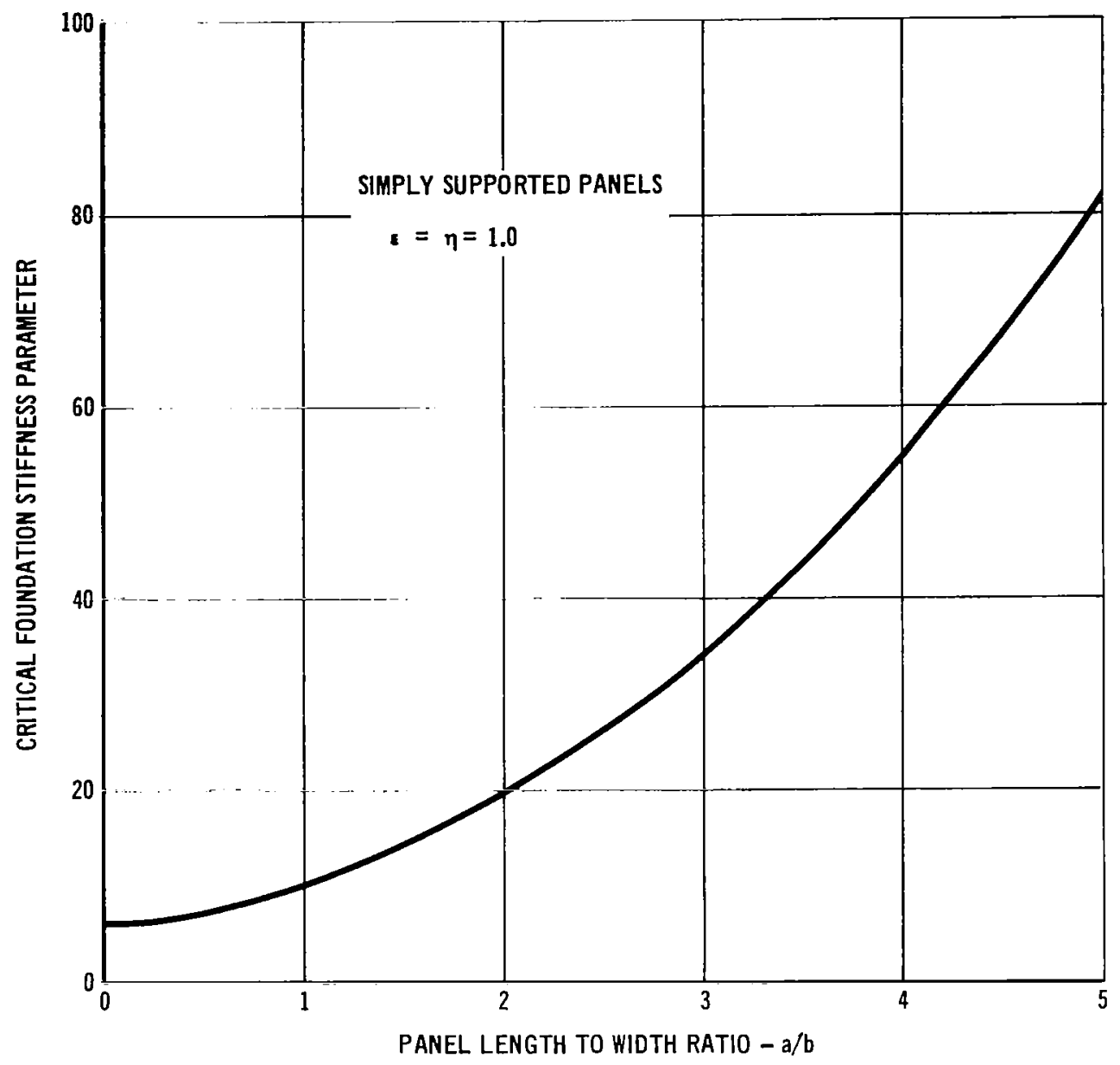

\section{FIGURE C-4 FLUTTER CRITICAL FOUNDATION STIFFNESS PARAMETER AS A} FUNCTION OF LENGTH TO WIDTH RATIO FOR EQUAL ISOTROPIC PANELS

Two mode results for an upper panel having twice and half the thickness of the lower panel are compared with results for equal panel thicknesses in figure C-5. These configurations have a critical foundation stiffness parameter $K$ values which result in low values for the flow parameter at flutter.

An analysis of elastically interconnected panels representative of the space shuttle thermal protection system is presented in reference 38 . In this 


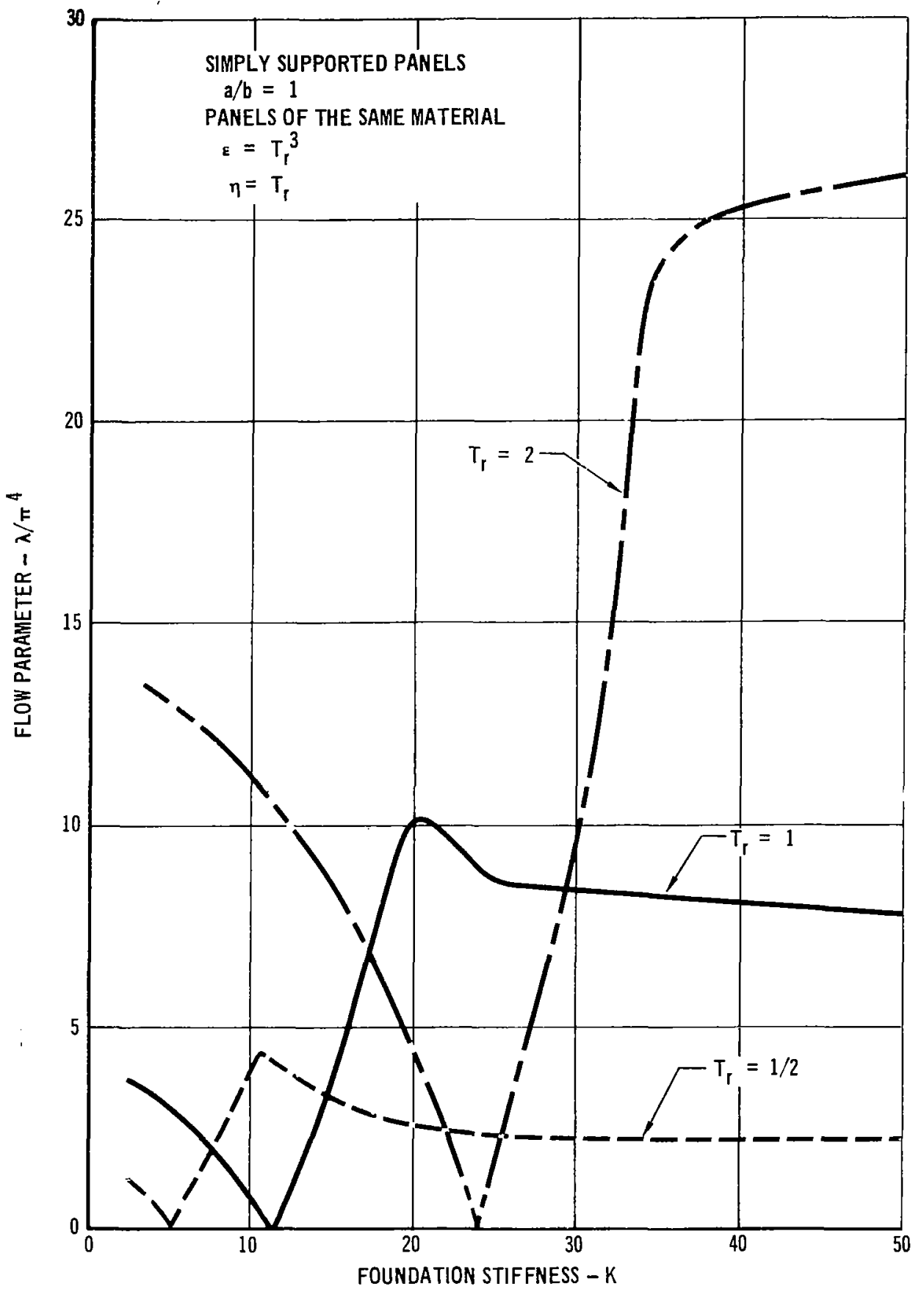

FIGURE C-5 FLUTTER RESULTS FOR PARALLEL ELASTICALLY INTERCONNECTED ISOTROPIC PANELS HAVING VARYING THICKNESS RATIOS 
configuration the upper panel consists of a relatively thick ceramic tile. Included in this investigation is the influence of several individual tiles supported by a common lower panel and interaction between adjacent tiles. The designer is referred to this work for detailed discussions of this type of panel configuration.

In the absence of more extensive theoretical and/or experimental results, the above two mode approach allows the evaluation of trends for parallel panel configurations. These procedures could be employed during preliminary design, but as with the case of a rigid substructure, detailed flutter studies must be conducted during later design efforts. 
APPENDIX D

PANEL FLUTTER TEST DATA

A tabulation of the experimental panel flutter data used in the verification of the flutter-free panel design boundary, Section 6.0, is presented on the following pages. In each case, the panel configuration (isotropic or orthotropic, flow angularity, inplane loads, etc.) is indicated. A separate table is given for the data obtained from a particular reference for a given panel configuration. Also presented is a cross reference with the figure number of section 6.0 in which each set of data is plotted. 
TABLE D-1

PANEL FLUTTER DATA FROM REFERENCE 10

Orthotropic panel with steam edge support flexibility

Data shown in figure 13

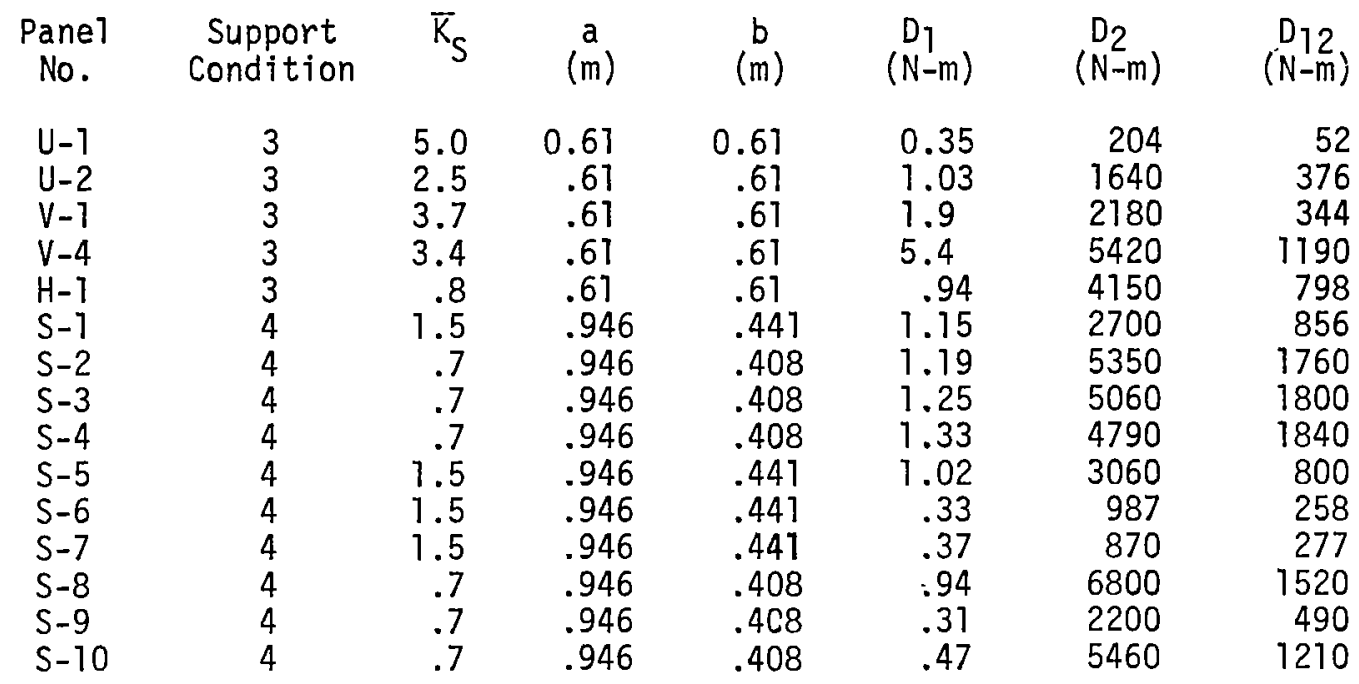

Note: Support condition definition and $\bar{K}_{S}$ calculation based on figure B-2, Appendix B and

$$
\lambda=\frac{2 a \cdot a^{3}}{D_{1} f(M)}
$$


TABLE D-1 (Concluded)

PANEL FLUTTER DATA FROM REFERENCE 10

$\begin{array}{llrrrr}\begin{array}{c}\text { Pane1 } \\ \text { No. }\end{array} & M & \begin{array}{c}\text { G } \\ \left(k^{2} \mathrm{~Pa}\right)\end{array} & \text { GP(1) } & \text { GP(2) } & \begin{array}{c}\text { FP } \\ \left(\times 10^{-5}\right)\end{array} \\ \text { U-1 } & 2.83 & 11.4 & 12.19 & 4.16 & 35.8 \\ \text { U-2 } & 1.63 & 10.0 & 19.11 & 3.25 & 53.5 \\ \text { U-2 } & 3.0 & 162.8 & 19.11 & 3.25 & 7.88 \\ \text { V-1 } & 1.63 & 24.6 & 13.46 & 4.56 & 40.1 \\ \text { V-4 } & 1.63 & 72.3 & 14.84 & 3.80 & 38.8 \\ \text { H-1 } & 3.0 & 138.8 & 29.14 & 2.03 & 8.43 \\ \text { S-1 } & 1.57 & 18.4 & 58.52 & 4.65 & 8.97 \\ \text { S-1 } & 1.85 & 25.1 & 58.52 & 4.65 & 8.43 \\ \text { S-1 } & 2.1 & 32.4 & 58.52 & 4.65 & 7.73 \\ \text { S-2 } & 1.57 & 21.3 & 89.17 & 3.38 & 8.04 \\ \text { S-2 } & 1.85 & 31.4 & 89.17 & 3.38 & 6.98 \\ \text { S-3 } & 1.85 & 53.3 & 87.99 & 3.25 & 4.31 \\ \text { S-3 } & 2.1 & 69.4 & 87.99 & 3.25 & 3.93 \\ \text { S-4 } & 1.57 & 49.8 & 86.24 & 3.13 & 3.85 \\ \text { S-4 } & 1.85 & 41.7 & 86.24 & 3.13 & 5.95 \\ \text { S-4 } & 2.1 & 51.4 & 86.24 & 3.13 & 5.64 \\ \text { S-5 } & 2.1 & 43.3 & 60.08 & 5.12 & 5.14 \\ \text { S-6 } & 2.1 & 15.6 & 59.98 & 5.12 & 4.61 \\ \text { S-7 } & 1.57 & 16.8 & 58.69 & 4.64 & 3.16 \\ \text { S-8 } & 2.1 & 45.9 & 93.24 & 4.10 & 4.46 \\ \text { S-9 } & 2.1 & 6.4 & 92.18 & 4.17 & 10.47 \\ \text { S-10 } & 1.57 & 32.0 & 117.65 & 4.12 & 2.11\end{array}$

Notes: 1. GP not corrected for $c^{2} / \bar{K}_{S}$ term.

2. GP corrected for $C^{2} / \bar{K}_{S}$ term. 
TABLE D-2

PANEL FLUTTER DATA FROM REFERENCE 18

Isotropic panel supported at all edges

Data shown in figure 13

$$
\begin{aligned}
E & =69 \mathrm{GN} / \mathrm{m}^{2} \\
h & =0.81 \mathrm{~mm} \\
a & =0.762 \mathrm{~m} \\
b & =0.17 \mathrm{~m} \\
G P & =4.48
\end{aligned}
$$

$\begin{array}{ccccc}\begin{array}{c}\text { Panel } \\ \text { No. }\end{array} & \text { Log } & \text { Mo. } & \begin{array}{c}\text { FP } \\ (\mathrm{kPa})\end{array} & \left(\times 10^{-4}\right) \\ 10 & 17 & 1.4 & 30.6 & 2.9 \\ 10 & 19 & 1.3 & 32.3 & 2.8 \\ 10 & 20 & 1.2 & 33.5 & 3.1 \\ 10 & 21 & 1.2 & 38.3 & 2.7 \\ 10 & 23 & 1.2 & 38.3 & 2.7 \\ 10 & 24 & 1.1 & 55.1 & 2.7 \\ 4 & 19 & 1.4 & 30.4 & 2.9 \\ 4 & 21 & 1.3 & 31.1 & 2.9 \\ 4 & 26 & 1.2 & 40.6 & 2.6 \\ 4 & 57 & 1.4 & 35.9 & 2.5 \\ 4 & 70 & 1.4 & 32.3 & 2.8 \\ 5 & 6 & 1.4 & 33.0 & 2.7 \\ 5 & 7 & 1.33 & 32.0 & 2.8 \\ 5 & 8 & 1.2 & 40.7 & 2.5 \\ 5 & 9 & 1.35 & 32.3 & 2.8 \\ 5 & 16 & 1.3 & 30.9 & 2.9 \\ 5 & 18 & 1.4 & 32.3 & 2.8 \\ 5 & 19 & 1.3 & 29.9 & 3.0 \\ 5 & 20 & 1.3 & 34.5 & 2.6 \\ 5 & 21 & 1.2 & 35.9 & 2.9 \\ 5 & 25 & 1.3 & 29.4 & 3.0 \\ 5 & 26 & 1.3 & 32.3 & 2.8 \\ 5 & 27 & 1.4 & 31.1 & 2.9 \\ 5 & 28 & 1.4 & 34.5 & 2.7 \\ 5 & 36 & 1.3 & 32.1 & 2.8 \\ 5 & 37 & 1.2 & 38.1 & 2.7 \\ 5 & 38 & 1.3 & 32.3 & 2.8 \\ 5 & 54 & 1.3 & 35.4 & 2.6 \\ 5 & 82 & 1.3 & 37.8 & 2.4 \\ 5 & 83 & 1.2 & 39.7 & 2.3 \\ 5 & 84 & 1.3 & & \end{array}$


TABLE D-2 (Concluded)

PANEL FLUTTER DATA FROM REFERENCE 18

$\begin{array}{ccccc}\begin{array}{c}\text { Pane1 } \\ \text { No. }\end{array} & \begin{array}{c}\text { Log } \\ \text { No. }\end{array} & M & \begin{array}{c}\mathrm{q} \\ (\mathrm{kPa})\end{array} & \begin{array}{c}\mathrm{FP} \\ \left(\times 10^{-4}\right)\end{array} \\ 6 & 6 & 1.4 & 35.2 & 2.6 \\ 6 & 7 & 1.3 & 34.2 & 2.6 \\ 6 & 8 & 1.2 & 40.0 & 2.7 \\ 6 & 14 & 1.3 & 39.5 & 2.3 \\ 6 & 35 & 1.3 & 47.2 & 2.2 \\ 6 & 36 & 1.3 & 41.4 & 2.2\end{array}$


TABLE $D-3$

PANEL FLUTTER DATA FROM REFERENICE 21

Isotropic panel supported at al1 edges Data shown irı figure 13

Panel $10-20-20$

$a=0.276 \mathrm{~m}$
$D=0.75 \mathrm{~N}-\mathrm{m}$

M

2.0

3.0

$a=0.216 \mathrm{~m}$

$D=0.39 \mathrm{~N}-\mathrm{m}$

M

2.0
3.0

$a=0.216 \mathrm{~m}$

$D=0.76 \mathrm{~N}-\mathrm{m}$

M

2.0

3.0

4.0

5.0 $\mathrm{b}=0.470 \mathrm{~m}$

$\mathrm{GP}=0.46$

\section{q}

( $\mathrm{kPa})$

29.44-36.82

$59.29-61.71$

Panel 10-20-16

$$
\begin{aligned}
& b=0.470 \mathrm{~m} \\
& G P=0.46
\end{aligned}
$$

$$
\left(\begin{array}{c}
\mathrm{q} \\
\mathrm{kPa})
\end{array}\right.
$$

$$
\left(\begin{array}{c}
\text { FP } \\
(\times 10-3)
\end{array}\right.
$$

17.17-19.65

$23.72-29.65$

3.87-3.37

4. $57-3.66$

Panel 10-20-12

$$
\begin{aligned}
& b=0.470 \mathrm{~m} \\
& G P=0.46
\end{aligned}
$$

$$
\begin{gathered}
\mathrm{q} \\
(\mathrm{kPa})
\end{gathered}
$$

$$
\begin{gathered}
\mathrm{FP} \\
(\times \quad 10-3)
\end{gathered}
$$

$7.38-8.58$

$11.86-14.83$

$20.74-22.62$

$26.21-27.31$
3.80-3.26

$3.79-3.03$

3. $05-2.72$

2.97-2.85

Note: The q data presented in this table were taken from figure 16 of reference 21 . 
TABLE D-3 (Continued)

PANEL FLUTTER DATA FROM REFERENCE 21

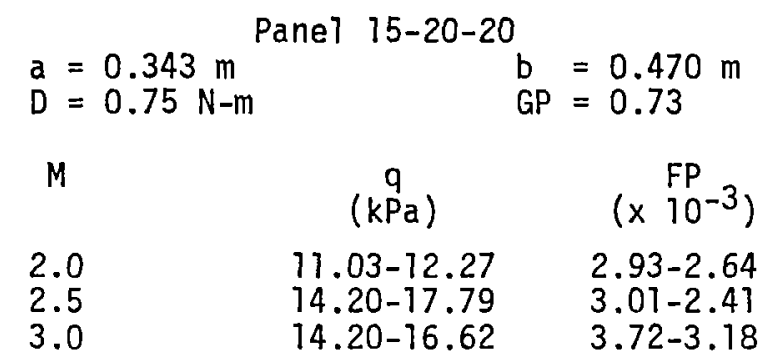

$a=0.470 \mathrm{~m}$
$D=0.75 \mathrm{~N}-\mathrm{m}$

Panel 20-15-20

$\begin{aligned} b & =0.343 \mathrm{~m} \\ G P & =1.37\end{aligned}$

M

2.0

3.0

4.0

4.5

$\begin{array}{cc}\mathrm{q} & \mathrm{FP} \\ (\mathrm{kPa}) & (\times 10-3) \\ 8.58-9.79 & 1.47-1.28 \\ 10.68-11.86 & 1.92-1.73 \\ 17.58-20.73 & 1.60-1.40 \\ 15.51-17.24 & 2.05-1.85\end{array}$

$\begin{array}{cc}\mathrm{q} & \mathrm{FP} \\ (\mathrm{kPa}) & (\times 10-3) \\ 8.58-9.79 & 1.47-1.28 \\ 10.68-11.86 & 1.92-1.73 \\ 17.58-20.73 & 1.60-1.40 \\ 15.51-17.24 & 2.05-1.85\end{array}$

Panel 20-10-25

$\mathrm{a}=0.470 \mathrm{~m}$
$\mathrm{D}=1.47 \mathrm{~N}-\mathrm{m}$

$\mathrm{b}=0.216 \mathrm{~m}$

$M$

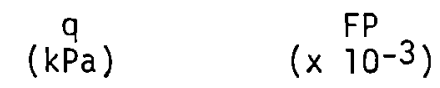

2.0

2.5

3.0

9.79-11.03

$2.51-2.23$

$17.79-22.20$

$1.83-1.46$

23.72-26.61

$1.69-1.51$

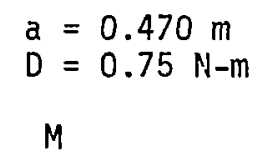

Panel 20-10-20

$b=0.216 \mathrm{~m}$
$\mathrm{GP}=2.18$

2.0

$$
\left(\begin{array}{c}
\mathrm{q} \\
\mathrm{kPa}
\end{array}\right)
$$

$14.75-19.65$

$23.72-26.68$

$$
\left(\begin{array}{l}
\mathrm{FP} \\
\times 10^{-4}
\end{array}\right)
$$

$8.51-6.40$

$8.66-7.70$ 
TABLE D-3 (Concluded)

PANEL FLUTTER DATA FROM REFERENCE 21

\begin{tabular}{lcc}
\multicolumn{3}{c}{ Panel 20-10-16 } \\
$a=0.470 \mathrm{~m}$ & $\mathrm{~b}=0.216 \mathrm{~m}$ \\
$\mathrm{D}=0.39 \mathrm{~N}-\mathrm{m}$ & & $\mathrm{GP}=2.18$ \\
$\mathrm{M}$ & $\mathrm{q}$ & $\mathrm{FP}$ \\
& $(\mathrm{kPa})$ & $\left(\times 10^{-4}\right)$ \\
2.0 & $7.38-9.79$ & $8.73-6.58$ \\
2.5 & $8.89-10.69$ & $9.58-7.97$ \\
3.0 & $9.48-11.86$ & $11.09-8.87$ \\
3.5 & $11.31-13.17$ & $11.03-9.47$ \\
4.0 & $13.86-15.10$ & $10.39-9.53$ \\
4.5 & $11.24-12.06$ & $14.51-13.52$ \\
5.0 & $22.75-25.02$ & $8.00-7.28$
\end{tabular}

Panel 20-06-12

$a=0.470 \mathrm{~m}$

$D=0.16 \mathrm{~N}-\mathrm{m}$

$M$
2.0
3.0
4.0

$$
\begin{aligned}
& b=0.114 \mathrm{~m} \\
& \mathrm{GP}=4.11
\end{aligned}
$$<smiles>[Mg][Mg]</smiles>

$12.27-14.75$

$20.75-23.72$

$25.77-30.20$

$$
\begin{gathered}
\mathrm{FP} \\
\left(\times 10^{-4}\right) \\
2.21-1.84 \\
2.14-1.87 \\
2.41-2.01
\end{gathered}
$$


TABLE D-4

PANEL FLUTTER DATA FROM REFERENCE 8

Orthotropic panel with flow angularity

Data shown in figure 15

$$
\begin{aligned}
& a=0.48 \mathrm{~m} \\
& b=0.48 \mathrm{~m} \\
& \bar{K}_{L T}=1.94 \\
& D_{12} / D_{1}=0.17 \\
& D_{2} / D_{1}=0.00026
\end{aligned}
$$

$\begin{array}{clll}\Lambda & \lambda & \text { GP } & \mathrm{FP} \\ \text { (deg) } & & & \left(\times 10^{-4}\right)\end{array}$

$\begin{array}{rrrr}30 & 11.50 & 3.26 & 1.42 \\ 45 & 8.90 & 3.32 & 1.12 \\ 60 & 7.05 & 3.34 & 1.02 \\ 75 & 7.05 & 3.34 & .86 \\ 90 & 8.16 & 3.35 & .64\end{array}$

Note: The above data were taken from figure 6 of reference 8 with a normalization factor on $\lambda$ of 371 where

$$
\lambda=\frac{2 q a^{3}}{D_{j} f(M)}
$$


TABLE D-5

PANEL FLUTTER DATA FROM REFERENICE 11

Orthotropic panel with flow angularity

Data shown in figures 15 and 16

\begin{tabular}{|c|c|c|c|c|c|c|}
\hline Panel & $\stackrel{a}{(m)}$ & $a / b$ & $\begin{array}{c}\mathrm{D}_{2} \\
(\mathrm{~N}-\mathrm{m})\end{array}$ & $D_{1} / D_{2}$ & $D_{12} / D_{2}$ & \\
\hline $\begin{array}{l}1 \\
2 \\
3 \\
4 \\
5\end{array}$ & $\begin{array}{r}0.572 \\
.356 \\
.356 \\
.356 \\
.356\end{array}$ & $\begin{array}{r}5 . \\
.933 \\
.933 \\
.933 \\
.933\end{array}$ & $\begin{array}{c}0.0982 \\
.405 \\
.405 \\
.405 \\
.405\end{array}$ & $\begin{array}{l}755 \\
420 \\
420 \\
420 \\
270\end{array}$ & $\begin{array}{l}1.5 \\
137 . \\
137 . \\
137 . \\
137 .\end{array}$ & $\begin{array}{r}C 7 \\
1 \\
1\end{array}$ \\
\hline & \multicolumn{6}{|c|}{ Panel 1} \\
\hline & $\stackrel{\Lambda}{(\operatorname{deg})}$ & & & GP & & $\begin{array}{c}F P \\
\left(\times 10^{-3}\right.\end{array}$ \\
\hline & $\begin{array}{l}31.6 \\
32.5 \\
33.5 \\
36.2 \\
46 . \\
46 . \\
50 . \\
57 .\end{array}$ & & & $\begin{array}{r}0.23 \\
.23 \\
.23 \\
.23 \\
.23 \\
.24 \\
.24 \\
.24\end{array}$ & & $\begin{array}{l}3.8 \\
3.9 \\
4.0 \\
3.9 \\
3.4 \\
3.2 \\
3.0 \\
2.9\end{array}$ \\
\hline
\end{tabular}

Note: The q's presented in this table were calculated from $q / f(M 1)$ data provided by Peter Shyprykevich, Grumman Aerospace Corporation. This information is summarized in figures 11 through 15, reference 11 . 
TABLE D-5 (Continued)

PANEL FLUTTER DATA FROM REFERENCE 11

Pane1 2

$\stackrel{\Lambda}{\text { (deg) }}$

19.8

19.8

21.7

24.2

28.8

30.2

32.

33.1

33.2

37.2

59.5

$\stackrel{\Lambda}{\text { (deg) }}$

35.6

36.1
36.5

39.

41.8

46.8

49.1

54.

64.8

69.4

90.5

(deg)

16.3

17.1

17.9

18.5

19.3

21.2

25.4 $\left(\begin{array}{c}\mathrm{q} \\ \mathrm{KPa}\end{array}\right.$

61.5

68.3

56.4

51.2

42.6

34.2

25.6

25.6

34.2

22.2

17.0

10.3
GP

1.81

1.82

1.82

1.84

1.87

1.90

1.91

1.92

1.92

1.92

1.93

1.96

Panel 3 $\left(\begin{array}{c}q \\ \mathrm{kPa}\end{array}\right)$

85.5

76.7

85.5

68.2

59.7

59.7

51.3

42.8

34.3

30.7

27.4

GP

1.93

1.93

1.93

1.94

1.94

1.95

1.95

1.96

1.97

1.97

1.97

\section{Panel 4}

$\left(\mathrm{kPa}^{\mathrm{q}}\right)$

25.7

34.3

17.1

42.8

51.4

17.1
GP

0.92

.92

.92

.92

.93

.93

.93

8.6

FP $\left(\times 10^{-3}\right)$

1.13

.97

1.17

1.16

1.23

1.24

1.57

1.47

1.05

1.62

1.84

1.71

FP $\left(\times 10^{-4}\right)$

3.87

4.23

3.75

4.33

4.53

3.94

4.33

4.61

4.66

4.88

4.74

FP

$$
\left(\times 10^{-3}\right)
$$

4.27

3.02

5.73

2.20

1.74

4.64

7.47 
TABLE D-5 (Concluded)

PANEL FLUTTER DATA FROM REFERENCE 11

Panet 5

$\begin{array}{cccc}\begin{array}{c}\Lambda \\ \text { (deg) }\end{array} & \begin{array}{c}q \\ (\mathrm{kPa})\end{array} & \text { GP } & \begin{array}{c}F P \\ \left(\times 10^{-3}\right)\end{array} \\ 15.5 & 85.6 & 1.17 & 1.11 \\ 17.5 & 77.0 & 1.18 & 1.11 \\ 20.5 & 68.4 & 1.19 & 1.01 \\ 23 . & 60.0 & 1.19 & 1.01 \\ 26 . & 51.4 & 1.20 & 1.02 \\ 30 . & 42.8 & 1.20 & 1.03 \\ 40.5 & 34.3 & 1.21 & .83 \\ 58.3 & 25.7 & 1.21 & .68\end{array}$


TABLE D-6

PANEL FLUTTER DATA FROM REFERENCE 12

Isotropic panel supported at all edges

with inplane loads

Data shown in figures 17 and 21

$$
\begin{aligned}
& \text { Pane1 } 1 \\
& D=0.343 \quad m \quad b=0.343 \mathrm{~m} \\
& \mathrm{~m}=7.085 \quad \mathrm{~N}-\mathrm{m} \quad \mathrm{M}=1.96 \\
& \mathrm{~K}_{S}=968
\end{aligned}
$$

$P_{C R}$

$\left(\begin{array}{c}q \\ P a\end{array}\right)$

GP

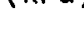

0.13

.17

.18

.24

.27

.48

.50

.57

.58

.70

.71

.92

66.6

61.1

61.7

51.4

51.4

33.7

33.7

20.0

20.6

14.6

14.6

8.6

0.932

.911

.905

.871

.854

.721

.707

.655

.648

.547

.538

FP

.92

.283

$\left(\times 10^{-3}\right)$

2.66

2.26

2.11

1.76

1.49

.87

.81

1.07

1.01

1.00

.97

1.00

${ }^{P_{C R}}$

$$
\begin{array}{rl}
\text { Pane } 12 & \\
a=0.622 m & b=0.318 \mathrm{~m} \\
D=13.839 \mathrm{~N}-\mathrm{m} & M=1.96 \\
\bar{K}_{S}=43.4
\end{array}
$$

$\left(\begin{array}{c}q \\ k \mathrm{~Pa}\end{array}\right)$

42.5

22.6

15.6

8.8

6.2

6.2
GP

1.90
1.63
1.28
1.18
1.04
.43

$$
\begin{gathered}
F P \\
\left(\times 10^{-3}\right) \\
1.77 \\
1.10 \\
.93 \\
1.48 \\
1.89 \\
1.45
\end{gathered}
$$

Hote: For all paneis the $P_{C R}$ and $q$ data were obtained from information shown in figure 9 , reference 12 . 
TABLE D-6 (Continued)

PANEL FLUTTER DATA FROM REFERENCE 12

$$
\begin{aligned}
& \text { Panet } 3 \\
& \begin{array}{ll}
a=0.622 \mathrm{~m} & b=0.257 \\
D=13.839^{\mathrm{N}} \mathrm{N} & \mathrm{M}=1.96
\end{array} \\
& \overline{\mathrm{K}}_{\mathrm{S}}=22.8
\end{aligned}
$$

${ }^{P}$ CR<smiles>[194In]</smiles>

GP

0.21

65.7

47.4

30.4

18.6

11.9

7.6

2.11

1.74

1.62

1.25

.75

.41

$\left(\times 10^{-3}\right)$

.97

Panel 4

$\mathrm{a}=0.622 \mathrm{~m} \quad \mathrm{~b}=0.216 \mathrm{~m}$

$D=7.085 \mathrm{~N}-\mathrm{m} \quad M=1.96$

$$
\bar{K}_{S}=25.7
$$

$P_{C R}$

( $\mathrm{kPa}$ )

GP

0.52

45

64

.85

1.74

1.68

0.13

.15

51.6

51.6

33.6

33.6

22.3

17.8

.56

9.2

9.1

2.64

2.60

2.41

2.38

2.06

1.87

.98

.28

FP $\left(\times 10^{-3}\right)$

0.45

.42

.57

.49

.58

.67

1.01 
TABLE D-6 (Continued)

PANEL FLUTTER DATA FROM REFERENCE 12

${ }_{\text {CR }}$

0.25

.38

.38

.39

.41

.43

.50

.52

.68

.70

.88

$P_{\text {CR }}$

0.10

.38

.41

.49

.64

.66

.68

.69

.78

.94

.95

$$
\begin{array}{cll}
a=0.622 & \text { Panel } & 5 \\
D=3.628 & \mathrm{~N}-\mathrm{m} & =0.165 \mathrm{~m} \\
& \bar{K}_{\mathrm{S}}= & \mathrm{M}=1.96 \\
\mathrm{q} & & \mathrm{GP} \\
(\mathrm{kPa}) &
\end{array}
$$

68.6

60.4

51.2

60.4

34.1

50.4

23.8

23.9

17.0

17.1

8.8

3.19

2.90

2.90

2.88

2.83

2.78

2.61

2.55

2.08

2.02

1.28

$$
\begin{array}{cl}
a=0.622 \mathrm{~m} & \mathrm{~b}=0.148 \mathrm{~m} \\
\mathrm{D}=3.628 \mathrm{~N}-\mathrm{m} & \mathrm{M}=1.96 \\
& \overline{\mathrm{K}}_{\mathrm{S}}=14.3
\end{array}
$$

$\left(\begin{array}{c}q \\ k P a\end{array}\right)$

GP

60.3

43.1

51.7

34.6

26.3

26.3

17.7

18.0

18.0

14.3

14.3

3.85

3.20

3.12

2.90

2.44

2. 37

2. 30

2.26

1.91

1.00

.91

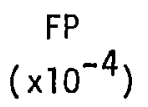

1.59

1.58

1.86

1.57

2.73

1.82

3.65

3.59

4.58

4.51

8.03 
TABLE D-6 (Continued)

PANEL FLUTTER DATA FROM REFERENCE 12

${ }^{P}$ CR

0.16

.39

.39

.42

.51

.52

.54

.58

.66

.69

.77

.90

$P_{C R}$

0.23

.24

.26

.27

.29

.63

.65

.70

.72

.90

.92

$$
\begin{aligned}
& a=0.343 \mathrm{~m}^{\text {Panel }} 7 \mathrm{~b}=0.343 \mathrm{~m} \\
& D=13.839 \mathrm{~N}-\mathrm{m} \quad M=1.96 \\
& \overline{\mathrm{K}}_{\mathrm{S}}=545
\end{aligned}
$$

$\left(\begin{array}{c}\mathrm{q} \\ \mathrm{PPa}\end{array}\right)$

57.9

63.8

57.9

52.0

34.1

17.5

42.6

26.0

17.5

12.6

11.7

13.8

GP

0.916

.780

.780

.761

.699

.692

.678

.647

.583

.556

.479

.316

FP

$\left(\times 10^{-3}\right)$

4.97

1.29

1.43

1.40

1.50

2.83

1.08

1.56

1.82

2.31

2.02

1.27

$$
\begin{aligned}
& \text { Panel } 8 \\
& a=0.622 \mathrm{~m} \quad \mathrm{~b}=0.318 \mathrm{~m} \\
& D=29.007 \mathrm{~N}-\mathrm{m} \quad \mathrm{M}=1.96 \\
& \mathrm{~K}_{\mathrm{S}}=21.6
\end{aligned}
$$

$\stackrel{9}{q}$

GP

$$
75.8
$$

42.8

42.8

58.0

57.7

22.6

22.6

17.5

22.0

8.6

8.6

1.68

1.67

1.64

1.63

1.61

1.16

1.73

1.05

1.01

.60

FP

$\left(\times 10^{-3}\right)$

0.87

1.40

1.32

.94

.90

1.21

1.17

1.42

1.10

2.30

2.26 
TABLE D-6 (Continued)

PANEL FLUTTER DATA FROM REFERENCE 12

$$
\begin{gathered}
\text { Panel } 9 \\
a=0.622 \mathrm{~m} \quad b=0.216 \mathrm{~m} \\
D=13.839 \mathrm{~N}-\mathrm{m}=1.96 \\
\bar{K}_{S}=10.2
\end{gathered}
$$

$P_{C R}$

0.09

.12

.15

.39

.40

.44

.46

.53

.58

.60

.63

.67

.69

.71

.73

.74

.76

.78

.81

$P_{C R}$

0.05

.14

.37

.53

.55

.58

.61

.61

.67

.67

.68

.78

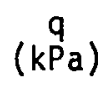

76.5

76.2

76.2

60.7

60.1

40.4

40.4

40.7

20.2

29.9

19.9

19.9

29.9

8.5

20.2

19.9

12.6

12.6

7.9

$a=0.622 \mathrm{~m} \quad b=0.165 \mathrm{~m}$

$D=7.085 \mathrm{~N}-\mathrm{m} \quad M=1.96$

$\overline{\mathrm{K}}_{\mathrm{S}}=8.45$

$\left(\begin{array}{c}\mathrm{q} \\ \mathrm{kPa}\end{array}\right.$

51.2

43.1

35.0

25.5

25.2

17.7

25.2

17.7

9.0

12.2

25.4

11.6
GP

2.62

2.58

2.53

2.15

2.13

2.06

2.02

1.88

1.78

1.74

1.67

1.58

1.53

1.48

1.43

1.40

1.35

1.29

1.20
3.47

3.31

2.83

2.44

2. 39

2.31

2.23

2.05

2.05

2.02
$\mathrm{FP}$
$\left(\times 10^{-3}\right)$

0.67

.61

.56

.46

.46

.65

.64

.59

1.73

.75

1.09

1.06

.69

2.40

.99

1.00

1.56

1.54

2.40

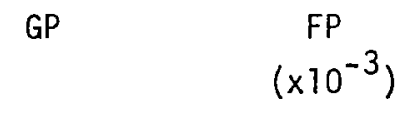

0.62

.58

.54

.65

.65

.91

.63

.89

1.70

1.25

.60

1.25 
TABLE D-6 (Continued)

PANEL FLUTTER DATA FROM REFERENCE 12

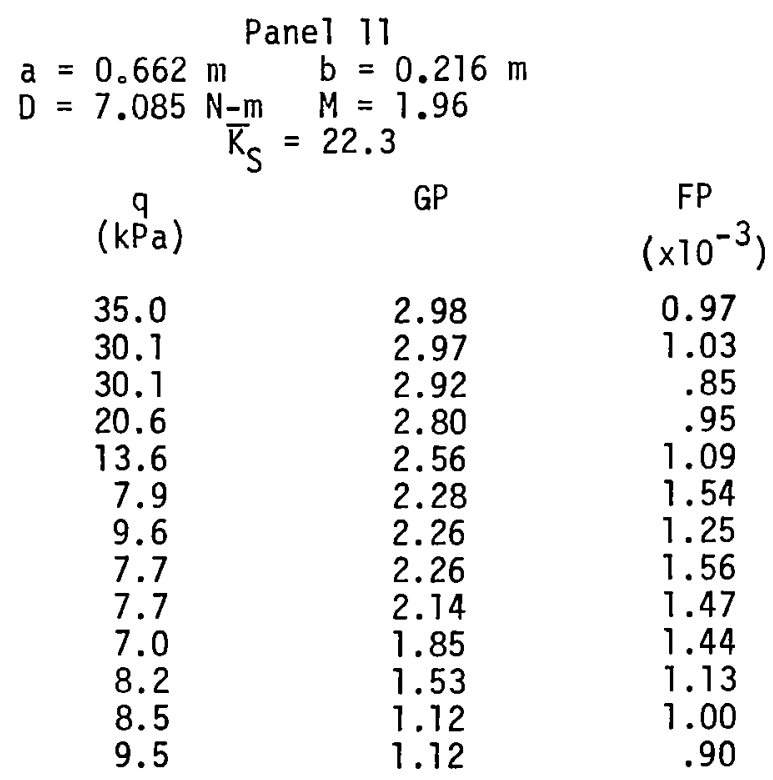

$$
\begin{array}{cl}
a=0.622 & \text { Panel } 12 \\
\mathrm{~m} & b=0.165 \mathrm{~m} \\
D=7.085 & \mathrm{~N}-\mathrm{m} \quad M=1.96 \\
\bar{K}_{S}=9.96
\end{array}
$$

$P_{\text {CR }}$

$\left(\begin{array}{c}q \\ k P a\end{array}\right)$

GP

FP

0.06

82.3

3.48

3.45

65.3

3.35

69.3

68.7

3.31

52.6

65.1

3.27

2.57

2.57

54.2

54.2

2.52

2.46

61.9

2.46

52.7

53.8

2.38

2.36

34.4

2. 33

$\left(\times 10^{-4}\right)$

3.71

3.49

3.92

3.55

3.47

3.25

2.63

3.11

3.07

2.69

3.10

3.01

.58 
TABLE D-6 (Concluded)

PANEL FLUTTER DATA FROM REFERENCE 12

Panel 12 (Concluded)

$P_{C R}$

.58

.60

.72

.76

.78

.80

.84

.85

${ }_{\text {CR }}$

0.11

.17

.21

.30

.37

.54 $\left(k^{q} a\right)$

53.8

34.3

26.5

26.2

16.5

17.0

18.4

18.7
GP

2.33

2.27

1.90

1.76

1.68

1.61

1.44

1.39
FP
$\left(\times 10^{-4}\right)$

\subsection{9}

4.64

5.62

5.57

8.76

8.42

7.64

7.48

$$
\begin{aligned}
& a=0.622 \mathrm{~m}^{\text {Panel }} \mathrm{b}=0.216 \mathrm{~m} \\
& D=7.085 \mathrm{~N}-\mathrm{m} \quad M=1.96 \\
& \overline{\mathrm{K}}_{\mathrm{S}}=14.1
\end{aligned}
$$

$\left(\begin{array}{c}q \\ k P a\end{array}\right)$

47.6

34.4

38.4

26.3

17.8

8.8
GP

2.63

2.54

2.47

2.33

2.21

1.89

$F P$
$\left(\times 10^{-3}\right)$
0.59
.60
.50
.62
.82
1.37


TABLE D-7

PANEL FLUTTER DATA FROM REFERENCE 7

Orthotropic panels with spring supported stream edges and inplane loads

Data shown in figure 18

$$
\begin{array}{rlrl}
\text { Panel } I & \\
a & =0.605 \mathrm{~m} & b & =0.605 \mathrm{n} \\
D_{1} & =1 \mathrm{~N}-\mathrm{m} & D_{2} & =1640 \mathrm{~N}-\mathrm{m} \\
D_{12} & =376 \mathrm{~N}-\mathrm{m} \\
\mathrm{M}=3 & \mathrm{~K}_{S} & =63
\end{array}
$$

$\begin{array}{ccccc}\text { Test } & P_{\mathrm{CR}} & \begin{array}{c}\mathrm{q} \\ (\mathrm{kPa})\end{array} & \text { GP } & \begin{array}{c}F P \\ \left(\times 10^{-4}\right)\end{array} \\ 1 & 0.74 & 110 & 6.42 & 1.15 \\ 1 & .92 & 101 & 3.56 & 1.24 \\ 2 & .40 & 134 & 9.76 & .95 \\ 2 & .71 & 115 & 6.79 & 1.10 \\ 4 & .72 & 118 & 6.67 & 1.07 \\ 5 & .43 & 137 & 9.51 & .93 \\ 6 & .61 & 106 & 7.87 & 1.19 \\ 8 & .80 & 107 & 5.63 & 1.18\end{array}$

Note: $P_{C R}$ 's determined from information shown in figure 8 , reference 7 .

$$
\begin{array}{rlrl}
\text { Panel } & \text { I I } \\
\mathrm{a} & =0.605 \mathrm{~m} & \mathrm{~b} & =0.605 \mathrm{~m} \\
D_{1} & =0.94 \mathrm{~N}-\mathrm{m} & \mathrm{D}_{2}^{2} & =4150 \\
D_{12} & =798 \mathrm{~N}-\mathrm{m} & \mathrm{K}_{\mathrm{S}} & =6.9
\end{array}
$$

$\begin{array}{ccccc}\text { Test } & P_{\mathrm{CR}} & \begin{array}{c}\mathrm{q} \\ (\mathrm{kPa})\end{array} & \text { GP } & \begin{array}{c}\mathrm{FP} \\ \left(\times 10^{-4}\right)\end{array} \\ 15 & 0.38 & 98 & 4.62 & 1.22 \\ 16 & .09 & 137 & 5.60 & .92 \\ 17 & .45 & 117 & 4.35 & 1.02 \\ 17 & .69 & 102 & 3.27 & 1.17 \\ 18 & .86 & 83 & 2.20 & 1.44\end{array}$

Note: ${ }^{P} C^{\prime}$ 's determined from information shown in figure 9, reference 7 . 
TABLE D-8

PANEL FLUTTER DATA FROM REFERENCE 19

Isotropic panel with inplane loads

Data shown in figures 18 and 20

$$
\begin{aligned}
& E=72.4 \mathrm{GN} / \mathrm{m}^{2} \\
& \mathrm{a}=0.66 \mathrm{~m} \\
& \mathrm{M}=3
\end{aligned}
$$

Partially Clamped Panel $a / b=3.3$

$\begin{array}{ccccc}\begin{array}{c}h \\ (\mathrm{~mm})\end{array} & P_{\mathrm{CR}} & \begin{array}{c}\mathrm{q} \\ (\mathrm{kPa})\end{array} & \mathrm{GP} & \begin{array}{c}\mathrm{FP} \\ \left(\times 10^{-3}\right)\end{array} \\ 1.4 & 0.44 & 117 & 2.47 & 0.43 \\ 1.4 & .62 & 69 & 2.03 & .63 \\ 2.03 & .63 & 158 & 2.01 & .84 \\ 2.03 & .78 & 138 & 1.55 & .88 \\ 2.03 & .77 & 117 & 1.58 & 1.04 \\ 2.03 & .85 & 83 & 1.28 & 1.40 \\ 2.03 & .94 & 69 & .81 & 1.61\end{array}$

Partially Clamped Panel

$$
a / b=3.3
$$

$\begin{array}{ccccc}h & \mathrm{q} & \mathrm{GP} & \mathrm{FP} \\ (\mathrm{mm}) & P_{\mathrm{CR}} & (\mathrm{kPa}) & & \left(\times 10^{-3}\right)\end{array}$

$\begin{array}{lrrrr}1.32 & 0.39 & 179 & 2.58 & 0.25 \\ 1.37 & .56 & 117 & 2.19 & .37 \\ 1.37 & .29 & 234 & 2.78 & .24 \\ 1.37 & .39 & 165 & 2.58 & .30 \\ 1.40 & .29 & 234 & 2.78 & .26 \\ 1.60 & .59 & 186 & 2.11 & .36 \\ 2.59 & .85 & 220 & 1.28 & 1.09 \\ 2.59 & .88 & 165 & 1.14 & 1.44 \\ 2.59 & .93 & 117 & .87 & 1.99 \\ 2.59 & .95 & 96 & .74 & 2.38 \\ 2.59 & .96 & 69 & .66 & 3.30\end{array}$

Note: $P_{C R}$ 's based on information shown in figures 10 and 11 , reference 19 . 
TABLE D-8 (Concluded)

PANEL FLUTTER DATA FROM REFERENCE 19

Fully. Clamped Panel

$$
a / b=3.3
$$

$\mathrm{h}$
$(\mathrm{mm})$

1.35

1.35

1.35

1.37

1.60

1.60

1.65

1.65

1.93

1.93

2.59

$h$
(mm)

1.37

1.37

1.37

1.37

1.62

1.62

1.62

1.62

1.62
$\mathrm{P}_{\mathrm{CR}}$

0.26

.46

.56

.61

.76

.69

.70

.47

.74

.81

.79 $\left(\begin{array}{c}\mathrm{q} \\ (\mathrm{kPa})\end{array}\right.$

186

110

69

83

69

96

110

165

110

96

172
GP

2.84

2.42

2.19

2.06

1.62

1.84

1.81

2.40

1.68

1.44

1.51 $\underset{\left(\times 10^{-3}\right)}{\mathrm{FP}}$

0.30

.40

.59

.50

.87

.65

.62

.49

.96

1.06

1.45

Fully Clamped Panel

$$
a / b=3.7
$$

$P_{C R}$

0.36

.55

.65

.71

.57
.78

.74

.87

.88 $\left(\begin{array}{c}\mathrm{q} \\ (\mathrm{PPa})\end{array}\right.$

$$
269
$$

200

138

117

269

96

83

69

76
GP

2.96

2.48

2.19

1.99

2.43

1.74

1.89

1.34

1.28 $\left(\times 10^{-3}\right)$

0.21

.25

.34

.39

.30

.75

.89

1.01 
TABLE D-9

PANEL FLUTTER DATA FROM REFERENCE 23

Supported isotropic panel with inplane loads

Data shown in figure 18

$$
\begin{gathered}
M=3 \\
E=72.4 \mathrm{GN} / \mathrm{m}^{2}
\end{gathered}
$$

\begin{tabular}{|c|c|c|c|c|c|c|c|c|}
\hline Panel & Test & $\begin{array}{c}h \\
\langle m m\end{array}$ & $\underset{(m)}{a}$ & $\begin{array}{c}b \\
(m)\end{array}$ & $P_{C R}$ & $\left(\begin{array}{c}q \\
k P a\end{array}\right)$ & $\mathrm{GP}$ & $\begin{array}{c}F P \\
\left(\times 70^{-5}\right)\end{array}$ \\
\hline $\begin{array}{l}2-A \\
2-A \\
2-A \\
4-A \\
4-A\end{array}$ & $\begin{array}{l}1 \\
5 \\
6 \\
8 \\
9\end{array}$ & $\begin{array}{r}0.64 \\
.81 \\
.81 \\
.64 \\
.64\end{array}$ & $\begin{array}{c}0.686 \\
.686 \\
.686 \\
.66 \\
.66\end{array}$ & $\begin{array}{c}0.0686 \\
.0686 \\
.0686 \\
.066 \\
.066\end{array}$ & $\begin{array}{l}0.58 \\
.86 \\
.86 \\
.46 \\
.71\end{array}$ & $\begin{array}{l}177 \\
212 \\
216 \\
240 \\
144\end{array}$ & $\begin{array}{l}6.48 \\
3.74 \\
3.74 \\
7.35 \\
5.39\end{array}$ & $\begin{array}{l}5.78 \\
9.59 \\
9.47 \\
4.84 \\
7.89\end{array}$ \\
\hline \multicolumn{9}{|c|}{$\begin{aligned} & M=3 \\
= & 200 \mathrm{GN} / \mathrm{m}^{2}\end{aligned}$} \\
\hline Panel & Test & $\underset{(\mathrm{mm})}{\mathrm{h}}$ & $\stackrel{a}{(m)}$ & $\stackrel{b}{b}$ & $P_{C R}$ & $(\stackrel{9}{\mathrm{kPa}})$ & GP & $\left(\begin{array}{c}F P \\
\left(x 10^{-5}\right)\end{array}\right.$ \\
\hline $\begin{array}{l}4-S_{2} \\
4-S_{2}^{2} \\
4-S_{2}^{2} \\
4-S_{2}^{2}\end{array}$ & $\begin{array}{l}3 \\
4 \\
5 \\
6\end{array}$ & $\begin{array}{r}0.51 \\
.51 \\
.51 \\
.57\end{array}$ & $\begin{array}{l}0.711 \\
.711 \\
.717 \\
.711\end{array}$ & $\begin{array}{r}0.0711 \\
.0711 \\
.0711 \\
.0711\end{array}$ & $\begin{array}{l}0.68 \\
.69 \\
.66 \\
.15\end{array}$ & $\begin{array}{l}237 \\
237 \\
199 \\
231\end{array}$ & $\begin{array}{l}5.66 \\
5.57 \\
5.83 \\
9.23\end{array}$ & $\begin{array}{l}5.37 \\
5.37 \\
6.47 \\
5.93\end{array}$ \\
\hline
\end{tabular}

Note: $P_{C R}$ 's based on information presented in table I, reference 23 . 
TABLE D-10

PANEL FLUTTER DATA FROM REFERENCE 24

Clamped isotropic panel with inplane loads

Data shown in figure 18

$$
\begin{aligned}
& a=0.635 \mathrm{~m} \\
& b=0.759 \mathrm{~m} \\
& E=72.4 \mathrm{GN} / \mathrm{m}^{2} \\
& M=3.0
\end{aligned}
$$

$\begin{array}{cccccc}\text { Test } & \begin{array}{c}\mathrm{h} \\ (\mathrm{mm})\end{array} & P_{C R} & \begin{array}{c}\mathrm{q} \\ (\mathrm{kPa})\end{array} & \mathrm{GP} & \begin{array}{c}\mathrm{FP} \\ \left(\times 10^{-3}\right)\end{array} \\ 2 & 1.6 & 0.20 & 240.8 & 3.58 & 0.54 \\ 3 & 1.6 & .95 & 166.1 & .89 & .48 \\ 4 & 1.6 & .95 & 119.2 & .89 & .67 \\ 5 & 2.06 & .51 & 274.0 & 2.80 & .99 \\ 6 & 2.06 & .88 & 78.5 & 1.39 & 2.24 \\ 7 & 3.18 & 1.00 & 236.5 & 0.0 & 2.61\end{array}$
Note: Determination of $P_{C R}$ 's based on information given in figure 14 ,
reference 24 . 
TABLE D-11

PANEL FLUTTER DATA FROM REFERENCE 25

Supported isotropic panel with inplane loads

Data shown in figure 18

$$
\begin{aligned}
& a=0.661 \mathrm{~m} \\
E= & 72.4 \mathrm{GN} / \mathrm{m}^{2} \\
M= & 3 \\
& a / b=2.5
\end{aligned}
$$

$\begin{array}{rcrrrr}\text { Test } & \begin{array}{c}\mathrm{h} \\ (\mathrm{mm})\end{array} & \mathrm{P}_{\mathrm{CR}} & \begin{array}{c}\mathrm{q} \\ (\mathrm{kPa})\end{array} & \mathrm{GP} & \begin{array}{c}\mathrm{FP} \\ \left(\mathrm{x} 10^{-3}\right)\end{array} \\ 1 & 1.6 & 0.96 & 129.5 & 0.50 & 0.26 \\ 2 & 1.6 & .56 & 187.2 & 1.66 & .26 \\ 3 & 1.8 & .29 & 141.0 & 2.11 & .73 \\ 4 & 1.8 & .39 & 93.8 & 1.95 & .92 \\ 5 & 1.8 & .52 & 70.9 & 1.73 & 1.03 \\ 6 & 2.62 & .56 & 151.3 & 1.66 & 1.41 \\ 8 & 2.62 & .65 & 140.3 & 1.48 & 1.38 \\ 10 & 2.62 & .77 & 232.0 & 1.20 & .75 \\ 11 & 2.62 & .65 & 174.3 & 1.48 & 1.71\end{array}$

Note: $P_{C R}$ 's based on information presented on figure 7, reference 25 .

$a / b=2.9$

$\begin{array}{rccccc}\text { Test } & \begin{array}{c}\mathrm{h} \\ (\mathrm{mm})\end{array} & \mathrm{P}_{\mathrm{CR}} & \begin{array}{c}\mathrm{q} \\ (\mathrm{kPa})\end{array} & \mathrm{GP} & \begin{array}{c}\mathrm{FP}-4 \\ \left(\mathrm{x} 10^{-4}\right)\end{array} \\ 1 & 2.06 & 0.52 & 235.6 & 2.01 & 5.49 \\ 2 & 2.06 & .77 & 187 . & 1.39 & 5.61 \\ 3 & 2.06 & .88 & 128.1 & 1.00 & 7.61 \\ 6 & 2.06 & .98 & 111.8 & .41 & 8.20 \\ 7 & 1.35 & .50 & 117.5 & 2.05 & 3.15 \\ 8 & 1.35 & .77 & 80.4 & 1.39 & 3.66 \\ 9 & 1.35 & .09 & 152.7 & 2.77 & 5.02 \\ 10 & 1.6 & .62 & 146.3 & 1.79 & 3.78 \\ 11 & 1.6 & .31 & 146.3 & 2.41 & 5.36 \\ 12 & 1.6 & .69 & 81.9 & 1.61 & 6.37 \\ 13 & 1.6 & .34 & 176 . & 2.36 & 4.25\end{array}$

Note: $P_{C R}$ 's based on information presented on figure 8 , reference 25 . 
TABLE D-12

PANEL FLUTTER DATA FROM REFERENCE 26

Orthotropic panels with spring supported stream edges and inplane loads

Data shown in figure 18

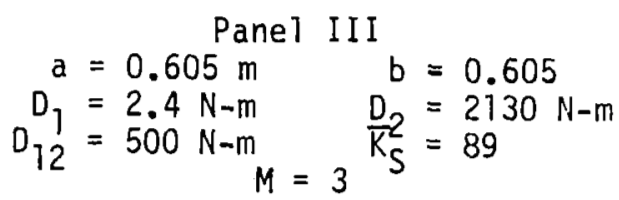

Test

$P_{C R}$

$\left(\begin{array}{c}\mathrm{q} \\ \mathrm{kPa}\end{array}\right)$

GP

$\stackrel{F P}{\left(\times 10^{-4}\right)}$

$\begin{array}{ll}2 & 0.54 \\ 3 & .42 \\ 4 & .44 \\ 5 & .36 \\ 6 & .42 \\ 7 & .30 \\ 7 & .78 \\ 7 & .78 \\ 7 & .75\end{array}$

204

221

225

220

213

232

179

201

212

7.86

8.83

8.68

9.28

8.83

9.70

5.44

5.44

5.79

1.48

1.38

1.35

1.39

1.43

1.32

1.67

1.49

1.41

Note: $P_{C R}{ }^{\prime} s$ determined from information shown in figure $8(a)$, reference 26 .

\begin{tabular}{|c|c|c|c|c|}
\hline \multirow[b]{2}{*}{ Test } & \multicolumn{3}{|c|}{$\begin{array}{rlrl}a & =0.483 \mathrm{~m} & \mathrm{~b} & =0.483 \\
\mathrm{D}_{1} & =0.87 \mathrm{~N}-\mathrm{m} & \mathrm{D}_{2}^{2} & =3380 \\
\mathrm{D}_{12} & =556 \mathrm{~N}-\mathrm{m} \\
\mathrm{K}_{\mathrm{M}=3} & & & \end{array}$} & \multirow[b]{2}{*}{$\begin{array}{l}\text { FP } \\
\left(\times 10^{-4}\right)\end{array}$} \\
\hline & ${ }^{P_{C R}}$ & $\left(\begin{array}{c}q \\
(\mathrm{kPa})\end{array}\right.$ & GP & \\
\hline $\begin{array}{l}1 \\
1 \\
2 \\
3 \\
4 \\
5 \\
5\end{array}$ & $\begin{array}{r}0.77 \\
.85 \\
.49 \\
.68 \\
.50 \\
.39 \\
.96\end{array}$ & $\begin{array}{r}154 \\
147 \\
190 \\
153 \\
213 \\
191 \\
95\end{array}$ & $\begin{array}{r}1.70 \\
1.37 \\
2.53 \\
2.00 \\
2.50 \\
2.76 \\
.71\end{array}$ & $\begin{array}{l}1.41 \\
1.54 \\
1.15 \\
1.42 \\
1.02 \\
1.14 \\
2.28\end{array}$ \\
\hline
\end{tabular}

Note: ${ }_{C R}{ }^{\prime} s$ determined from information shown in figure $8(b)$, reference 26. 
TABLE D-13

PANEL FLUTTER DATA FROM REFERENCE 10

Orthotropic panel with stream edge support flexibility and pressure differential effects

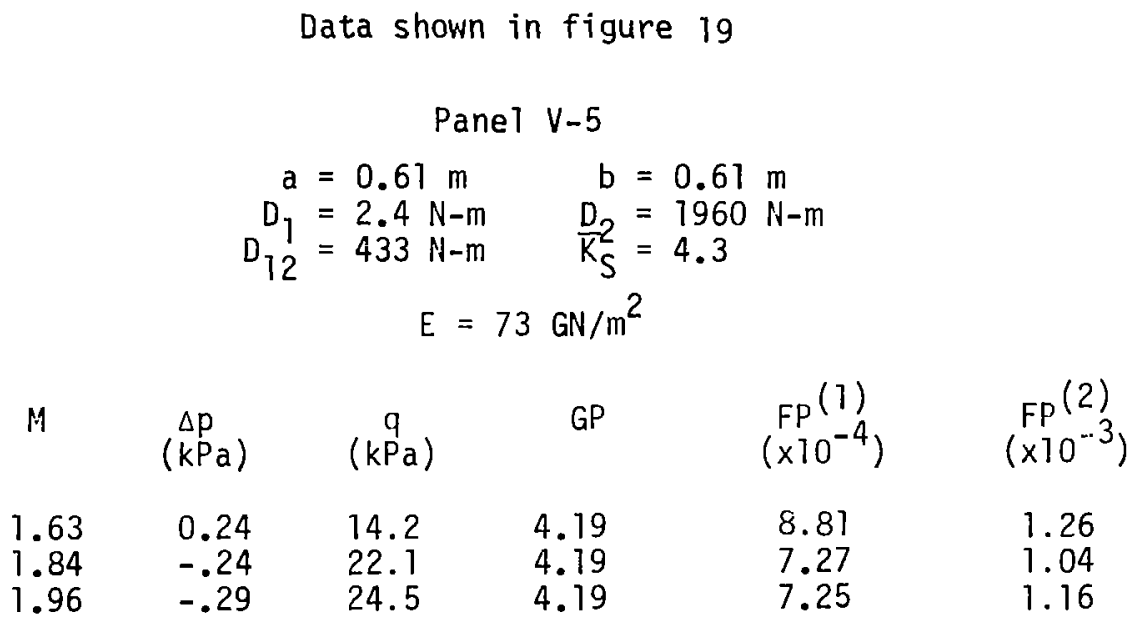

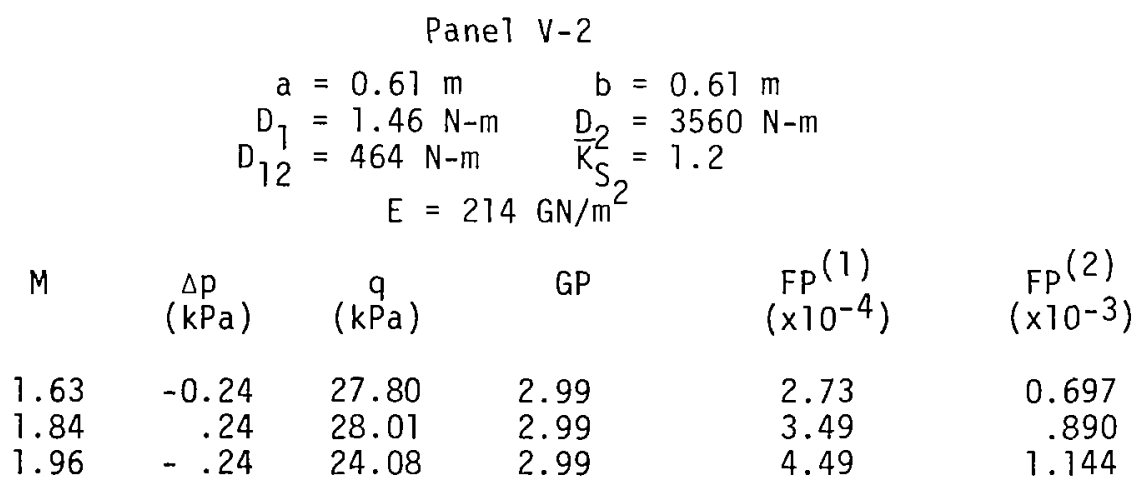

Notes: 1. FP not corrected for $\triangle p$ effects.

2. FP corrected for $\Delta p$ effects. 
TABLE $\quad 0-14$

\section{PANEL FLUTTER DATA FROM REFERENCE 27}

Isotropic panel at low supersonic flow

Data shown in figure 22

$$
\begin{aligned}
& a=0.229 \mathrm{~m} \\
& b=0.457 \mathrm{~m} \\
& h=1.019 \mathrm{~mm} \\
& E=38.6 \mathrm{GN} / \mathrm{m}^{2}
\end{aligned}
$$

M

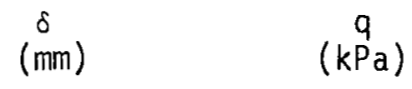

1.05
1.1
1.1
1.2
1.2
1.2
1.2
1.2
1.2
1.3
1.3
1.4
1.4

24.13

26.16

7.62

$25.91^{\circ}$

19.56

13.21

11.68

8.64

7.11

24.38

7.11

22.61

6.86

50.3

49.6

29.2

48.7

42.3

36.7

34.2

32.9

29.0

52.6

42.2

61.8

56.9

Note: The quantity $\delta$ is the boundary layer thickness at the test conditions. 
TABLE D-15

PANEL FLUTTER DATA FROM REFERENCE 28

Isotropic panel at low supersonic flow

Data shown in figure 22

$$
\begin{aligned}
& a=0.229 \mathrm{~m} \\
& b=0.457 \mathrm{~m} \\
& h=0.488 \mathrm{~mm} \\
& E=144.8 \mathrm{GN} / \mathrm{m}^{2}
\end{aligned}
$$

$\begin{array}{lcc}M & \begin{array}{c}\delta \\ (\mathrm{mm})\end{array} & \begin{array}{c}\mathrm{q} \\ (\mathrm{kPa})\end{array} \\ 1.2 & 28.96 & 19.3 \\ 1.2 & 20.83 & 15.6 \\ 1.2 & 16.76 & 12.3 \\ 1.2 & 11.68 & 10.6 \\ 1.3 & 29.21 & 22.2 \\ 1.3 & 9.65 & 13.4 \\ 1.3 & 8.13 & 12.7 \\ 1.4 & 11.94 & 18.7 \\ 1.4 & 8.64 & 17.7\end{array}$

Hote: The quantity $\delta$ is the Loundary layer thickness at the test conditions. 
$\cdot$ 


\section{REFERENCES}

\section{Cited References}

1. Kordes, Eldon E.; Tuovila, Weimer J.; and Guy, Lawrence D.: Flutter Research on Skin Panels. NASA TN D-451, 1960.

2. Mirowitz, L. I.; Zimmerman, N. H.; and Schweiker, J. W.: Panel Flutter Survey and Design Criteria. Aerospace Industries Association Report ARTC-32, 1962.

3. Kordes, Eldon E.; and Nol1, Richard B.: Theoretical Flutter Analysis of Flat Rectangular Panels in Uniform Coplanar Flow with Arbitrary Direction. NASA TN D-1156, 1962.

4. Anon.: Panel Flutter. NASA Space Vehicle Design Criteria (Structures). NASA SP-8004, 1964, Revised 1972.

5. Lemley, C.E.: Design Criteria for the Prevention of Panel Flutter, Vols. I \& II, Air Force Flight Dynamics Lab. Rept. TR67-140, Aug. 1968.

6. Bohon, Herman L.: Flutter of Flat Rectangular Orthotropic Panels with Biaxial Loading and Arbitrary Flow Direction. NASA TN D-1949, 1963.

7. Bohon, Herman L.: Experimental Flutter Results for CorrugationStiffened Panels at Mach Number of 3. NASA TN D-2293, 1964.

8. Bohon, Herman L.; and Shore, Charles P.: Application of Recent Panel Flutter Research to the Space Shuttle, Part II - Influence of Edge Clips and Flow Angularity. NASA TM X-2274, 1971.

9. Bohon, Herman L.; and Anderson, Melvin S.: Role of Boundary Conditions on Flutter of Orthotropic Panels. AIAA J., vol. 4, no. 7, July 1966, pp $1241-1248$.

10. Weidman, Deene J.: Experimental Flutter Results for CorrugationStiffened and Unstiffened Panels. NASA TN D-3301, 1966.

11. Shyprykevich, Peter.: Experimental Investigation of Orthotropic Pane1 Flutter at Arbitrary Yaw Angles, and Comparison with Theory. NASA CR-2265, 1973.

12. Hess, Robert W.: Experimental and Analytical Investigation of the Flutter of Flat Built-Up Panels Under Streamwise Inplane Load. NASA TR R-330, 1970. 
13. Roark, Raymond J.: Formulas for Stress and Strain. Third ed., McGrawHill Book Co., Inc., 1954.

14. Timoshenko, Stephen P.; and Gere, James M.: Theory of Elastic Stability. Second ed., McGraw-Hil1 Book Co., Inc., 1961.

15. Shore, Charles P.: Flutter Design Charts for Biaxially Loaded Isotropic Panels. J. Aircraft, vol. 7, no. 4, July-Aug. 1970, pp 325-329.

16. Sawyer, James Wayne: Supersonic Flutter of Panels Loaded with Inplane Shear. NASA TN D-7888, 1975.

17. Dowe11, E.H.: Panel Flutter: A Review of the Aeroelastic Stability of Plates and Shells. AIAA J., vol. 8, no. 3, March 1970, pp. 385-399.

18. Kappus, H. P.; Lemley, C. E.; and Zimmerman, N. H.: An Experimental Investigation of High Amplitude Panel Flutter. NASA CR-1837, 1971.

19. Shore, Charles P.: Experimental Investigation of Flutter at Mach 3 of Rotationally Restrained Panels and Comparison with Theory.

NASA TN D-5508, 1969.

20. Hedgepeth, John M.: Flutter of Rectangular Simply Supported Panels at High Supersonic Speeds. J. Aeron. Sci., vol. 24, Aug. 1957, pp. 563-573, 586 .

21. Dowel1, E. H.; and Voss, H. M.: Theoretical and Experimental Panel Flutter Studies in the Mach Number Range 1.0 to 5.0. AIAA J., vol. 3, no. 12, Dec. 1965, pp. 2292-2304.

22. Shyprykevich, P.; and Sawyer, J. W.: Orthotropic Panel Flutter at Arbitrary Yaw Angles - Experiment and Correlation with Theory. AIAA Paper 73-192, Presented at AIAA 11 th Aerospace Sciences Meeting (Washington, D.C.), Jan. 10-12, 1973.

23. Guy, Lawrence D.; and Bohon, Herman L.: Flutter of Aerodynamicaliy Heated Aluminum-Alloy and Stainless-Steel Panels With Length-Width Ratio of 10 at Mach Number of 3.0. NASA TN D-1353, 1962.

24. Dixon, Sidney C.: Application of Transtability Concept to Flutter of Finite Panels and Experimental Results. NASA TN D-1948, 1963.

25. Shideler, John L.; Dixon, Sidney C.; and Shore, Charles P.: Flutter at Mach 3 of Thermaily Stressed Panels and Comparison With Theory for Panels With Edge Rotational Restraint. NASA TN D-3498, 1966.

26. Bohon, Herman L.: Flutter of Corrugation-Stiffened Panels at Mach 3 and Comparison with Theory. NASA TN D-4321, 1968. 
27. Muhlstein, Lado, Jr.; Gaspers, Peter A., Jr.; and Riddle, Dennis W.: An Experimental Study of the Influence of the Turbulent Boundary Layer on Panel Flutter. NASA TN D-4486, 1968.

28. Gaspers, Peter A., Jr.; Mulhstein, Lado, Jr.; and Petroff, Daniel N.: Further Experimental Results on the Influence of the Turbulent Boundary Layer on Panel Flutter. NASA TN D-5798, 1970.

29. Stein, Manuel: Flutter of Panels on Discrete Flexible Supports. NASA TN D-7443, 1974.

30. Stroud, W. Jefferson: Elastic Constants for Bending and Twisting of Corrugation-Stiffened Panels. NASA TR R-166, 1963.

31. Timoshenko, S.; and Woinowsky-Krieger, S.: Theory of Plates and Shells. Second ed., McGraw-Hil1 Book Co., Inc., 1962.

32. Hoppmann, W. H.: Bending of Orthogonally Stiffened Plates, J. Appl. Mech., vol. 22, no. 2, June 1955, pp. 267-271.

33. Beckett, R. E.; Bohrmann, R. J.; and Ives, K. D.: An Experimental Method for Determining the Elastic Constants of Orthogonally Stiffened Plates. Proc. 1st Int. Congress Exp. Mech., Pergamon Press., 1963, pp. $129-148$.

34. Dugundji, John: Theoretical Considerations of Panel Flutter at High Supersonic Mach Numbers. AIAA. J., vol. 4, no. 7, July 1966, pp. 1257-1266.

35. Dowel1, E. H.: Dynamic Analysis of an Elastic Plate on a Thin, Elastic Foundation. J. Sound Vib., vol. 35, no. 3, 1974, pp. 343-360.

36. McElman, John A.: Flutter of Two Parallel Flat Plates Connected by an Elastic Medium. AIAA J., vol. 2, no. 2, Feb. 1964, pp 377-379.

37. Johns, D. J.; and Taylor, P. W.: Vibration and Flutter of Parallel Flat Plates Connected by an Elastic Medium. Paper presented at AIAA/ASME 17 th Structures, Structural Dynamics, and Materials Conference (Denver, Co), Apri1 1970.

38. Dowel 1, Earl H.: Vibration and Flutter Analysis of Reusable Surface Insulation Panels. J. Spacecraft Rockets, vol. 12, no. 1, Jan. 75, pp. 44-50.

\section{Additional References}

39. Sylvester, Maurice A.; and Baker, John E.: Some Experimental Studies of Panel Flutter at Mach Number 1.3. NACA TN 3914, 1957. 
40. Johns, D. J.; and Parks, P. C.: Effect of Structural Damping on Panel Flutter. Aircraft Eng., vo1. 32, no. 380, 0ct. 1960, pp. 304-308.

41. Sylvester, Maurice A.: Experimental Studies of Flutter of Buckled Rectangular Panels at Mach Numbers From T.2 to 3.0 Including Effects of Pressure Differential and of Panel Width-Length Ratio. NASA TN D-833, 1961 .

42. Dixon, Sidney C.; Griffith, George E.; and Bohon, Herman L.: Experimental Investigation of Mach Number 3.0 of the Effects of Therma 7 Stress and Buckling on the Flutter of Four-Bay Aluminum Alloy Panels with LengthWidth Ratios of 10. NASA TN D-921, 1961.

43. Kordes, Eldon E.; and Nol1, Richard B.: Flight Flutter Results for Flat Rectangular Panels. NASA TN D-1058, 1962.

44. Hess, Robert W.; and Gibson, Frederick W.: Experimental Investigations of the Effects of Compressive Stress on the Flutter of a Curved Panel and a Flat Panel at Supersonic Mach Numbers. NASA TN D-1386, 1962.

45. Dixon, Sidney C.: Experimental Investigation at Mach Number 3.0 of Effects of Thermal Stress and Buckling on Flutter Characteristics of Flat Single-Bay Panels of Length-Width Ratio 0.96. NASA TN D-1485, 1962.

46. Bohon, Herman L.: Panel Flutter Tests on Full-Scale X-15 Lower Vertical Stabilizer at Mach Number of 3.0. NASA TN D-1385, 1962.

47. Bisplinghoff, Raymond L.; and Ashley, Holt: Principles of Aeroelasticity. John Wiley and Sons, Inc., 1962.

48. Fung, Y. C.: On Corrugation-Stiffened Panels. Grad. Aero. Lab., Calif. Inst. Tech., June 1962.

49. Fralich, Robert W.: Postbuckling Effects on the Flutter of Simply Supported Rectangular Panels at Supersonic Speeds. NASA TN D-1615, 1963.

50. Dixon, Sidney C.; and Shore, Charles P.: Effects of Differential Pressure, Thermal Stress, and Buckling on Flutter of Flat Panels with Length-Width Ratio of 2. NASA TN D-2047, 1963.

51. Dowe11, E. H.; and Voss, H. M.: The Effect of a Cavity on Panel Flutter. AIAA J., vol. T, no. 2, Feb. 1963, pp. 476-477.

52. Eisley, J. G.; and Luessen, G.: Flutter of Thin Plates under Combined Shear and Normal Edge Forces. AIAA J., vol. 1, no. 3, March 1963, pp. 620-626.

53. Dugundji, John; Dowe11, Earl; and Perkin, Brian: Subsonic Flutter of Panels on Continuous Elastic Foundations. AIAA J., vol. 1, no. 5, May 1.963, pp. 1146-1154. 
54. Pride, Richard A.; Royster, Dick M.; and Helms, Bobbie F.: Design, Tests, and Analysis of a Hot Structure for Lifting Reentry Vehicles. NASA TN D-2186, 1964.

55. Voss, H. M.; and Dowe11, E. H.: Effect of Aerodynamic Damping on Flutter of Thin Panels. AIAA J., vol. 2, no. 1, Jan. 1964, pp. 119-120.

56. Bohon, H. L.; and Dixon, S. C.: Some Recent Developments in Flutter of Flat Panels. J. Aircraft, vo1. 1, no. 5, Sept.-Oct. 1964, pp. 280-288.

57. Weeks, George E.; and Schideler, John L.: Effect of Edge Loading on the Vibration of Rectangular Plates with Various Boundary Conditions. NASA TN D-2815, 1965.

58. Schaeffer, Harry G.; and Heard, Walter L., Jr.: Supersonic Flutter of a Thermally Stressed Flat Panel with Uniform Edge Loads. NASA TN D-3077, 1965.

59. Zeydel, E. F. E.; and Kobett, D. R.: : Flutter of Flat Plates with Partially Clamped Edges in the Low Supersonic Region. AIAA J., vol 3, no. 1, Jan. 1965, pp 17-22.

60. Schaeffer, Harry G.; and Heard, Walter L., Jr.: Flutter of a Simply Supported Panel Subjected to a Nonlinear Temperature Distribution and Supersonic Flow. AIAA Paper No. 65-112, Presented at AIAA 2nd Aerospace Sciences Meeting (New York, N.Y.), Jan. 25-27, 1965.

61. Erickson, Larry L.: Supersoric Flutter of Flat Rectangular Orthotropic Panels Elastically Restrained Against Edge Rotation. NASA TN D-3500, 1966.

62. Gaspers, Peter A., Jr.; and Redd, Bass.: A Theoretical Analysis of the Flutter of Orthotropic Panels Exposed to a High Supersonic Stream of Arbitrary Direction. NASA TN D-3551, 1966.

63. Dixon, Sidney C.: Comparison of Panel Flutter Results from Approximate Aerodynamic Theory with Results from Exact Inviscid Theory and Experiment. NASA TN D-3649, 1966.

64. Dowe11, E. H.: Nonlinear nscillations of a Fluttering Plate. AIAA J., vol. 4, no. 7, July 1966, pp 1267-1275.

65. Cunningham, Herbert J.: Flutter Analys is of Flat Rectangular Panels Based on Three-Dimensional Supersonic Unsteady Potential Flow. NASA TR R-256, 1967.

66. Durvasula, Somayajulu: Flutter of Simply Supported, Parallelogrammic, Flat Plates in Supersonic Flow. AIAA J., vol. 5, no. 9, Sept.7967, pp 1668-1673.

67. Pritchard, Anthony J.: Stability Boundaries for a Two-Dimensional Panel. AIAA J., vol. 6, no. 8, Aug. 1968, pp 1590-1592. 
68. Dowe11, E. H.: Theoretical-Experimental Correlation of Plate Flutter Boundaries at Low Supersonic Speeds. AIAA J., vol. 6, no. 9, Sept. 1968, pp 1810-1811.

69. Ellen, C. H.: Influence of Structural Damping on Panel Flutter, AIAA J., vol. 6, no. 11, Nov. 1968, pp 2169-2174.

70. Leissa, A. W.: Vibration of Plates. NASA SP 160, 1969.

71. Shore, Charles P.: Effects of Structural Damping on Flutter of Stressed Panels. NASA TN D-4990, 1969.

72. Bohon, Herman L.; Anderson, Melvin S.; and Heard, Walter L., Jr.: Flutter Design of Stiffened-Skin Panels for Hypersonic Aircraft. NASA TN D-5555, 1969.

73. Johns, D. J.: Static Instability of Rectangular Orthotropic Panels Subjected to Uniform In-Plane Loads and Deflection-Dependent Lateral Loads. R\&M No. 3569, British A. R. C., 1969.

74. Zimmerman, N. H.; and Lemley, C. E.: Cavity Effect on Panel FlutterJust How Significant?. Presented at the 40th Shock and Vibration Symposium (Langley, Va.), Oct. 21-23, 1969.

75. Heard, Waiter L.; and Bohon, Herman L.: Natural Vibration and Flutter of Elastically Supported Corrugation-Stiffened Panels - Experiment and Theory. NASA TN D-5986, 1970.

76. Sikand, Harmohan Singh; and Libove, Charles: Supersonic Flutter of a Thermally Stressed Flat Plate with Edge Stiffeners. NASA CR-1574, 1970.

77. Dixon, Sidney C.; and Shore, Charles P.: State of the Art for Panel Flutter as Applied to the Space Shuttle Heat Shields. NASA TM X-52876, vol. II, 1970, pp. 583-584.

78. Dowe11, E. H.: Flutter of Buckled Plates at Zero Dynamic Pressure. AIAA J., vol. 8, no. 3, March 1970, pp. 583-584

79. Ventres, C. S.; and Dowe11, E. H.: Comparison of Theory and Experiment for Nonlinear Flutter of Loaded Plates. AIAA J., vol. 8, no. 11, Nov. 1970, pp. 2022-2030.

80. Ventres, C. S.: Flutter of a Buckled Plate Exposed to a Static Pressure Differential. AIAA J., vo1. 9, no. 6, May 1971, pp. 958-960.

81. Sawyer, James Wayne: Flutter of Elastically Supported Orthotropic Panels Including the Effects of Flow Angle. NASA TN D-7491, 1974.

82. Chopra, Inderjit: Flutter of a Panel Supported on an Elastic Foundation. AIAA J., vol. 13, no. 5, May 1975, pp. 687-688. 
83. Shore, Charles P.: Flutter Analysis of Two Parallel Elastically Coupled Flat Plates. NASA TN D-8085, 1975. 